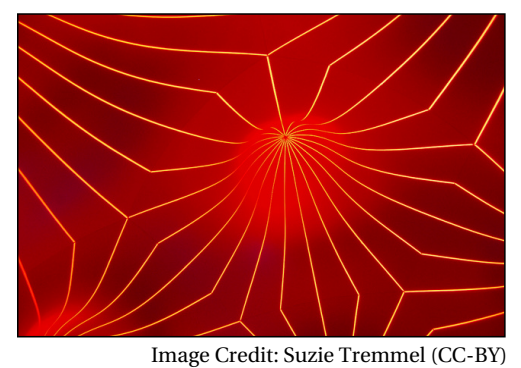

\section{Inclusive Innovation in Developed Countries}

Welcome to the February issue of the Technology Innovation Management Review. We welcome your comments on the articles in this issue as well as suggestions for future article topics and issue themes.

Edlitorial: Inclusive Innovation in Developed Countries

Chris McPhee, R. Sandra Schillo, Louise Earl, and Jeff Kinder

Smart Farming: Including Rights Holders for Responsible Agricultural

Innovation Kelly Bronson

Gender-Specific Constraints on Academic Entrepreneurship and

Engagement in Knowledge and Technology Transfer Anna Sinell, Roda Müller-Wieland, and Antonia Muschner

Inclusive Innovation in Biohacker Spaces: The Role of Systems and

Networks Jeremy de Beer and Vipal Jain

Supporting Self-Determined Indigenous Innovations: Rethinking the

Digital Divide in Canada Jasmin Winter and Justine Boudreau

Convergent Innovation in Food through Big Data and Artificial

Intelligence for Societal-Scale Inclusive Growth

Laurette Dubé, Pan Du, Cameron McRae, Neha Sharma, Srinivasan

Jayaraman, and Jian-Yun Nie

Author Guidelines 


\section{Publisher}

The Technology Innovation Management Review is a monthly publication of the Talent First Network.

\section{ISSN}

1927-0321

\section{Editor-in-Chief}

Chris McPhee

\section{Advisory Board}

Tony Bailetti, Carleton University, Canada

Peter Carbone, Ottawa, Canada

Parm Gill, Gill Group, Canada

Leslie Hawthorn, Red Hat, United States

Michael Weiss, Carleton University, Canada

\section{Review Board}

Tony Bailetti, Carleton University, Canada

Peter Carbone, Ottawa, Canada

Parm Gill, Gill Group, Canada

G R Gangadharan, IBM, India

Seppo Leminen, Laurea University of Applied Sciences

and Aalto University, Finland

Colin Mason, University of Glasgow, United Kingdom

Steven Muegge, Carleton University, Canada

Jennifer Percival, University of Massachusetts, United States

Risto Rajala, Aalto University, Finland

Sandra Schillo, University of Ottawa, Canada

Marina Solesvik, Nord University, Norway

Stoyan Tanev, University of Southern Denmark, Denmark

Michael Weiss, Carleton University, Canada

Mika Westerlund, Carleton University, Canada

Blair Winsor, Memorial University, Canada

(C) $2007-2018$

Talent First Network

www.timreview.ca

\section{Overview}

The Technology Innovation Management Review (TIM Review) provides insights about the issues and emerging trends relevant to launching and growing technology businesses. The TIM Review focuses on the theories, strategies, and tools that help small and large technology companies succeed.

Our readers are looking for practical ideas they can apply within their own organizations. The TIM Review brings together diverse viewpoints - from academics, entrepreneurs, companies of all sizes, the public sector, the community sector, and others - to bridge the gap between theory and practice. In particular, we focus on the topics of technology and global entrepreneurship in small and large companies.

We welcome input from readers into upcoming themes. Please visit timreview.ca to suggest themes and nominate authors and guest editors.

\section{Contribute}

Contribute to the TIM Review in the following ways:

- Read and comment on articles.

- Review the upcoming themes and tell us what topics you would like to see covered.

- Write an article for a future issue; see the author guidelines and editorial process for details.

- Recommend colleagues as authors or guest editors.

- Give feedback on the website or any other aspect of this publication.

- Sponsor or advertise in the TIM Review.

- Tell a friend or colleague about the TIM Review.

Please contact the Editor if you have any questions or comments: timreview.ca/contact

\section{About TIM}

The TIM Review has international contributors and readers, and it is published in association with the Technology Innovation Management program (TIM; timprogram.ca), an international graduate program at Carleton University in Ottawa, Canada. 


\section{Editorial: Inclusive Innovation in Developed Countries Chris McPhee, Editor-in-Chief R. Sandra Schillo, Louise Earl, and Jeff Kinder, Guest Editors}

\section{From the Editor-in-Chief}

Welcome to the February 2018 issue of the Technology Innovation Management Review. This month's editorial theme is Inclusive Innovation in Developed Countries, and it is my pleasure to introduce our Guest Editors: Sandra Schillo, Assistant Professor in the Telfer School of Management at the University of Ottawa, Louise Earl, Section Chief in the Investment, Science and Technology Division at Statistics Canada, and Jeff Kinder, Director of the Innovation Lab at the Institute on Governance.

Following a regular issue in March, we will examine the theme of Frugal Innovation in April with Guest Editors Deepak S. Gupta, Executive Director of Applied Research, Innovation and Entrepreneurship Services (ARIES) at Centennial College in Toronto, Canada and Mokter Hossain, Assistant Professor in the Center for Industrial Production at Aalborg University, Denmark.

We have also recently issued a call for papers (tinyurl .com/y76k3kkb) for a special issue on Transdisciplinary Innovation with Guest Editors Martin Bliemel and Mieke van der Bijl-Brouwer from the Faculty of Transdisciplinary Innovation at the University of Technology Sydney, Australia.

For future issues, we are accepting general submissions of articles on technology entrepreneurship, innovation management, and other topics relevant to launching and growing technology companies and solving practical problems in emerging domains. Please contact us (timreview.ca/contact) with potential article topics and submissions, and proposals for future special issues.

Chris McPhee

Editor-in-Chief

\section{From the Guest Editors}

The ambition of inclusive innovation is to make innovation relevant and beneficial to societal groups that are disadvantaged or risk becoming disadvantaged. It aims to deliver solutions to issues of social inequalities and to lock-ins in innovation pathways.

Traditionally, academic research has referred to inclusive innovation in the context of developing countries, but recent work (Schillo \& Robinson, 2017) in this journal provided a framework for consideration of inclusiveness in innovation in developed countries, partially as a reflection of the increasing public and policy interest, for example as expressed in the work of the OECD and policy directives in the Canadian government. The framework highlights the far-reaching implications of considering the inclusiveness of innovation along the four dimensions of "people, activities, outcomes, and governance: i) individuals and groups participating in the innovation process at all levels; ii) the types of innovation activities considered; iii) the consideration of all positive and negative outcomes of innovation (including economic, social, and environmental); and iv) the governance of innovation systems" (Schillo \& Robinson, 2017).

This special issue of the TIM Review builds on this work, presenting inclusive innovation considerations in concrete application contexts. The articles in this issue present balanced perspectives on innovation, offsetting the high ambitions and achievements of scientific and social advances against the backdrop of exclusion, barriers of access to employment or new technology, prejudices against social participation and technology adoption, food insecurity, costs of medical attention, and other concerns that may accompany the introduction of innovations.

Kelly Bronson from the Faculty of Social Sciences and the Institute for Science, Society and Policy at the University of Ottawa, Canada, challenges policy makers to better manage societal impacts of new technologies, 


\title{
Editorial: Inclusive Innovation in Developed Countries
}

\author{
Chris McPhee, R. Sandra Schillo, Louise Earl, and Jeff Kinder
}

proactively rather than reactively, within the agricultural sector and rural Canada. This opening article effectively discounts any myths that Canada's farmers are late adopters of new techniques, technologies, or products. It documents how farmers ranging from large commercial enterprises to small family farms are responding to their suppliers' (and competitors') new business models that impose costly entrance fees on the user, including the provision of detailed production information. Farming in Canada is an early adopter of big data analytics employing new data collection methods and combining proprietorial data with formal and informal public or accessible data. These "smart" business practices and technologies have the potential to disrupt Canadian agriculture through the displacement of small farmers by large commercial farmers. The buyin or entry costs to "smart" farming technology and tools are often prohibitive to smaller farms whose yields and size are not scalable to the new business models. Bronson argues the need for responsible implementation of innovation activities that considers their potential societal consequences.

Anna Sinell, Roda Müller-Wieland, and Antonia Muschner from the Center for Responsible Research and Innovation at Fraunhofer IAO in Berlin, Germany, approach inclusiveness of innovation from a social perspective. This article explores gender-based differences and exclusion in knowledge and technology transfer (KTT) in academia and entrepreneurship by male and female scientists. Based on 40 case studies, the authors argue that better engagement of female scientists and engineers in KTT and entrepreneurship will lead to transfer outcomes with different goals and in different markets. Commercialization activities of male scientists appear to have higher individual career-oriented motivations than those of female scientists that seem to orient research more towards resolving societal challenges. The article concludes with a call to develop practices and programs that support, reward, and recognize KTT and entrepreneurship activities of both male and female scientists in order to meet the policy imperatives and strategies to enhance the innovation capacity of academic research.

Jeremy de Beer and Vipal Jain from the University of Ottawa's Faculty of Law investigate the biohacking movement as an example of open and inclusive innovation. This article argues that, in the case of biotechnology, research is moving outside of traditional labs into "biohacker spaces". The biohacking movement depends on collaboration between formal research institutions and informal research spaces requiring open and transparent sharing of data, ideas, and resources. This example of open innovation thrives within flexible regulatory and intellectual property systems. The authors discuss the underlying tension between formal and informal research and explore when and where regulatory systems assist or detract from innovation. They conclude that the construction of an environment (ecosystem) that supports biohacker spaces is required to reap the benefits of their innovations.

Next, Jasmin Winter from the First Nations Technology Council in British Columbia and Justine Boudreau from the University of Ottawa explore social exclusion of indigenous peoples through distortion of technological adoption, preconceptions of cultural mores, and their biased misrepresentations in early photography. Opening with a famous photograph that they show was "photoshopped" to meet the colonial preconceptions of indigenous life, they argue that indigenous communities continuously have employed technological advancements strategically as tools for survival. This article shows how indigenous communities are adopting social media to write their current and future stories based on their worldviews and their histories. This approach revises, reconciles, and addresses past misrepresentations. The authors promote the potential of "makerspaces" towards improving inclusiveness by bridging digital and social divides. Makerspaces bring together tools, projects, and skills to devise new techniques and applications on a gamut of activities ranging from woodworking and sewing to cutting-edge robotics and machine learning. The appeal of makerspaces lies in their accessibility, facilitation of inclusivity, and acceptance of diversity.

The final article, by Laurette Dubé, Pan Du, Cameron McRae, Neha Sharma, and Srinivasan Jayaraman from McGill University in Montreal, Canada, and Jian-Yun Nie from the Université de Montréal, provides exploratory research employing deep learning and other artificial intelligence techniques to consumer behaviour towards food. Centred within convergent innovation theory, the authors argue that affordable and accessible foods as well as consumer education are important to inclusive growth and equitable health and wealth. Their conclusions provide insights into consumer behaviour towards food innovation and direction for future research. The authors provide a thorough discussion of their approaches to user-generated content through social media sources to develop their data for analysis. Their model and approach are food for thought for researchers intending to explore unstructured web-based data as primary data sources. 


\title{
Editorial: Inclusive Innovation in Developed Countries
}

\author{
Chris McPhee, R. Sandra Schillo, Louise Earl, and Jeff Kinder
}

Taken together, the contributions to this TIM Review special issue further the discussion on inclusive innovation in developed countries. They provide a sampling of perspectives that clearly demonstrate that developed economies also face challenges associated with inclusion. They also document the global extent of the challenges of inclusiveness across political boundaries and across cultural, gender, and digital divides, and they emphasize the interrelatedness of multinational enterprises, regulatory environments, and communities. In this way, this special issue is a call to view innovation as impacting social, economic, environmental, cultural, and technological divides in developed countries - and to carefully assess both positive and negative consequences of innovation.

\section{R. Sandra Schillo, Louise Earl, and Jeff Kinder Guest Editors}

\section{Acknowledgements}

The guest editors wish to thank all the contributors to this special issue, including both the authors who shared their insights and the anonymous reviewers who helped improve their work. The articles and comments expressed in this special issue reflect those of the individual authors and not their organizations.

\section{About the Editors}

Chris McPhee is Editor-in-Chief of the Technology Innovation Management Review. Chris holds an MASc degree in Technology Innovation Management from Carleton University in Ottawa, Canada, and BScH and MSc degrees in Biology from Queen's University in Kingston, Canada. He has nearly 20 years of management, design, and content-development experience in Canada and Scotland, primarily in the science, health, and education sectors. As an advisor and editor, he helps entrepreneurs, executives, and researchers develop and express their ideas.

R. Sandra Schillo is an Assistant Professor in Innovation and Entrepreneurship at the Telfer School of Management, University of Ottawa, Canada, and an affiliate of the Institute for Science, Society and Policy at the University of Ottawa. Prof. Schillo's research investigates systems aspects of innovation and entrepreneurship in her academic work and places emphasis on contributions to practice. Prof. Schillo holds a $\mathrm{PhD}$ in management from the University of Kiel, Germany, and a Master's (Diplom) in engineering management from the University of Karlsruhe, Germany.

Louise Earl is a Section Chief in the Investment, Science and Technology Division at Statistics Canada has been active in the measurement and analysis of science, technology and innovation since 2000. Louise holds a Master of Arts from Queen's University, Kingston and a Bachelor of Arts degree with first class honours from the University of New Brunswick. Louise is a vice chair of the Organisation for Economic Co-operation and Development's (OECD) Working Party of National Experts on Science and Technology Indicators. She is actively involved in the soon to be concluded revision of the OECD's Oslo Manual, Guidelines for Collecting and Interpreting Innovation Data. She contributed to the Frascati Manual 2015, Proposed Standard Practice for Surveys on Research and Development revision. She is the co-editor of National Innovation, Indicators and Policy (2006, Edward Elgar) and is the author of chapters in Measuring Knowledge Management in the Business Sector: First Steps (2003, OECD). Her analytical works at Statistics Canada on topics such as impacts of science, technology and innovation; organization and technological change in the public and private sectors; indicators of growth firms; knowledge management practices; household e-commerce; and wage gaps have been published in the Canadian Economic Observer, Perspectives on Labour and Income, Services Indicators, Health Reports, Focus on Culture, and various working papers series.

Continued on next page... 


\section{Editorial: Inclusive Innovation in Developed Countries}

Chris McPhee, R. Sandra Schillo, Louise Earl, and Jeff Kinder

Jeff Kinder, Director of Innovation at the Institute on Governance has almost 30 years of experience in government science, technology and innovation policy in the US and Canada. His US experience includes the National Science Foundation, the National Academies and the Naval Research Laboratory. In Canada, Jeff has worked at Industry Canada, Natural Resources Canada and the Council of Science and Technology Advisors. In 2014, he supported the External Advisory Group on Federal S\&T (the Knox Panel). Most recently, he led the Federal Science and Technology Secretariat supporting the Minister of Science, the Deputy Minister Champion for Federal S\&T and related initiatives. He is now on interchange with the Institute on Governance where he leads the ASPIRE Innovation Collaboratory. At the University of Ottawa, Jeff is a Fellow of the Institute for Science, Society and Policy and an adjunct professor at the Telfer School of Management. He is author and co-editor with Paul Dufour of A Lantern on the Bow: A History of the Science Council of Canada (forthcoming from Invenire), author of Government Science 2020: Re-thinking Public Science in a Networked Age and co-author with Bruce Doern of Strategic Science in the Public Interest: Canada's Government Laboratories and Science-Based Agencies (U. Toronto Press, 2007). He holds a PhD in public policy, a Master's in science, technology, and public policy, and a BS in physics.

\section{References}

Schillo, R. S., \& Robinson, R. M. 2017. Inclusive Innovation in Developed Countries: The Who, What, Why, and How. Technology Innovation Management Review, 7(7): 34-46.

http://timreview.ca/article/1089

Citation: McPhee, C., Schillo, R. S., Earl, L., \& Kinder, J. 2018. Editorial: Inclusive Innovation in Developed 


\title{
Smart Farming: Including Rights Holders for Responsible Agricultural Innovation
}

\author{
Kelly Bronson
}

\author{
"It is not from ourselves that we learn to be better") \\ than we are.
}

\author{
Wendell Berry \\ Novelist, poet, activist, and farmer
}

\begin{abstract}
This article draws on the literature of responsible innovation to suggest concrete processes for including rights holders in the "smart" agricultural revolution. It first draws upon historical agricultural research in Canada to highlight how productivist values drove seed innovations with particular consequences for the distribution of power in the food system. Next, the article uses document analysis to suggest that a similar value framework is motivating public investment in smart farming innovations. The article is of interest to smart farming's decision makers (from farmers to governance actors) and a broader audience - anyone interested in engendering equity through innovation-led societal transitions.
\end{abstract}

\section{Introduction}

This article begins from the foundational premise that values are endemic to innovation. This premise goes against the dominant view in which innovation design (and to a certain extent governance) is seen as highly technical and objective work that addresses a narrow set of practical problems. Innovations not only solve design problems but they also reorder society, fostering particular distributions of power and authority and giving rise to some social realities, necessarily at the expense of others (Winner, 1986). Therefore, innovating with foresight requires having broad conversations early on in the innovation process about the kinds of societies we want to enable (or disable) (Stilgoe et al., 2013). What kind of society do we want and what innovation features will get us there? Such a question cannot be answered technocratically; instead, answering values-based questions requires the wide involvement of rights holders, not least because engineers and technical policy actors are highly specialized experts whose life experiences and training do not equip them to anticipate the broad ethical and political implications of innovations (Ottinger \& Cohen, 2011; Sarewitz, 2004; Yearly, 2004). Unlike "stakeholders", or anyone with a stake in the innovation process, rights holders might be thought of as those for whom the realization of their livelihood is inextricably linked to governance decisions.
This article details emergent "smart" agricultural innovations in their wider historical context - framed in continuity with longstanding values and goals, which have driven agricultural innovations that have both delivered a productive but also an inequitable global food system (Lang \& Heasman, 2004; Patel, 2008). The socalled "smart farming" approach is one where farm decisions are informed by big data collected and made sense of by intelligent machines (Wolfert et al., 2017). It is also referred to as digital agriculture, precision agriculture or big data in agriculture (Bronson \& Knezevic, 2016a, 2016b). Ultimately, this article uses research in the burgeoning area of scholarship and practice called "responsible innovation" to lay out potential inclusive decision processes that could help engender justice and equity through current innovation-led agricultural transformations.

\section{What is the "Smart" Farming "Revolution"?}

Farming is said to be undergoing a "smart" technology "revolution" (Datafloq, 2015). John Deere now fits each of its "precision" tractors with sensors that collect data about soil and crop conditions. The software used in John Deere's tractor is proprietary and the data it collects are not openly accessible. Instead, the corporation invites farmers to subscribe (and pay) for access to information it generates from aggregated datasets and 


\section{Smart Farming: Including Rights Holders for Responsible Agricultural Innovation}

Kelly Bronson

which is accessible using a "My Farm Manager" mobile application. Proponents of smart agricultural innovations such as precision tractors suggest that these tools introduce incredible business efficiency into farming. For example, farmers can use big data to create a fertilizer application map that allows them to continuously vary fertilizer rates as a crop is being seeded.

Farming has been empirically driven for over a century though arguably the "big" data of smart farming is different from historical information gathering in terms of its volume. As early as the 1920s, Agriculture Canada scientists meticulously recorded wheat yields and weather patterns on experimental farms, all with the goal of increasing crop productivity. Today's empirical approach is also marked as different by the sophisticated analytical capacity of computer algorithms, which are written to use voluminous data for generating particular, or even entirely unexpected insights (Gitelman \& Jackson, 2013). Big data is thought to improve upon human limitations such that it represents a revolution in the scientific approach (Anderson, 2018).

Corporations and governments evidently recognize the economic potential in smart innovations applied to food production. One only has to look at Monsanto Corporation's purchasing habits. In 2013, Monsanto bought the digital tool developer Climate Corporation for $\$ 930$ million USD. Under a platform called Integrated Field Systems (IFS) released in 2014, Monsanto offers farmers a suite of digital tools for collecting and analyzing farm data. Farmers are being encouraged to use Monsanto's IFS tools that collect data about soil conditions, weed varieties, and weather. Monsanto's computer software, farmers are told, will generate information that can help minimize financial risk and streamline business decision making. Beyond these benefits to the farmer, there are likely secondary benefits to the corporation from the collection of agricultural data. Monsanto-derived "Weed ID" is an app that allows farmers to map novel weeds in digital software made available to them without charge. While helping farmers identify unknown weeds, Monsanto can use farm-level data to promote its proprietary chemicals and farmers' (qua field researchers') data collection to drive research and development. Whether the individual farmer benefits commensurately with the corporation is an ethical question that has yet to be answered and is not unlike pressing questions surrounding the use of social media data (Elmer et al., 2015).
It is clear that the Canadian federal government recognizes the economic gains presented by smart agricultural innovations: it is investing significant public money into the development of innovations in data and machine intelligence applied to agriculture in the hope that they will help meet sustainability challenges (through emission reductions) and demand for jobs among Canadians (GOC, 2017). In February 2017, the federal "Barton Report" flagged agricultural innovation as having high potential to drive economic growth and societal wellbeing.

While there are undoubtedly opportunities associated with smart farming innovations beyond economic gains (e.g., environmental gains through reduced input use, see Wolfert et al., 2017), there are potentially negative outcomes, especially socio-ethical implications for humans and non-humans (Carbonell, 2016; Driessen \& Heutinck, 2015; Millar, 2000). To date, only a handful of studies have looked at these potential implications of smart farming. It is possible, however, to make inferences from the application of smart innovations in other sectors. The World Economic Forum has extrapolated from the automotive sector to predict wide-scale "technological unemployment" resulting from the application of automation in sectors such as agriculture (WEF, 2016). Changes in rural work populations could have a major impact on social cohesion in many communities and on the livelihoods of many labourers (Carolan, 2016). Studies of the application of smart innovations to the dairy sector in Australia reveal a reshaping of the practice of farming, with less hands-on management and more "data-driven" decisions (Eastwood et al., 2012). Given the ethical issues presented with the "mining" of health data, we can infer that the use of environmental big data collected by precision tractors will present challenges in determining which data to collect in order to meet societal not just corporate goals, and challenges in determining how much access to societally important datasets to enable. Indeed, the United Nations' Global Open Data for Agriculture and Nutrition (GODAN; godan.info) programme calls for open access to agricultural data as a basic right because they feel it will help with the pressing humanitarian crisis that is global food insecurity. The bulk of research on innovation and society would suggest that, no matter what we know about smart farming in particular, it is inevitable that it will produce both benefits and risks (Beck, 1992). 


\section{Smart Farming: Including Rights Holders for Responsible Agricultural Innovation}

Kelly Bronson

\section{When Old Is New: Smart Agriculture's Value Frameworks}

Innovations by definition offer technical novelties and ingenuity, but they often reproduce, rather than disrupt, societal relationships of power and authority (Marvin, 1988). Consider briefly, for example, the history of seed science in Canada (but see Bronson, 2015, for a more detailed treatment of the subject). In the early to mid-20th century, the Canadian federal government devoted money to establishing seed research or plant breeding housed in universities across the country (Kuyek, 2000). The innovative hybrid seeds that came out of these research networks - ones that included farmer/on-farm experimentation - were driven by the technical goal of boosting production (and under certain adverse environmental conditions). Hardworking and clever scientists developed drought-tolerant and dwarf plant varietals in staple commodity crops such as corn (GOC, 2009). Because these seeds, as well as their successors - genetically engineered seed systems - were designed to work in tandem with chemical fertilizers and pesticides, their uptake led to a concentration of market power among already-powerful chemical corporations. This market distortion became further exaggerated as the chemical corporations bought up seed research facilities and refigured themselves as "life sciences" corporations responsible for multiple agricultural inputs (Howard, 2015; Qualman, 2005). Smaller family farmers, unable to compete by taking on the economic risks associated with increasing productivity (such as buying certified seeds) have slowly been incorporated into larger farms such that commercial farms now dominate the Canadian rural landscape (Statistics Canada, 2016). This pattern of "rationalization" was laid out as a policy goal in the Government of Canada's 1969 Task Force on Agriculture, though today's leading agencies (e.g., the United Nations) call out the irrationality of food system reliance on corporate farming (see IPES-Food, 2016). Yet Canadian hybrid seed innovators were never intentionally working to displace farmers; rather, they were myopically focused on boosting yield and were not working with a full view of what the future of agriculture and rural living would look like guided by productivist values (see Kneen, 1992).

Current smart farming research and investment decisions appear to turn on the same agricultural values and goals as those that guided hybrid and biotechnology seed innovation: boosting yield through intensive agricultural production of staple commodities destined for distant markets. At the global level, the World
Bank's Agriculture Action Plan (2015) and Climate Action Plan (2016) describe how the application of smart agricultural innovations promise to make input-intensive agricultural practices (e.g., irrigation and livestock farming) more precise and economically efficient. These reports explicitly lay out the need to further the established priorities of dominant stake-holders in the global food system such as large agribusinesses and philanthropic organizations (e.g., The Gates Foundation). Similarly, a corporate video - Farm Forward that is meant to project John Deere's vision for the future of its precision agriculture equipment shows images of fully automated tractors, centrally controlled sensing and monitoring and other imagined (not yet realized) innovations supporting large-scale and mono-crop production. The American farmer of the future, like "Terry" pictured in this campaign video, is able to farm from the comfort of his living room where these tools give him a god's eye view of his fields (translated into data points); this is a positive view on the displacement of farm labourers by innovations in automation.

Smart farming research and investment decisions in Canada also appear motivated by those problems facing larger commodity-crop farmers, at least according to a survey of prominent farm papers. Farm papers are read by a variety of food system actors and are powerful spaces where agricultural advice is shared and technological forecasting happens. A document scan of five farm papers over a six-month period (Dec. 2016-May 2017) reveals that every article mentioning smart agricultural tools - from drones to phone apps - enacts a dominant "foodscape", which is a place where food is produced, prepared, or generally where people gather meaning about food and its production (Winson, 2005). Only large, input-intensive farms are pictured in the images or described in the copy of these articles. One article on a Lightbar system for GPS tractors suggests that this innovation allows the farmer that same omniscience as John Deere imagines for Terry: a "heads up" and remote view of potential natural and subsequently financial risks.

It appears that smart agricultural innovations being developed and deployed in the public sector are being guided by productivist values. Current government investments seem to presuppose, and thus tacitly promote, large-scale capital-intensive farms. As example, in 2016, the federal government invested nearly half a million dollars into the corporate development of a "clean" seeder meant to reduce emissions as well as, according to Minister of Innovation Navdeep Bains, 


\section{Smart Farming: Including Rights Holders for Responsible Agricultural Innovation}

Kelly Bronson

"modernize" the farm and grow jobs for "skilled workers" (Flamini, 2016). Tools like this are developed for large-scale farmers requiring newer and larger machinery, who can weather financial risk by distributing costs over thousands of acres. The CX-6 Smart Seeder will be costly in terms of capital and also in terms of managerial time - a farmer untrained in computer science is ill-equipped to understand, tinker with, and fix such a device (Solon, 2017). While not an explicit directive vis-à-vis such public investments, training a rural workforce in Internet technology skills (e.g., coding) is obviously a key part of agricultural "modernization"; said differently, smart farming innovations are intended to serve farmers to some extent by replacing them. As part of a larger, qualitative research project on "smart" farming in Canada, the author interviewed engineers and data scientists in government and industry, as well as farmers, to sketch some of the societal transitions enabled by these emergent innovations. One data scientist working with Agriculture and Agri-food Canada said that "intelligent" tractors are the future: "it's just progression... where you're able to make quick decisions, or something's able to make those decisions for you."

\section{Inclusion for Ethical Innovation: Recommendations for Smart Agriculture's Decision Makers}

Smart farming innovation in Canada currently has a blind spot: the needs and concerns of smaller- and medium-sized labour-intensive farms. To many decisionmakers, this area of "undone science" (Frickel et al., 2010) is not controversial but reflects the market, with technological trajectories, for example, following those who can pay. The data scientist quoted above puts it this way:

"I suspect some intermediary of value-added service provider is taking [the data we prepare] and doing something neat with it. We don't get into the sandbox, we just let industry and private sector deal with it and they go where they're gonna make the money."

It is now firmly established in the innovation literature that technology development cannot be understood without reference to market demands (Palm \& Hansson, 2004), and that agricultural innovations become embedded within political economic infrastructures (see Hellstrom, 2003). A very recent study by Eastwood and colleagues (2017) shows how the desire to anticipate and prevent potential negative consequences from smart dairying in New Zealand is complicated by the commercially-driven nature of these innovations.
That smart innovations appear set to advantage alreadypowerful players in the food system in Canada may indeed be a market reality but it is simultaneously a democratic problem. The Canadian government therefore has an opportunity vis-à-vis smart agricultural innovation: the investment of public money can be used to advance larger societal interests and guard against the sequestration of power among the few (Jasanoff, 2017). Given historical experience with agricultural innovations, we know that technological equity and broad social progress has to be secured through careful and ethical decisions taken by key players in the innovation ecosystem.

An important question is, thus: How do smart farming's decision makers anticipate and attend to the needs and concerns of a wide variety of rights holders in the food system? One suggestion, drawn from an area of scholarship and practice called responsible innovation, is to stage reasoned deliberations on technological needs and concerns between historically marginalized food system actors and prominent decision makers in government. Responsible innovation is a rubric for guiding innovation toward socially and ethically acceptable ends (Stilgoe et al., 2013) with links to European technology assessments as well as to corporate social responsibility (Iatridis \& Schroeder, 2016). Unlike corporate social responsibility, responsible innovation is meant to seek redress for ethical considerations often made invisible within an innovation's ecosystem, including existing inequities; this means that, unlike with corporate social responsibility methods for engaging "stakeholders", responsible innovation prioritizes the inclusion of rights holders historically marginalized in innovation decision processes (e.g., under-represented genders, see Wickson \& Carew, 2014). As well, unlike technology assessments that consider pros and cons or risks and benefits, responsible innovation leads with broader and valuesbased inquiries into innovations in society.

Table 1 provides three concrete suggestions for Canadian smart farming's decision makers that build closely off of a recent study conducted on smart dairying in New Zealand (Eastwood et al., 2017), which in turn builds off of foundational literature on responsible innovation $(\mathrm{Gu}-$ ston et al., 2014; Stilgoe et al., 2013; see also Macnaghten, 2016; Macnaghten et al., 2014, c.f. Asveld et al., 2015; Bronson, 2015). There is also a now well-developed body of literature, some of which comes from key Canadian scholars such as Michael Burgess, on the methodological particulars of how to deliver a deliberative process for assessing societal needs and concerns around innovation (see Blacksher et al., 2012; Einsiedel et al., 2001; Longstaff \& Burgess, 2009; O’Doherty et al., 2012). 


\section{Smart Farming: Including Rights Holders for Responsible Agricultural Innovation} Kelly Bronson

Table 1. Concrete suggestions for decision makers involved with smart farming innovation, inspired by Eastwood and colleagues (2017)

\begin{tabular}{lll}
\hline Inclusive Innovation Action & Description & Potential Methods or Activities \\
\hline Involving rights holders & $\begin{array}{l}\text { Get a range of end users and citizens } \\
\text { involved in deliberations meant to glean } \\
\text { their concerns and their knowledge of } \\
\text { potential social and ethical risks. Attend } \\
\text { to recruiting small landholders and } \\
\text { alternative producers. }\end{array}$ & $\begin{array}{l}\begin{array}{l}\text { Citizens juries or workshops deploying } \\
\text { methods aimed at gathering critical feedback } \\
\text { (i.e. nonsensus) }\end{array} \\
\text { Private sector engagement }\end{array}$ \\
$\begin{array}{ll}\text { Engage private sector partners in public- } \\
\text { industry research in conversations about } \\
\text { public needs (established via the } \\
\text { deliberations with rights holders) }\end{array}$ & $\begin{array}{l}\text { Feedback from citizens and end users about } \\
\text { what society they want innovations to help } \\
\text { deliver is fed to private sector actors in plain } \\
\text { language reports }\end{array}$ \\
\hline Encouraging feedback and mutual design & $\begin{array}{l}\text { Designers and multiple stakeholders } \\
\text { engaged in mutual learning and open } \\
\text { R\&D projects }\end{array}$ & $\begin{array}{l}\text { Open innovation; user-centred design; online } \\
\text { feedback on public-sector innovations } \\
\text { "upstream" }\end{array}$ \\
\hline
\end{tabular}

As illustrated in the case example of Canadian seed science given in this article, decision makers are often firmly entrenched within hegemonic value frameworks, in part because they are themselves members of the dominant groups (Palm \& Hansson, 2006). Moreover, given the nature of gaining specialized expertise in technical policy making - usually gathered through a long process of enculturation in domain-specific knowledge (Collins, 2007) - technology developers are rarely conscious of the wider effects of their products, perhaps especially on historically marginalized players in the innovation ecosystem (Ottinger \& Cohen, 2013).

Thus, the inclusion of rights holders in broad, valuesbased inquiries related to technology development has been suggested as a method for improving outcomes (ones engendering equity) and also for improving trust in the innovation process (Asveld et al., 2015). Wickson and Carew (2014) have shown that open design projects can enable interaction between wider social values and technological potential; at the design stage, innovations are not yet entrenched into infrastructures (e.g., regulations) or cultural habits, which means early intervention can help mitigate the dreaded "lag" between proscriptive policy making and rapid technological change (Ogburn, 1957).

\section{Conclusion}

Amidst what appears to be incredible enthusiasm for a "smart" agricultural revolution, significant questions are emerging about how digital innovations, such as tractors that collect data and algorithms "mining" them, ought to be understood and managed. This article has drawn on the rubric of responsible innovation to make suggestions for those driving smart innovation to critically reflect upon the value frameworks motivating innovation for the ways in which these may be privileging already privileged actors in the food system. There is an indication that innovations in big data and machine intelligence, just as with genetically engineered seed systems, may enable by their very design consolidation of power among agribusinesses. For example, Monsanto's Fieldscripts, a platform for integrating farm-level big data, makes use of a proprietary algorithm that identifies which seeds are the "best match" for a field's conditions and then creates a variable rate seeding "prescription". The route by which the algorithm functions to arrive at a "prescription" is completely opaque, protected (understandably) as corporate intellectual property, and there is a similar lack of transparency around the profit-generating uses of Fieldscripts big data. Moreover, the "prescription", administered by a Monsanto employee/seed dealer, consists of recommendations that purportedly match the conditions of a farmer's field to one of Monsanto's hybrid seeds and proprietary chemicals - products bought as part and parcel of this "prescription", also through the seed dealer. To use FieldScripts, then, farmers are necessarily tethered to Monsanto Corporation who stands to gain enormously from the bundling of precision machinery, data, seeds, and chemicals. 


\section{Smart Farming: Including Rights Holders for Responsible Agricultural Innovation}

Kelly Bronson

Corporations have a legal mandate to maximize profit but, especially in publicly funded research, the government has a democratic mandate to ensure that the technologies it helps to develop contribute to the good of society as a whole and not just the interests of the already rich and powerful. It is not yet obvious the extent to which smaller and alternative producers will be increasingly marginalized or sustained by a smart agricultural revolution; however, it does seem that Canadian smart farming decision makers are captured by productivist values and are focusing their efforts on streamlining economic decisions and promoting high yields. Obfuscated in these "imaginaries" (Jasanoff, 2015) for smart agricultural innovations are questions about rural livelihood and food justice: What kind of rural societies do a variety of Canadians want to sustain? What farm strategies are important to Canadians? Certainly, recent reports at the level of the United Nations suggest the need for a "multi-functional" approach to food production in food systems around the world (see IPES-Food, 2016). Values-based questioning ought to be foregrounded, as a normative matter, in inclusive processes of decision-making on smart agriculture.

The tag line for the 1939 World's Fair was, "Science discovers, technology creates, man adapts." But innovations do not drop from the sky; rather, certain people steer innovation directions, within political economic contexts and, importantly, cultural values. Right now (or even yesterday) is the time to use inclusive innovation processes to critically reflect upon the wider contexts of smart agricultural innovation - before the difficult-toundo systems surrounding these tools become solidified (Bowker \& Star, 1999; Bronson, 2015).

\section{Acknowledgements}

The author acknowledges the Social Sciences and Humanities Research Council for funding the broader research project which helps to inform this article. As well, the author is thankful for the hard work of two research assistants (Megan Beaulieu and Matthew Zucca) and the helpful comments of a reviewer who weighed in on an earlier draft.

\section{About the Author}

Kelly Bronson is an Assistant Professor in the Faculty of Social Sciences and the Institute for Science, Society, and Policy at the University of Ottawa, Canada. She is a social scientist studying sciencesociety tensions that erupt around controversial technologies and their governance - from GMOs to big data. Her research aims to bring community values into conversation with technical knowledge in the production of evidence-based decision-making. She has published her work in regional Journal of New Brunswick Studies), national (Canadian Journal of Communication), and international journals (Journal of Responsible Innovation, Big Data and Society).

\section{References}

Anderson, C. 2008. The End of Theory: The Data Deluge Makes the Scientific Method Obsolete. Wired, June 23, 2008. Accessed February 15, 2018:

https://www.wired.com/2008/06/pb-theory/

Beck, U. 1992. Risk Society: Towards a New Modernity. London, UK: Sage Publications.

Blacksher, E., Diebal, A., Forest, P. G., Goold, S. D., \& Abelson, J. 2012. What is Public Deliberation? The Hastings Center Report, 42(2): 14-17.

http://doi.org/10.1002/hast.26

Bronson, K., \& Knezevic, I. 2016a. Food Studies Scholars Can No Longer Ignore the Rise of Big Data. Canadian Food Studies, 3(1): 9-19.

http://dx.doi.org/10.15353/cfs-rcea.v3i1.138

Bronson, K., \& Knezevic, I. 2016b. Big Data in Food and Agriculture. Big Data and Society, 2(1): 1-5.

https://doi.org/10.1177/2053951716648174

Bronson, K. 2015. Responsible to Whom? Seed Innovations and the Corporatization of North American Agriculture. Journal of Responsible Innovation, 2(1): 62-77.

https://doi.org/10.1080/23299460.2015.1010769

Bowker, G. C., \& Star, S. L. 1999. Sorting Things Out: Classification and Its Consequences. Cambridge, MA: MIT Press.

Carbonell, I. 2016. The Ethics of Big Data in Agriculture. Internet Policy Review, 5(1).

https://doi.org/10.14763/2016.1.405

Carolan, M. 2016. Publicising Food: Big Data, Precision Agriculture, and Co-Experimental Techniques of Addition. Sociologia Ruralis, 57(2): 135-154.

https://doi.org/10.1111/soru.12120

Collins, H. M. 2007. Rethinking Expertise. Chicago, IL: University of Chicago Press. 


\section{Smart Farming: Including Rights Holders for Responsible Agricultural Innovation}

\section{Kelly Bronson}

Driessen, C., \& Heutinck, L. F. M. 2015. Cows Desiring to Be Milked? Milking Robots and the Co-Evolution of Ethics and Technology on Dutch Dairy Farms. Agriculture and Human Values, 32(1): 3-20. https://doi.org/10.1007/s10460-014-9515-5

Flammini, D. 2016. Government of Canada Invests $\$ 425 \mathrm{~K}$ into Precision Agriculture. Farms.com, November 25, 2016. Accessed February 15, 2018:

http://www.farms.com/ag-industry-news/government-of-canadainvests-425k-into-precision-agriculture-927.aspx

Hellstrom, T. 2003. Systemic Innovation and Risk: Technology Assessment and the Challenge of Responsible Innovation. Technology in Society, 25(3): 369-384.

https://doi.org/10.1016/S0160-791X(03)00041-1

Iatridis, K., \& Schroeder, D. 2016. Responsible Research and Innovation in Industry: The Case for Corporate Responsibility Tools. Cham, Switzerland: Springer International Publishing. http://doi.org/10.1007/978-3-319-21693-5

Jasanoff, S. 2017. The Ethics of Invention, Technology and the Human Future. New York: Norton Publishing.

O’Doherty, K., Gauvin, F.-P., Grogan, C., \& Friedman, W. 2012. Implementing a Public Deliberative Forum. The Hastings Center Report, 42(2): 20-23.

Solon, O. 2017. A Right to Repair: Why Nebraska Farmers Are Taking on John Deere and Apple. The Guardian, March 6, 2017. Accessed February 15, 2018:

https://www.theguardian.com/environment/2017/mar/06/nebras ka-farmers-right-to-repair-john-deere-apple

Einsiedel, E. F., Erling, J., \& Breck, T. 2001. Publics at the Technology Table: The Consensus Conference in Denmark, Canada, and Australia. Public Understanding of Science, 10(1): 83-98. https://doi.org/10.3109/a036857

Elmer, G., Langlois, G., \& Redden, J. 2015. Compromised Data: From Social Media to Big Data. London: Bloomsbury.

GOC. 2017. Budget 2017: Skills and Innovation. Ottawa: Government of Canada (GOC).

http://www.budget.gc.ca/2017/docs/bb/brief-brefen.html\#section 1

GOC. 2017. Unleashing the Growth Potential of Key Sectors. Ottawa: Government of Canada (GOC), Advisory Committee on Economic Growth.

https://www.budget.gc.ca/aceg-cce/pdf/key-sectors-secteurscles-eng.pdf

Frickel, S., Gibbon, S., Howard, J., Kempner, J., Ottinger, G., \& Hess, D. 2010. Undone Science: Charting Social Movement and Civil Society Challenges to Research Agenda Setting. Science, Technology, \& Human Values, 35(4): 444-473. https://doi.org/10.1177/0162243909345836

Guston, D. H., Fisher, E., Grunwald, A., Owen, R., Swierstra, T., \& van der Burg, S. 2014. Responsible Innovation: Motivations for a New Journal. Journal of Responsible Innovation, 1(1): 1-8. https://doi.org/10.1080/23299460.2014.885175

Hansen, T., \& Coenen, L. 2015. The Geography of Sustainability Transitions: Review, Synthesis and Reflections on an Emergent Research Field. Environmental Innovation and Societal Transitions, 17: 92-109.

https://doi.org/10.1016/j.eist.2014.11.001
IPES-Food. 2016. From Uniformity to Diversity: a Paradigm Shift From Industrial Agriculture to Diversified Agroecological Systems. Brussels: International Panel of Experts on Sustainable Food Systems (IPES-Food).

Kinchy, A. 2012. Seeds, Science and Struggle. Cambridge, MA: MIT Press.

Kneen, B. 1992. The Rape of Canola. Toronto: Dundurn Press.

Kuyek, D. 2000. Lords of Poison: The Pesticide Cartel. Grain, June 15, 2000. Accessed February 15, 2018:

https:/ / www.grain.org/e/293

Lang, T., \& Heasman, M. 2004. Food Wars: The Global Battle for Mouths, Minds and Markets. London: Routledge.

Longstaff, H., \& Burgess, M. M. 2009. Recruiting for Representation in Public Deliberation on the Ethics of Biobanks. Public Understanding of Science, 19(2): 212-224.

https://doi.org/10.1177/0963662508097626

Macnaghten, P. 2016. Responsible Innovation and the Reshaping of Existing Technological Trajectories: The Hard Case of Genetically Modified Crops. Journal of Responsible Innovation, 3(3): 282-298. https://doi.org/10.1080/23299460.2016.1255700

Macnaghten, P., Owen, R., Stilgoe, J., Wynne, B. Azevedo, A., de Campos, A., Chilvers, J., Dagnino, R., di Giulio, G., Frow, E., Garvey, B., Groves, C., Hartley, S., Knobel, M., Kobayashi, E., Lehtonen, M., Lezaun, J., Mello, L., Monteiro, M., Pamplona da Costa, J., Rigolin, C., Rondani, B., Staykova, M., Taddei, R., Till, C., Tyfield, D., Wilford, S., \& Velho, L. 2014. Responsible Innovation Across Borders: Tensions, Paradoxes and Possibilities. Journal of Responsible Innovation, 1(2): 191-199.

http://doi.org/10.1080/23299460.2014.922249

Marvin, C. 1988. When Old Technologies are New, Thinking about Electric Communication in the Late 19th Century. Oxford: Oxford University Press.

Millar, K. M. 2000. Respect for Animal Autonomy in Bioethical Analysis: The Case of Automatic Milking Systems (AMS). Journal of Agricultural and Environmental Ethics, 12(1): 41-50. https://doi.org/10.1023/A:1009548025408

Moffat, M. 2017. Inclusive Innovation: The Importance of Place. Paper presented at the Inclusive Innovation Workshop, University of Ottawa, September 8, 2017.

O’Doherty, K., Gauvin, F.-P., Grogan, C., \& Friedman, W. 2012. Implementing a Public Deliberative Forum. The Hastings Center Report, 42(2): 20-23. http://doi.org/10.1002/hast.28

Ogburn, W. F. 1957. Cultural Lag as Theory. Sociology \& Social Research, 41:167-174.

Ottinger, G., \& Cohen, B. 2011. Technoscience and Environmental Justice. Cambridge, MA: MIT Press.

Owen, R., Macnaghten, P., \& Stilgoe, J. 2012. Responsible Research and Innovation: From Science in Society to Science for Society, with Society. Science and Public Policy, 39(6): 751-760. https://doi.org/10.1093/scipol/scs093

Palm, E., \& Hansson, S. O. 2006. The Case for Ethical Technology Assessment (eTA). Technological Forecasting and Social Change, 73(5): 543-558. https://doi.org/10.1016/j.techfore.2005.06.002 


\section{Smart Farming: Including Rights Holders for Responsible Agricultural Innovation}

Kelly Bronson

Patel, R. 2008. Stuffed and Starved, Power and the Hidden Battle for the World Food System. London: Portobello Books.

Sarewitz, D. 2004. How Science Makes Environmental Controversies Worse. Environmental Science and Policy, 7(4): 385-403.

https://doi.org/10.1016/j.envsci.2004.06.001

Soete, L. 2017. Reflections on Inclusive Innovation. Paper presented at the Inclusive Innovation Workshop, University of Ottawa, September 8, 2017.

Stilgoe, J., Owen, R., \& Macnaghten, P. 2013. Developing a Framework for Responsible Innovation. Research Policy, 42(9): 1568-1580. https://doi.org/10.1016/j.respol.2013.05.008

Statistics Canada. 2016. 2016 Census of Agriculture. Ottawa: Statistics Canada.

https://www.statcan.gc.ca/eng/ca2016

Winson, A. 2004. Bringing Political Economy into the Obesity Epidemic. Agriculture and Human Values, 21(4): 299-312.

https://doi.org/10.1007/s10460-003-1206-6

WEF. 2016. The Future of Jobs. Geneva: World Economic Forum (WEF).

https://www.weforum.org/reports/the-future-of-jobs

Wickson, F., \& Carew, A. L. 2014. Quality Criteria and Indicators for Responsible Research and Innovation: Learning from Transdisciplinarity. Journal of Responsible Innovation, 1(3): 254-273.

http://doi.org/10.1080/23299460.2014.963004

Wolfert, S., Ge, L., Verdouw, C., \& Bogaardt, M.-J. 2017. Big Data in Smart Farming: A Review. Agricultural Systems, 153: 69-80.

https://doi.org/10.1016/j.agsy.2017.01.023

World Bank. 2015. Agriculture Action Plan. Washington: World Bank.

World Bank. 2016. World Bank Group Climate Change Action Plan 2016-2020. Washington: World Bank.

Yearly, S. 2004. Making Sense of Science. London: Sage Publications.

Citation: Bronson, K. 2018. Smart Farming: Including Rights Holders for Responsible Agricultural Innovation. Technology Innovation Management Review, 8(2): 7-14. http://doi.org/10.22215/timreview/1135

Keywords: big data, machine intelligence, automation, agriculture, smart agriculture, responsible innovation, technological values, power 


\title{
Gender-Specific Constraints on Academic Entrepreneurship and Engagement in Knowledge and Technology Transfer
}

\author{
Anna Sinell, Roda Müller-Wieland, and Antonia Muschner
}

\author{
(" To be honest, setting up a spin-off is the greatest") \\ way to exploit a research result. The effort is \\ extraordinary, which deters some. Probably a lot \\ of colleagues here think, hey, you are founding a \\ company - you might as well be planning a \\ mission to the moon!
}

A male scientist at a research institute and interview subject for this study

\begin{abstract}
This article analyzes gender-specific constraints impacting scientists' engagement in knowledge and technology transfer and entrepreneurial activities at public research institutions in the fields of science, technology, engineering, and mathematics (STEM). To this end, we followed an exploratory case study approach and conducted qualitative, semistructured interviews with 40 academic entrepreneurs. The analysis revealed constraints impacting scientists' active engagement in transfer and entrepreneurship on two levels. On the meta-level, we identified constraints related to: i) nationwide transfer culture and ii) funding guidelines and structures. On the operational level, we identified constraints related to: i) organizational strategies and practices; ii) organizational culture; and iii) individual attributes and attitudes. By analyzing gender differences among these constraints, the study contributes to an understanding of varying needs for gender-specific founding support programs. The study also derives several implications for managing transfer at research organizations.
\end{abstract}

\section{Introduction}

The promotion of innovation capacity is a key element in political strategy in developed countries. In this regard, new impulses for the development of technological and social innovation are expected from academia: research is not to be conducted for its own sake, rather it is to be transferred to other stakeholders of the innovation systems including industry, politics, and society in order to create an impact beyond the "ivory tower" of academia. Increasingly valued in political agenda setting and funding schemes, this knowledge and technology transfer has become imperative for institutions in academia in various national innovation systems in recent years (Acs et al., 2017; Carayannis \& Campbell, 2009; Grimaldi et al., 2011; The Wissenschaftsrat, 2016). Knowledge and technology transfer - and academic entrepreneurship as a particular form of transfer - are valued as means of enhancing innovation capacity.
Despite their various benefits and the outlined political pressure, contemporary measures have fallen short of expectations (European Commission, 2017). In Germany, only $6 \%$ of newly founded companies constitute academic spin-offs, and this number has even decreased in the past decade (Braun-Thürmann et al., 2010; BMBF, 2017).

Among these academic entrepreneurs, only $10 \%$ are women (Best et al., 2016). Moreover, female scientists interact less often with industry (Link et al., 2007; Perkmann et al., 2013) and submit fewer patent applications (Haller et al., 2007). Therefore, research institutions need to develop new approaches and support services that meet the needs of all scientists in order to engage both men and women in transfer and entrepreneurial activities.

By addressing the gender gap and engaging more women in knowledge and technology transfer, such activities can be fostered both quantitatively and qualitatively. 


\section{Gender-Specific Constraints on Academic Entrepreneurship and Engagement in Knowledge and Technology Transfer Anna Sinell, Roda Müller-Wieland, and Antonia Muschner}

Promoting the participation of female scientists can lead to transfer outcomes that pursue different goals and address different markets. In the case of entrepreneurship, research has shown that female-led companies do not solely aim for quick commercial success but follow a financially sustainable strategy (Dalborg et al., 2012; Reichborn-Kjennerud \& Svare, 2014). Women-led companies also differ in their objective - oftentimes they pursue a goal of solving societal challenges (Lortie et al., 2017). Looking at academic founders specifically, recent research confirms this tendency. Examining different motives of female and male academic entrepreneurs, Iffländer, Sinell, and Schraudner (in press) showed in their qualitative study that male scientists are more likely to be motivated by career-related benefits and the potential of capitalizing on their research, whereas female scientists are more likely to aim to solve a societal challenge and to foster the utilization of their research. Considering women as producers of innovation and thereby focusing on the inclusion of a specific group of people, this article contributes to the understanding of the "people dimension" of the suggested framework for inclusive innovation by Schillo and Robinson (2017).

Based on these observations, the article aims to shed light on reasons for insufficient innovation capacity in Germany. We therefore analyze the following research questions:

- What constraints prevent scientists from engaging in knowledge and technology transfer and entrepreneurial activities at public research institutions in STEM fields?

\section{- Do women and men face different constraints that im- pact their engagement in transfer activities?}

We thereby aim to derive implications for practice to help overcome and reduce such constraints and thus foster innovation and technology transfer at research institutions.

In what follows, we review existing research on constraints and factors influencing the formation of academic spin-offs by scientists. We then present and discuss our findings on constraints in STEM fields of German academia.

\section{Factors Impacting Knowledge and Technology Transfer and Entrepreneurial Engagement}

Academic entrepreneurship encompasses different transfer activities including patenting and licensing, contract research, and spin-off creation (Wright et al., 2008).
Given that there are different definitions of academic spin-offs (Fryges \& Wright, 2014; Pirnay et al., 2003) we herein define academic spin-offs in accordance with our empirical cases as research-based companies i) whose business model is based on the transfer of knowledge (e.g., a technology) from an academic institution and ii) are initiated by scientists of this academic institution while or after being affiliated with the organization (Clarysse \& Moray, 2004). Academic spin-offs are considered to play a primary role in knowledge and technology transfer because they have been associated with various long-term advantages. For instance, they help to transfer scientific innovations directly to the public, create jobs, and promote national competitiveness and business growth (Egeln et al., 2003; Vincett, 2010; Walter \& Auer, 2009). Because of their remarkable capacity for innovation, they are linked to the production of profound economic impact that will encompass multiple markets (Dickel, 2009)

On a practical level, the increased significance of knowledge and technology transfer and academic entrepreneurship has led to diversified support measures provided by academic institutions (Siegel \& Wright, 2015a) as well as external actors, slowly establishing an entrepreneurial ecosystem supporting academic founders. On a theoretical level, academic entrepreneurship has become a research topic in its own right, resulting in numerous publications employing different theoretical lenses as well as research foci (Rothaermel et al., 2007; Skute et al., 2017). To meet the increased political demand for successful knowledge and technology transfer, one large stream of research is trying to understand successful transfer strategies and the factors influencing scientists transfer engagement as well as successful spin-off creation and company development.

The focus and narrative prevailing in those articles address positive influences on transfer activities. Barriers and constraints implicitly accompany findings but are seldom the whole focus. Influencing factors on transfer engagement and on founding in general will be discussed in the following sub-section, referencing genderspecific findings when available. Reviewing this literature, these aspects can be grouped into two different segments - meta-level factors and operational-level factors - following a systematization by Sinell, Iffländer, and Muschner (2018).

Meta-level factors

Considering the meta-level, findings address factors that may be specific to national innovation systems, 


\section{Gender-Specific Constraints on Academic Entrepreneurship and Engagement in Knowledge and Technology Transfer Anna Sinell, Roda Müller-Wieland, and Antonia Muschner}

while others can be generalized for developed countries and are systemic for societies at large. Acquainting oneself with relevant national laws, policies, and administrative procedures for starting a business requires different amounts of effort depending on the specifics of the national innovation system. A need for substantial investment of temporal and financial resources constitutes an obstacle to founding (EFI, 2014).

Further, the entrepreneurial sphere is highly connoted with being male and led by men (Dautzenberg et al., 2013), suggesting that individuals with female gender identities may have a harder time asserting themselves in a culture that favours male-gendered approaches (Benschop \& Doorewaard, 1998). A case in point are studies that demonstrate that there is a gender bias in the financing of startups, showing that, with identical pitches in front of investors, male entrepreneurs are favoured over female entrepreneurs (Brooks et al., 2014). Masculine hegemony is challenged when there are female partners in the venture capital firms, making it $50 \%$ more likely that startups with female members will receive investment (Brush et al., 2014). In the case of founding an academic spin-off, the perception prevails that entrepreneurship and academia systematically differ in their work logics (Sinell et al., 2015; van der Sijde et al., 2014): entrepreneurship is seen to have little appeal to scientists who are also uncertain about how to cross over into the business sphere.

\section{Operational-level factors}

Considering the influences on transfer engagement on an operational level, findings are more specific for academic entrepreneurship, particularly with respect to the organizational characteristics of research institutions and universities. In order to support transfer activities, numerous organizations implemented technology transfer offices, hoping they will bridge gaps between academia and industry (Siegel \& Wright, 2015b). However, studies show that the mere existence of technology transfer offices is not necessarily sufficient to increase founding rates, and scientists are often not even aware of their existence (Clarysse et al., 2011; Huyghe et al., 2016). Important factors that determine the acceptance by scientists as well as their success include strategy (Link et al., 2015; Sinell et al., 2018), interdisciplinarity, and established structures (Caldera \& Debande, 2010; Lautenschläger et al., 2014). Also, the presence of role models, interaction with entrepreneurial peers, and financial and career-relevant incentives rewarding founding efforts positively influence spin-off formation (Fritsch \& Krabel, 2012; Huyghe \& Knockaert, 2015; Moog et al., 2015).
Essential for the success of these measures is a proactive communication strategy that ensures scientists are aware of the measures (Lautenschläger et al., 2014). A lack of awareness is a key reason scientists bypass technology transfer offices (Huyghe et al., 2016). On the level of the direct work environment of the scientist, norms and rules influence the decision of the individual scientist to partake in knowledge and technology transfer (Jong, 2006; Stuart \& Ding, 2006). If the leader of the group or other direct colleagues have previously been involved in knowledge and technology transfer, scientists feel encouraged and are more likely to engage in such activities themselves (Bercovitz \& Feldman, 2008).

Research has shown that, instead of supplanting one another, different modes of transfer interrelate and reinforce one another; in other words, a previous commitment to transfer activities may lead to future transfer engagement (Crespi et al., 2011; Perkmann et al., 2013; van Looy et al., 2011). Sufficient resources to promote transfer activity are also necessary prerequisites for scientists to consider commercializing (Rasmussen et al., 2014). According to Busolt and Kugele (2009), female scientists have fewer resources at their disposal than their male colleagues with respect to financial resources, lab time, and time for research and training.

Ultimately, the decision to get involved in knowledge and technology transfer and academic entrepreneurship is an individual one. Field of study and business experience, proximity to application, diverse capabilities, and self-confidence in one's own abilities positively influence engagement in knowledge and technology transfer (Fritsch \& Krabel, 2012; Kirkwood, 2009; Kulicke, 2006; Moog et al., 2015).

For the most part, the findings discussed above focus on supportive factors for fostering transfer activities of scientists. However, they do not consider whether female and male scientists perceive obstacles and promoting aspects the same way. Taking into account that motivations differ (Iffländer et al., in press), it is also plausible that female and male scientist are discouraged by different circumstances.

\section{Method and Sample}

Our analysis is based on 40 qualitative semi-structured interviews with scientists. The sample consisted of scientists in STEM fields who are employed by universities or public research organizations of applied science 


\section{Gender-Specific Constraints on Academic Entrepreneurship and Engagement in Knowledge and Technology Transfer Anna Sinell, Roda Müller-Wieland, and Antonia Muschner}

and who either intended to incorporate an academic spin-off or had done so recently (see Table 1 for the sample description). The interviews were conducted either by telephone or face-to-face between October 2016 and January 2017, lasted approximately 90 minutes, and were recorded and then transcribed. The data was gathered within the project "Gender in Knowledge and Technology Transfer" project (tinyurl.com/ y6veglvx), which is funded by the German Ministry of Education and Research. The project aims at developing new approaches that can help encourage researchers, particularly women, to participate in knowledge and technology transfer. This article presents the findings from this project that describe specific barriers to transfer and spin-off activities in Germany.

The semi-structured interview guideline was developed with reference to a review of the relevant literature. The questions focused on personal traits, motives of entrepreneurial involvement, relevant conditions and barriers for transfer and entrepreneurial activities - in particular, the decision-making and business-starting processes, gender-related experiences, as well as the employers' work conditions, culture, and support.
However, only results regarding barriers and constraints are considered in the current article, and they were analyzed using Mayring's (2010) open-ended, qualitative method of content analysis. The identified main constraints are assigned to the meta-level and the level of operation, referring to the present state of research as well as to Lundvall (2010), Best and colleagues (2016), and Sinell and colleagues (2018). Whereas constraints on the meta-level act rather indirectly, constraints on the level of operation are more multilayered and act directly. The findings are described in detail in the following sections, accompanied by quotations from the interview subjects to clarify the argumentation of the presented characteristics (Haas \& Scheibelhofer, 1998).

Given that the study is exploratory in nature, generalization of the presented findings on gender beyond the sample should be made cautiously. Even though gender was evenly distributed among the sample, the influence of intervening factors such as differing organizational cultures and local work environment was not fully controlled. The findings serve as propositions for future research regarding gender and inclusive innovation.

Table 1. Sample demographics

\begin{tabular}{llccc} 
& & Female & Male & Total \\
\cline { 3 - 5 } Item and Sample Size & Category & $\mathbf{1 9}$ & $\mathbf{2 1}$ & $\mathbf{4 0}$ \\
\hline $\begin{array}{l}\text { Age in years } \\
\mathrm{n}=37\end{array}$ & $20-29$ & 5 & 3 & 8 \\
& $30-39$ & 8 & 13 & 21 \\
& $40-49$ & 2 & 3 & 5 \\
& $50-59$ & 2 & 1 & 3 \\
\hline $\begin{array}{l}\text { Most recent employer } \\
\mathrm{n}=40\end{array}$ & University & 10 & 2 & 12 \\
& Research institute & 8 & 17 & 25 \\
& Business firm & 1 & 2 & 3 \\
\hline $\begin{array}{l}\text { Field of expertise } \\
\mathrm{n}=36\end{array}$ & Physics or Mathematics & 3 & 2 & 5 \\
& Chemistry, Biology, or Medicine & 7 & 3 & 10 \\
& Humanities & 1 & 2 & 3 \\
& Engineering & 5 & 12 & 17 \\
& Media Technology & 1 & 0 & 1 \\
\hline
\end{tabular}




\section{Gender-Specific Constraints on Academic Entrepreneurship and Engagement in Knowledge and Technology Transfer Anna Sinell, Roda Müller-Wieland, and Antonia Muschner}

\section{Findings: Constraints on the Meta-Level}

Consistent with Sinell, Iffländer, and Muschner (2018), constraints on this level include structural and national factors, such as relevant stakeholders and funding programs of the innovation ecosystem or national regulations, procedures, and transfer culture. Findings on this level conglomerate to the two broader sublevels "nationwide transfer culture" and "funding guidelines and structures", which are described below and are listed in Table 2.

\section{Nationwide transfer culture}

Interviewees reported poor sensitization and enlightenment about the transfer options and alternative career pathways in general. Moreover, transfer priorities in the research system were perceived as counterproductive, which prevented them from engaging in founding academic spin-offs: Most interviewees observed publications to be the first transfer priority, because there are no incentives, such as prestige or career advantages, for patent applications or academic spin-offs. This perception was amplified by the lack of option for a scientist to return to their original position in the research system if their spin-off fails. Interviewed scientists closely connected such counterproductive transfer priorities - referring to the intended promotion of innovation capacity - to the general German science culture, which lacks role models who commercialize their results and who demonstrate that science and industry are not as incongruent as widely assumed.

"You're the bad guys who want to make money [with science]. This is a question of mentality, education, and socialization. I don't know. It's not so valued that science can lead to something of commercial use." (Female scientist, university)

"[...] actually, our life here is secured by the publications, which lead to more and more job contracts." (Female scientist, research institute)

\section{Funding guidelines and structures}

Once scientists decided to get involved in entrepreneurial activities and specifically spin-off creation, they assessed the funding guidelines and structures as non-transparent, stiff, competitive, unfair, complicated, and incompatible. Many public funding programs have strict requirements, for instance, regarding team composition. Interviewees stated that applications demand a large amount of effort and time, whereas the subsequent funding processes are slow and bureaucratic.

\begin{abstract}
"It is often the case that this process [of applying for funding programs] takes far too long in Germany. This is a process that is connected with 20- or 30page pamphlets that then are passed through expert mills for half a year. And the expert mills then pass it on to a different expert, who still has critical questions, about which the investment manager, who decides, has no idea. And then another answer is required for that." (Male scientist, research institute)
\end{abstract}

Some programs provide the grants only at a later stage of the founding, some necessitate equity share, and others end their funding abruptly. Interviewees mentioned a gap of finances after the end of a funding program, as such programs often only last for a short period and do not offer follow-up financing. Beside promotion programs, some interviewees judged financing via investors as challenging. First, interviewees found it hard to identify and convince adequate investors. Second, many investors prefer to invest in ideas with very likely profit maximization rather than in socially or ecologically valuable ideas.

\section{"Another challenge, at least for us, was the selection or search for suitable investors. I believe that this is a particularly big issue for scientists." (Female sci- entist, university)}

\section{Gender differences on the meta-level}

The analysis allows weak assumptions regarding gender differences in the above-mentioned constraints. Male interviewees apparently perceived stronger constraints on the meta-level than females. Only the male subjects criticized the lack of role models in the science system and the slow processes of funding programs. Moreover, male interviewees mentioned the counterproductive transfer priorities more often than females and demanded alternative career models more often than females. Female interviewees, however, emphasized the strict and complicated requirements of funding and support programs more often than their male colleagues, but there was no gender difference regarding the insufficient financing of such programs. Additionally, male and female equally claimed that they were not aware of the different transfer options and possibilities.

\section{Findings: Constraints on the Operational Level}

Following Sinell, Iffländer, and Muschner (2018), constraints on the operational level derive from the work environment, including the organizational culture, 


\section{Gender-Specific Constraints on Academic Entrepreneurship and Engagement in Knowledge and Technology Transfer Anna Sinell, Roda Müller-Wieland, and Antonia Muschner}

Table 2. Identified meta-level and operational constraints impacting entrepreneurial attitudes and transfer engagement. Prevalence indicates the frequency at which the constraint was mentioned by interviewees; gender difference indicates which gender experienced the specific constraint.

\begin{tabular}{|c|c|c|}
\hline Level and Constraint & Prevalence & Gender Difference \\
\hline \multicolumn{3}{|l|}{ META-LEVEL } \\
\hline \multicolumn{3}{|l|}{ Nationwide transfer culture } \\
\hline Early sensitization and awareness raising & $20 \%$ & - \\
\hline Offering alternative career pathways & $17.5 \%$ & Male \\
\hline Counterproductive transfer priorities & $12.5 \%$ & Male \\
\hline Incongruence of science and industry & $10 \%$ & - \\
\hline Lack of role models & $5 \%$ & Male \\
\hline \multicolumn{3}{|l|}{ Funding guidelines and structures } \\
\hline Strict requirements & $22.5 \%$ & Female \\
\hline Insufficient financing & $15 \%$ & - \\
\hline Interaction with investors & $12.5 \%$ & Male \\
\hline Deficient process of programs & $10 \%$ & Male \\
\hline \multicolumn{3}{|l|}{ OPERATIONAL LEVEL } \\
\hline \multicolumn{3}{|l|}{ Organizational strategies and practices } \\
\hline License agreements & $25 \%$ & Female \\
\hline Dual role of institutes & $22.5 \%$ & Male \\
\hline \multicolumn{3}{|l|}{ Organizational culture } \\
\hline Lack of support from managers and peers & $45 \%$ & - \\
\hline $\begin{array}{l}\text { Non-transparency of processes and } \\
\text { responsibilities }\end{array}$ & $10 \%$ & Male \\
\hline \multicolumn{3}{|l|}{ Individual attributes and attitudes } \\
\hline Business idea and concept & $50 \%$ & Male \\
\hline Lack of time & $40 \%$ & Female \\
\hline Lack of financial resources & $40 \%$ & Female \\
\hline Lack of human resources & $37.5 \%$ & Female \\
\hline Lack of knowledge & $20 \%$ & Female \\
\hline Lack of exchange with peers & $17.5 \%$ & Female \\
\hline Mentality & $17.5 \%$ & Male \\
\hline Lack of networks & $12.5 \%$ & Male \\
\hline Interaction with externals & $10 \%$ & Male \\
\hline Compatibility of family and work & $7.5 \%$ & Male \\
\hline
\end{tabular}

strategies, and practices as well as the individual attributes and attitudes (see Table 2). Although half of the interviewees found the development of their business idea and concept challenging, this obstacle is not executed in detail in the following, since it is not specific for academic spin-offs.

\section{Organizational culture}

The results reveal the pivotal role of the organization's highest authorities to establish an entrepreneurial culture in which academic entrepreneurship is promoted and appreciated. Interviewees claimed an entrepreneurial supportive environment with different entrepren- eurship support programs as helpful to overcome constraints. Still, many interviewees reported a lack of support from managers and peers.

"I believe that the main obstacle is always a different one: that's culture." (Male scientist, research institute)

Managers who would have been able to guide scientists through reported internal non-transparent processes, responsibilities, and structures were often not supporting the spin-off idea of the scientist. They also did not encourage the acquisition of customers, industry, or 


\section{Gender-Specific Constraints on Academic Entrepreneurship and Engagement in Knowledge and Technology Transfer Anna Sinell, Roda Müller-Wieland, and Antonia Muschner}

important network partners, usually because of the fear that the researcher leaves the institute in favour of an outside job offering.

"This is an institute director who is now two years away from retirement. This is the generation that thinks that all this new German technology transfer is nonsense. They think a research institute is there for research. They say that's just an end in itself." (Male scientist, research institute)

"We were then, when we were founded, or probably still are now, always looked upon as the people who 'soiled our own nest' and were always seen as those who are now somehow capitalizing on science. We can already see that this is actually nonsense-you can earn money with the science you have made." (Female scientist, university)

\section{Organizational strategies and practices}

Once scientists defied the organizational constraints and committed themselves to the spin-off formation, institutes often connected the employee's transfer activities with license and patent agreements and demanded substantial shares in the spin-off. Such license and patent agreements were either perceived as non-transparent, strict, or non-consensual. For instance, public institutes and universities demanded excessive prices that deterred potential investors and they did not support the "open source" attitude of the scientist.

\section{"Institutes always try to keep the IP [intellectual property] in house and issue licenses. And that is counterproductive for spin-offs. No investor goes into a license history. An investor always wants to have the IP inside, always in the company. And then there are terribly protracted negotiations with the investors and also with the institutes that the IP is to enter the company and that then the li- cense... there can still be agreed upon a license fee." (Male scientist, research institute)}

Moreover, close cooperation with industry or contract research as a mode of commercializing research findings is in some organizations institutionally-supported and highly desired in contrast to academic spin-offs. Although contract research contributes to the scientist's reputation within the organization, it inhibits their reputation within the scientific community because data from industry projects is often not disclosed and thus is unlikely to be available for use in publications.
The interviewees from research organizations were particularly ambivalent about the dual role of the institutes: institutes are under pressure to grow and develop, but concurrently, spin-offs need resources in terms of both personnel and time. Additional challenges arise when the spin-off's activities are competing with the institute's activities and resources. According to some interviewees, institutes feared the migration of the scientists, in particular when scientists followed their transfer activities as second jobs or self-employment. The ambivalence of the dual role of public institutes was also described by scientists when the spin-off was fundamentally based on the scientist's work in the institute and thus had to be finished before temporary job contracts ended.

“Our positions are so short - in two years you can't seriously do research, write research proposals, write publications. [...] And then, incidentally, to push ahead with things such that a patent is applied for or that you get a grant for founding, which is basically not possible within a two-year period of time." (Female scientist, research institute)

\section{Individual attributes and attitudes}

According to most interviewees, daily projects and, in some cases, the high benchmark for industry acquisition result in a lack of time to engage in entrepreneurial activities. In particular, a lack of time comes along with several constraints: interviewees reported not having time to build up knowledge about how to start a spin-off, to network with relevant stakeholders, to recruit adequate teams, and, finally, to care for their families. Additionally, temporary job contracts in the science system increase the time pressure during simultaneously slow bureaucratic processes.

"...the most important thing would be to have the freedom to work on your founding idea..." (Male scientist, research institute)

Financial insecurity and the lack of option to return to the organization in case of a failure hampers entrepreneurial engagement or only allows founding activities as part-time work. Lack of financial resources results in a lack of human resources, because academic spin-offs cannot offer attractive job positions to high-potential employees with the required competences. Once they had formed their teams, interviewees reported difficulties keeping the team members together and find additional personnel in order to grow. 


\section{Gender-Specific Constraints on Academic Entrepreneurship and Engagement in Knowledge and Technology Transfer Anna Sinell, Roda Müller-Wieland, and Antonia Muschner}

\begin{abstract}
"More competencies are needed; more freedom is needed. And it also requires the decision-making powers to be able to start running with a certain budget. And not to be accountable at all points." (Male scientist, university)

"In this phase, it's just extremely difficult to get good team members, because you can't offer anything at all. You cannot offer a job, nor can you offer any kind of security. And the only people I could talk to were people from my circle of friends. Everything else was not possible. And then, of course, only people who just happened to have no job themselves. Because no one would have quit their job at this stage to come to me. We were simply too insignificant for that, it was far too risky. It was very difficult." (Female scientist, university)
\end{abstract}

In some cases, financial insecurity also negatively affected the scientists' founding mentality. Exchange with peers was suggested as one way to reduce insecurity and foster networking and idea creation.

\section{Gender differences on the operational level}

Although both male and female interviewees agreed that organizational culture was a decisive factor, the males found that internal communication and decisionmaking processes were non-transparent and criticized the dual role of the institute more often than the females. However, female interviewees more often described the license and patent agreement an impediment. Slightly more females than males registered the lack of time and financial resources. However, the results reveal notable gender-differences with regard to a lack of human resources, knowledge, and exchange with peers: the females mentioned those constraints clearly more often than the males. On the other hand, the males more often reported struggles with their business ideas and concepts, their interactions with external actors, and their mentality.

\section{Conclusion and Implications}

Due to the increasing pressure public research organizations face to demonstrate their relevance to society and promote their knowledge and technology transfer, support programs and entrepreneurship ecosystems have gradually diversified in recent years (Siegel \& Wright, 2015a). This study contributes to a deeper understanding of scientists' decisions to actively engage in transfer and entrepreneurial activities by revealing central constraints for knowledge and technology transfer at public research organizations in STEM fields. In order to develop needs-oriented support programs and thereby support all scientists to the same degree, we particularly analyzed gender differences in perceived constraints. This study is the first to reveal insights on gender-specific constraints impacting individual transfer engagement. Due to its explorative nature, findings of the study serve as propositions for future research in fields of gender and inclusive innovation. To conclude this article, we summarize the findings and derive implications for research organizations for more inclusive measures to foster entrepreneurial activities

In line with research on challenges in founding a business in general, major constraints and barriers impacting scientists' engagement in spin-off activities make it challenging to develop a valuable business idea and concept. The analysis therefore contributes to previous studies calling for further educational development programs for scientists to increase business skills and market knowledge (Brodack \& Sinell, 2017). To tackle these challenges, research organizations could establish match-making events with experienced entrepreneurs and business coaches. Such events can, on the one hand, help scientists elaborate and foster their business ideas and concepts; on the other hand, the informal exchange can lead to new spin-off ideas. Moreover, such personal exchange can help deconstruct the perceived differences between academic employment and entrepreneurship.

The main constraints specific to academic entrepreneurship and transfer activities identified in this study are on the operational level: i) a hostile organizational culture, ii) a lack of time and financial resources, and iii) a lack of human resources. The analysis of gender differences revealed that females perceive the lack of resources (i.e., time, money, people) and knowledge more often and as greater challenges than their male colleagues. Both women and men stressed the need for relevant support services and awareness raising initiatives for transfer activities. The findings are in line with previous studies (Huyghe \& Knockaert, 2015) and underline the importance of early sensitization and role models in the work environment for fostering academic entrepreneurship.

In order to address the identified barriers and thereby foster engagement in transfer and academic entrepreneurship, research institutions need to take action and both create new and modify existing needs-oriented support and funding services. As has been outlined, one major barrier lies in the lack of acknowledgement 


\section{Gender-Specific Constraints on Academic Entrepreneurship and Engagement in Knowledge and Technology Transfer Anna Sinell, Roda Müller-Wieland, and Antonia Muschner}

of, and awareness raising for, transfer and entrepreneurial activities. These challenges can be reduced by establishing gender-sensitive incentive schemes relating to different dimensions such as promotion, tenure, or remuneration. The findings moreover indicate that not only the scientists, but also their department heads and transfer managers, need to be rewarded for their transfer engagement. In addition to incentive schemes, research organizations should implement innovation scouting activities to enhance the visibility of the transfer office and discover potential technologies. Ultimately, in order to raise the awareness for transfer and academic entrepreneurship, research organizations must develop communication strategies and actively promote spin-off successes as well as learnings from failures.

To foster inclusive innovation in terms of social groups, the consideration of gender diversity in founding teams must be acknowledged and addressed by support programs. In this study, female interviewees in particular assessed programs' requirements as strict and reported a lack of knowledge and resources. As women and men are likely to follow different business strategies and motivations, the need for gender-specific communication and arrangement of programs becomes apparent. Research institutions should therefore aim to achieve an impact with their research and transfer activities that goes beyond economic dimensions.

Given its exploratory approach, this study has limitations; however, the presented findings may induce further research and in-depth analysis on this matter. Even though the gender distribution within the sample is practically equal, variations in different factors occurred. The majority of female scientists were employed in universities when founding their spin-off, whereas men were employed by research universities. As the local work environments and institute cultures differ, the different institutional settings could provide an alternating explanation over the gender dimension. Further research is therefore necessary to confirm and expand upon these findings.

\section{About the Authors}

Anna Sinell is a Senior Scientist at the Center for Responsible Research and Innovation at Fraunhofer IAO in Berlin, Germany. Her research focus lies on knowledge and technology transfer, especially with regards to the analysis of academic entrepreneurship. She recently completed her $\mathrm{PhD}$ dissertation on the topic of "Strategies for Fostering Academic Entrepreneurship" at Technische Universität Berlin. Through her interdisciplinary studies of psychology and engineering, she gained multiple competencies in fields of empirical testing methods and techniques.

Roda Müller-Wieland is a Research Assistant at the Center for Responsible Research and Innovation at Fraunhofer IAO in Berlin, Germany. Her research focuses on the analysis of organizational culture, change and innovation processes, as well as on academic entrepreneurship in the context of knowledge and technology transfer. In her research, gender equality is taken into account as a cross-cutting theme. She holds an MSc in Psychology from Stellenbosch University in South Africa and the University of Hamburg, Germany, through which she gained multiple competencies in qualitative research methods and techniques.

Antonia Muschner is a Research Assistant at the Center for Responsible Research and Innovation at Fraunhofer IAO in Berlin, Germany. Her research focuses on various aspects of knowledge and technology transfer such as academic entrepreneurship, university-industry cooperation, and new formats of collaboration in innovation ecosystems. Furthermore, she was involved in projects looking at gender equality in German academia. She holds an MA in Sociology of Technology and has studied both sociology and cultural studies with a focus on qualitative research methods, sustainable innovation, and entrepreneurship in Berlin, Frankfurt/Oder, and Warsaw. 


\section{Gender-Specific Constraints on Academic Entrepreneurship and Engagement in Knowledge and Technology Transfer Anna Sinell, Roda Müller-Wieland, and Antonia Muschner}

\section{References}

Acs, Z. J., Audretsch, D. B., Lehmann, E. E., \& Licht, G. 2017. National Systems of Innovation. The Journal of Technology Transfer, 42(5): 997-1008.

http://doi.org/10.1007/s10961-016-9481-8

Benschop, Y., \& Doorewaard, H. 1998. Covered by Equality: The Gender Subtext of Organizations. Organization Studies, 19(5): 787-805.

http://doi.org/10.1177/017084069801900504

Bercovitz, J., \& Feldman, M. 2008. Academic Entrepreneurs: Organizational Change at the Individual Level. Organization Science, 19(1): 69-89.

http://doi.org/10.1007/s10961-005-5029-z

Best, K., Sinell, A., Heidingsfelder, M. L., \& Schraudner, M. 2016. The Gender Dimension in Knowledge and Technology Transfer - The German Case. European Journal of Innovation Management, 19(1): $2-25$.

http://doi.org/10.1108/EJIM-07-2015-0052

BMBF. 2017. Mehr Chancen für Gründungen: Fünf Punkte für eine neue Gründerzeit. Bonn, Germany: Bundesministerium für Bildung und Forschung (BMBF).

https://www.bmbf.de/pub/Konzept_5_Punkte_Gruenderzeit_mit_ IHV.pdf

Braun-Thürmann, H., Knie, A., \& Simon, D. 2010. Unternehmen Wissenschaft: Ausgründungen als Grenzüberschreitungen akademischer Forschung. Bielefeld, Germany: Transcript.

Brodack, F., \& Sinell, A. 2017. Promoting Entrepreneurial Commitment: The Benefits of Interdisciplinarity. Technology Innovation Management Review, 7(12): 6-13.

http://doi.org/10.22215/timreview/1123

Brooks, A. W., Huang, L., Kearney, S. W., \& Murray, F. E. 2014. Investors Prefer Entrepreneurial Ventures Pitched by Attractive Men. Proceedings of the National Academy of Sciences of the United States of America, 111(12): 4427-4431. http://doi.org/10.1073/pnas.1321202111

Brush, C., Green, P., Balachandra, L., \& Davis, A. E. 2014. Women Entrepreneurs 2014: Bridging the Gender Gap in Venture Capital: Diana Report. Wellesley, MA: Babson College.

Busolt, U., \& Kugele, K. 2009. The Gender Innovation and Research Productivity Gap in Europe. International Journal of Innovation and Sustainable Development, 4(2/3): 109-122.

http://doi.org/10.1504/IJISD.2009.028066

Caldera, A., \& Debande, O. 2010. Performance of Spanish Universities in Technology Transfer: An Empirical Analysis. Research Policy, 39(9): 1160-1173.

http://doi.org/10.1016/j.respol.2010.05.016

Carayannis, E. G., \& Campbell, D. F. J. 2009. 'Mode 3' and 'Quadruple Helix': Toward a 21st Century Fractal Innovation Ecosystem. International Journal of Technology Management, 46(3/4): 201-234.

Clarysse, B., \& Moray, N. 2004. A Process Study of Entrepreneurial Team Formation: The Case of a Research-Based Spin-Off. Journal of Business Venturing, 19(1): 55-79.

http://doi.org/10.1016/S0883-9026(02)00113-1
Clarysse, B., Tartari, V., \& Salter, A. 2011. The Impact of Entrepreneurial Capacity, Experience and Organizational Support on Academic Entrepreneurship. Research Policy, 40(8): 1084-1093. http://doi.org/10.1016/j.respol.2011.05.010

Crespi, G., D'Este, P., Fontana, R., \& Geuna, A. 2011. The Impact of Academic Patenting on University Research and Its Transfer. Research Policy, 40(1): 55-68. http://doi.org/10.1016/j.respol.2010.09.010

Dalborg, C., von Friedrichs, Y., \& Wincent, J. 2012. Beyond the Numbers: Qualitative Growth in Women's Businesses. International Journal of Gender and Entrepreneurship, 4(3): 289-315.

http://doi.org/10.1108/17566261211264163

Dautzenberg, K., Steinbrück, A., Brenning, L., \& Zinke, G. 2013. Wachstumspotenziale inhaberinnengeführter Unternehmen - wo steht Deutschland im EU-Vergleich?: Studie im Auftrag des Bundesministeriums für Wirtschaft und Technologie. Endbericht. Berlin: Rambøll Management Consultig GmbH.

Dickel, P. 2009. Marktbezogenes Lernen in Akademischen Spin-offs: Gewinnung und Integration von Marktinformationen in der frühen Phase technologiebasierter Ausgründungen. Wiesbaden, Germany: Gabler Verlag.

EFI. 2014. Research, Innovation and Technological Performance in Germany - EFI Report 2014. Berlin: Commission of Experts for Research and Innovation (EFI).

http://www.e-

fi.de/fileadmin/Gutachten_2014/EFI_Report_2014.pdf

Egeln, J., Gottschalk, S., Rammer, C., \& Spielkamp, A. 2003. SpinoffGründungen aus der öffentlichen Forschung in Deutschland: Gutachten für das Bundesministerium für Bildung und Forschung. Wirtschaftsanalysen no. 03-02. Mannheim, Germany: Centre for European Economic Research.

European Commission. 2017. The European Technology Transfer Offices Circle. European Commission. Accessed September 12, 2017:

https://ec.europa.eu/jrc/communities/community/629/about

Fritsch, M., \& Krabel, S. 2012. Ready to Leave the Ivory Tower? Academic Scientists' Appeal to Work in the Private Sector. The Journal of Technology Transfer, 37(3): 271-296. http://doi.org/10.1007/s10961-010-9174-7

Fryges, H., \& Wright, M. 2014. The Origin of Spin-Offs: A Typology of Corporate and Academic Spin-Offs. Small Business Economics, 43(2): 245-259. http://doi.org/10.1007/s11187-013-9535-3

Grimaldi, R., Kenney, M., Siegel, D. S., \& Wright, M. 2011. 30 Years After Bayh-Dole: Reassessing Academic Entrepreneurship. Research Policy, 40(8): 1045-1057. http://doi.org/10.1016/j.respol.2011.04.005

Haas, B., \& Scheibelhofer, E. 1998. Typenbildung in der qualitativen Sozialforschung: Eine methodologische Analyse anhand ausgewählter Beispiele. Wien: Institut für Höhere Studien.

Haller, I., Vrohlings, M., Frietsch, R., \& Grupp, H. 2007. Analyse des technischen und wissenschaftlichen Beitrags von Frauen. Studien zum deutschen Innovationssystem no. 18-2007. Berlin: Fraunhofer. 


\section{Gender-Specific Constraints on Academic Entrepreneurship and Engagement in Knowledge and Technology Transfer Anna Sinell, Roda Müller-Wieland, and Antonia Muschner}

Huyghe, A., \& Knockaert, M. 2015. The Influence of Organizational Culture and Climate on Entrepreneurial Intentions among Research Scientists. The Journal of Technology Transfer, 40(1): $138-160$.

http://doi.org/10.1007/s10961-014-9333-3

Huyghe, A., Knockaert, M., Piva, E., \& Wright, M. 2016. Are Researchers Deliberately Bypassing the Technology Transfer Office? An Analysis of TTO Awareness. Small Business Economics, 47(3): 589-607.

http://doi.org/10.1007/s11187-016-9757-2

Iffländer, V., Sinell, A., \& Schraudner, M. In press. Does Gender Make a Difference? Gender Differences in the Motivations and Strategies of Female and Male Academic Entrepreneurs. In S. Birkner, K. Ettl, I. Ebbers \& F. Welter (Eds.), Women's Entrepreneurship in Europe: Multidimensional Research and Case Study Insights. Berlin: Springer.

Jong, S. 2006. How Organizational Structures in Science Shape SpinOff Firms: The Biochemistry Departments of Berkeley, Stanford, and UCSF and the Birth of the Biotech Industry. Industrial and Corporate Change, 15(2): 251-283. http://doi.org/10.1093/icc/dtj014

Kirkwood, J. 2009. Is a Lack of Self-Confidence Hindering Women Entrepreneurs? International Journal of Gender and Entrepreneurship, 1(2): 118-133. http://doi.org/10.1108/17566260910969670

Kulicke, M. 2006. EXIST - Existenzgründungen aus Hochschulen: Bericht der wissenschaftlichen Begleitung zum Förderzeitraum 1998 bis 2005. Kurzfassung. Karlsruhe, Germany: Fraunhofer Institut für System- und Innovationsforschung (ISI).

Lautenschläger, A., Haase, H., \& Kratzer, J. 2014. Contingency Factors on University Spin-Off Formation: An Empirical Study in Germany. Journal of Entrepreneurship and Public Policy, 3(1): 160-176.

http://doi.org/10.1108/JEPP-02-2012-0013

Link, A. N., Siegel, D. S., \& Bozeman, B. 2007. An Empirical Analysis of the Propensity of Academics to Engage in Informal University Technology Transfer. Industrial and Corporate Change, 16(4): 641-655.

http://doi.org/10.1093/icc/dtm020

Link, A. N., Siegel, D. S., \& Wright, M. (Eds.) 2015. The Chicago Handbook of University Technology Transfer and Academic Entrepreneurship. Chicago: The University of Chicago Press.

Lortie, J., Castrogiovanni, G. J., \& Cox, K. C. 2017. Gender, Social Salience, and Social Performance: How Women Pursue and Perform in Social Ventures. Entrepreneurship \& Regional Development, 29(1-2): 155-173.

http://doi.org/10.1080/08985626.2016.1255433

Lundvall, B.-Å. 2010. National Systems of Innovation: Toward a Theory of Innovation and Interactive Learning. New York: Anthem.

Mayring, P. 2010. Qualitative Inhaltsanalyse: Grundlagen und Techniken. Weinheim, Germany: Beltz.

Moog, P., Werner, A., Houweling, S., \& Backes-Gellner, U. 2015. The Impact of Skills, Working Time Allocation and Peer Effects on the Entrepreneurial Intentions of Scientists. The Journal of Technology Transfer, 40(3): 493-511.

http://doi.org/10.1007/s10961-014-9347-x
Perkmann, M., Tartari, V., McKelvey, M., Autio, E., Broström, A., D’Este, P., Fini, R., Geuna, A., Grimaldi, R., Hughes, A., Krabel, S., Kitson, M., Llerena, P., Lissoni, F., Salter, A., \& Sobrero, M. 2013. Academic Engagement and Commercialisation: A Review of the Literature on University-Industry Relations. Research Policy, 42(2): 423-442.

http://doi.org/10.1016/j.respol.2012.09.007

Pirnay, F., Surlemont, B., \& Nlemvo, F. 2003. Toward a Typology of University Spin-offs. Small Business Economics, 21(4): 355-369. http://doi.org/10.1023/A:1026167105153

Rasmussen, E., Mosey, S., \& Wright, M. 2014. The Influence of University Departments on the Evolution of Entrepreneurial Competencies in Spin-Off Ventures. Research Policy, 43(1): 92-106. http://doi.org/10.1016/j.respol.2013.06.007

Reichborn-Kjennerud, K., \& Svare, H. 2014. Entrepreneurial Growth Strategies: The Female Touch. International Journal of Gender and Entrepreneurship, 6(2): 181-199.

http://doi.org/10.1108/IJGE-04-2013-0043

Rothaermel, F. T., Agung, S. D., \& Jiang, L. 2007. University Entrepreneurship: A Taxonomy of the Literature. Industrial and Corporate Change, 16(4): 691-791. http://doi.org/10.1093/icc/dtm023

Schillo, S. R., \& Robinson, R. M. 2017. Inclusive Innovation in Developed Countries: The Who, What, Why, and How. Technology Innovation Management Review, 7(7): 34-46. https://timreview.ca/article/1089

Siegel, D. S., \& Wright, M. 2015a. Academic Entrepreneurship: Time for a Rethink? British Journal of Management, 26(4): 582-595. http://doi.org/10.1111/1467-8551.12116

Siegel, D. S., \& Wright, M. 2015b. University Technology Transfer Offices, Licensing, and Start-Ups. In A. N. Link, D. S. Siegel \& M. Wright (Eds.), The Chicago Handbook of University Technology Transfer and Academic Entrepreneurship: 1-40. Chicago: The University of Chicago Press.

Sinell, A., Heidingsfelder, M., \& Schraudner, M. 2015. Entrepreneurship and Academic Employment - More Alike than You'd Think. Journal of Technology Management \& Innovation, 10(3): 1-10.

http://doi.org/10.4067/S0718-27242015000300001

Sinell, A., Iffländer, V., \& Muschner, A. 2018. Uncovering Transfer - A Cross-National Comparative Analysis. European Journal of Innovation Management, 20(1): 70-95. http://doi.org/10.1108/EJIM-01-2017-0006

Skute, I., Zalewska-Kurek, K., Hatak, I., \& de Weerd-Nederhof, P. 2017. Mapping the Field: A Bibliometric Analysis of the Literature on University-Industry Collaborations. The Journal of Technology Transfer, 62(2): 163.

http://doi.org/10.1007/s10961-017-9637-1

Stuart, T. E., \& Ding, W. W. 2006. When Do Scientists Become Entrepreneurs? The Social Structural Antecedents of Commercial Activity in the Academic Life Sciences. American Journal of Sociology, 112(1): 97-144. http://doi.org/10.1086/502691

van der Sijde, P., David, F., Frederik, H., \& Redondo Carretero, M. 2014. University-Business Cooperation: A Tale of Two Logics. In T. Kliewe \& T. Kesting (Eds.), Moderne Konzepte des organisationalen Marketing: 145-160. Berlin: Springer. 


\section{Gender-Specific Constraints on Academic Entrepreneurship and Engagement in Knowledge and Technology Transfer Anna Sinell, Roda Müller-Wieland, and Antonia Muschner}

van Looy, B., Landoni, P., Callaert, J., van Pottelsberghe, B., Sapsalis, E., \& Debackere, K. 2011. Entrepreneurial Effectiveness of European Universities: An Empirical Assessment of Antecedents and Trade-Offs. Research Policy, 40(4): 553-564.

http://doi.org/10.1016/j.respol.2011.02.001

Vincett, P. S. 2010. The Economic Impacts of Academic Spin-Off Companies, and Their Implications for Public Policy. Research Policy, 39(6): 736-747.

http://doi.org/10.1016/j.respol.2010.02.001

Walter, A., \& Auer, M. (Eds.) 2009. Academic Entrepreneurship: Unternehmertum in der Forschung. Wiesbaden, Germany: Gabler Verlag / Springer.

The Wissenschaftsrat. 2016. Wissens- und Technologietransfer als Gegenstand institutioneller Strategien: Positionspapier. Cologne, Germany: The Wissenschaftsrat (WR; German Council of Science and Humanities).

https://www.wissenschaftsrat.de/download/archiv/5665-16.pdf

Wright, M., Clarysse, B., Lockett, A., \& Knockaert, M. 2008. Mid-Range Universities' Linkages with Industry: Knowledge Types and the Role of Intermediaries. Research Policy, 37(8): 1205-1223.

http://doi.org/10.1016/j.respol.2008.04.021

Citation: Sinell, A., Müller-Wieland, R., \& Muschner, A.

2018. Gender-Specific Constraints on Academic

(cc) BY

Entrepreneurship and Engagement in Knowledge and

Technology Transfer. Technology Innovation

Management Review, 8(2): 15-26.

http://doi.org/10.22215/timreview/1136

Keywords: academic spin-offs, academic

entrepreneurship, gender, qualitative study, research-

based companies 


\title{
Inclusive Innovation in Biohacker Spaces: The Role of Systems and Networks Jeremy de Beer and Vipal Jain
}

\author{
"If, as I believe that my theory is true \& if it be" \\ accepted even by one competent judge, it will be \\ a considerable step in science.
}

Charles Darwin (1809-1882)

Naturalist, geologist, and biologist

In a letter to his wife, Emma, July 5, 1844

\begin{abstract}
In this article, we examine the development of biohacker spaces and their impact on innovation systems through the lens of inclusive innovation. Examining issues associated with people, activities, outcomes, and governance, we observe that biohacker spaces offer an alternative approach to biotechnological research outside the orthodox walls of academia, industry, and government. We explain that harnessing the full innovative potential of these spaces depends on flexible legal and regulatory systems, including appropriate biosafety regulations and intellectual property policies and practices, and organic, community-based social and financial networking.
\end{abstract}

\section{Introduction}

The biohacking movement is changing who can innovate in biotechnology. Driven by principles of inclusivity and open science, the biohacking movement encourages sharing and transparency of data, ideas, and resources. As a result, innovation is now happening outside of traditional research labs, in unconventional spaces - do-it-yourself (DIY) biology labs known as "biohacker spaces". Labelled like "maker spaces" (which contain the fabrication, metal/woodworking, additive manufacturing/3D printing, digitization, and related tools that "makers" use to tinker with hardware and software), biohacker spaces are attracting a growing number of entrepreneurs, students, scientists, and members of the public.

A biohacker space is a space where people with an interest in biotechnology gather to tinker with biological materials. These spaces, such as Genspace (genspace.org) in New York, Biotown (biotown.ca) in Ottawa, and La Paillasse (lapaillasse.org) in Paris, exist outside of traditional academic and research labs with the aim of democratizing and advancing science by providing shared access to tools and resources (Scheifele \& Burkett, 2016).
Biohacker spaces hold great potential for promoting innovation. Numerous innovative projects have emerged from these spaces. For example, biohackers have developed cheaper tools and equipment (Crook, 2011; see also Bancroft, 2016). They are also working to develop low-cost medicines for conditions such as diabetes (Ossolo, 2015). There is a general, often unspoken assumption that the openness of biohacker spaces facilitates greater participation in biotechnology research, and therefore, more inclusive innovation. In this article, we explore that assumption using the inclusive innovation framework developed by Schillo and Robinson (2017).

Inclusive innovation requires that opportunities for participation are broadly available to all and that the benefits of innovation are broadly shared by all (Centre for the Study of Living Standards, 2016). In Schillo and Robinson's framework, there are four dimensions along which innovation may be inclusive:

1. The people involved in innovation (who)

2. The type of innovation activities (what)

3 . The range of outcomes to be captured (why)

4. The governance mechanism of innovation (how) 


\section{Inclusive Innovation in Biohacker Spaces: The Role of Systems and Networks}

\section{Jeremy de Beer and Vipal Jain}

More particularly, inclusive innovation policy must consider historically excluded groups (i.e., women, youth, and informal sector entrepreneurs) as well as groups predicted to be negatively impacted by innovation (i.e., people with jobs that are predicted to be replaced by artificial intelligence) (Schillo \& Robinson, 2017). Inclusive innovation requires considering activities not just in the economic sphere but also in the social sphere (European Commission, 1995; see also Planes-Satorra \& Paunov, 2017). It also requires considering all positive and negative outcomes of innovation, such as economic, social, and environmental aspects (Kuhlmann \& Rip, 2014). Lastly, inclusive innovation requires developing a governance mechanism that allows the inclusion of excluded groups as stakeholders in the innovation process (Schillo \& Robinson, 2017).

In assessing the inclusivity of biohacker spaces, we have developed a concentric model, as depicted in Figure 1. The concept of space is at the centre of our analysis. Space is important for biohacking because physical location matters. In that respect, biohacking is more analogous to hardware engineering than software programming. Unlike software programming, where coders can collaborate asynchronously across vast distances, hardware engineering usually requires access to a physical space with tools and equipment beyond just a computer. That is also true for biohacking. The space for biohacking can take on different forms. It can be large or small, and range from a garage, bedroom, or kitchen to a biology-oriented community lab.

\section{Four Dimensions of Inclusivity}

In this part of the article, we examine the four dimensions of inclusive innovation in quadrants clustered around biohacker spaces. The four dimensions of inclusive innovation overlap to some extent with the three types variables used by de Beer and colleagues (2017a) in a recent scan of South Africa's maker movement. They looked at three clusters of variables - management variables, spatial variables, and activity variables - oriented around communities of practice. In our application of Schillo and Robinson's (2017) framework, biohacker communities can be understood in relation to the context of the inclusiveness of people as well as through other dimensions of inclusivity.

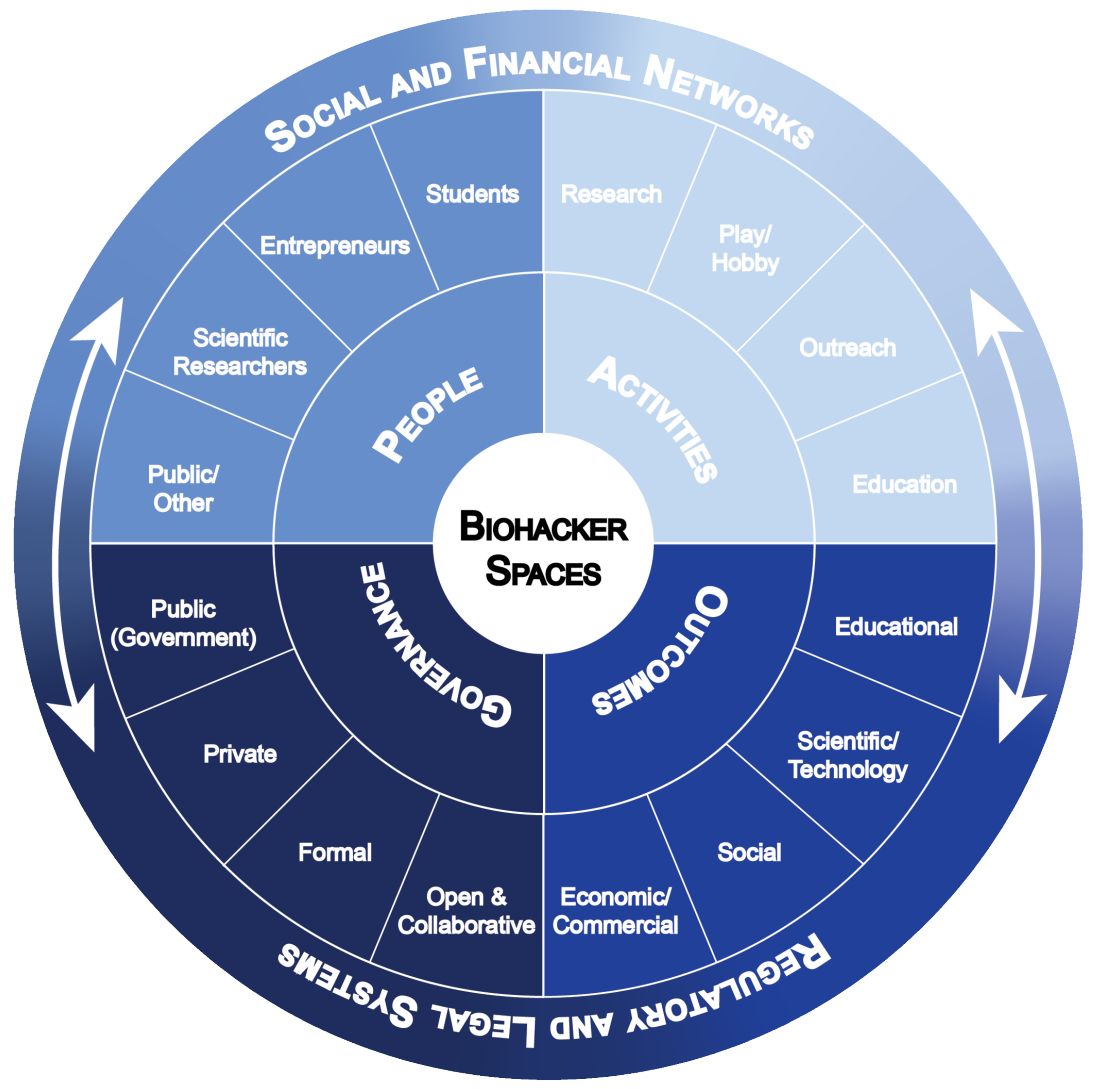

Figure 1. Context and constraints for inclusive innovation at biohacker spaces 


\title{
Inclusive Innovation in Biohacker Spaces: The Role of Systems and Networks
}

\author{
Jeremy de Beer and Vipal Jain
}

Below, for each of the four dimensions illustrated in Figure 1, we explain some of the diverse traits of biohacker spaces that make them more or less inclusive. Of course, because every biohacker space is unique in some way, our analysis is illustrative not definitive. We then look at two broader characteristics of the innovation ecosystem, as opposed to biohacker spaces themselves, that we suggest especially impact inclusivity: social and financial networks, and legal and regulatory systems.

\section{People}

Biohacker spaces open a new possibility of participating in biotechnology to people in fields outside of formal, academic, or industrial scientific research. In contrast to academic labs, biohacker spaces usually provide access to everyone, regardless of their expertise and academic background (Landrain et al., 2013). They offer tools, resources, and training that benefit a diverse group of people: from students, to scientific researchers, to entrepreneurs, to members of the public simply interested in working creatively with biology (Meyer, 2012). With greater access, artists and designers can also use the technology and think of their own ideas, which may be different from what major companies do (Landrain et al., 2013). In these ways, the communities of people who use biohacker spaces are different than the communities who work with biotechnology in the conventional triple-helix innovation system involving university, industry, and government settings.

\section{Activities}

The activities that take place in biohacker spaces can be diverse, but we have classified them into four general categories: research, play/hobby, outreach, and education. Biohacker spaces give individuals a place to engage in scientific research; they also allow curious minds to play and tinker with biotechnology (Landrain et al., 2013). Spaces such as DIYBio Toronto (diybio toronto.com) are committed also to public science education, and host events to engage citizens in biotechnology. Some spaces, such as Genspace in New York, host regular crash courses geared towards teaching amateurs the fundamentals of biohacking. In all of the activities of biohacker spaces, there are aspects of either formal or informal skills training, which help to make these spaces more inclusive.

\section{Outcomes}

Biohacker spaces may be associated with economic, social, scientific, and educational outcomes. On an economic level, biohacker spaces facilitate entrepren- eurship by providing tools, training, and resources to help people prototype their biotechnology-based ideas. Biohacker spaces also help advance scientific research. There are many examples of ambitious projects that have derived from these spaces such as vegan cheese protein (D'haeseleer et al., 2014), genetically engineered bacteria that can sense arsenic (iGEM UCL, 2012), as well as robots that can automate lab work (OpenTrons, 2015). These projects have the potential to produce new breakthroughs in science. Socially, biohacking enhances public interest in biotechnology. A space itself can foster creativity and allow an exchange of ideas by allowing individuals of different experiences and expertise to meet and collaborate on projects. On an educational level, biohacker spaces help train individuals in biology and can improve individual skills through hands-on learning.

\section{Governance}

The governance of biohacker spaces may follow one of several general models. Governance may be formal and hierarchical, or it may be open and collaborative. It may be led by the private sector (i.e., corporate, community, or non-governmental organizations), the public sector (i.e., municipal governments or university), or public-private partnerships. Biohacker spaces may include for-profit, not-for-profit, as well as informal spaces (see Scheifele \& Burkett, 2016). Spaces that are not-for-profit or for-profit are also impacted by their formal governance structures, such as executive management or a board of directors. The management or board itself may have responsibilities, such as handling the space's finances. Some spaces, such as DIYbio Toronto, enable member involvement in governing the space by hosting member meetings, where discussions regarding the space happen in person.

Globally, many spaces identify open science as a governing principle of their space (Delfanti, 2013; see also Delfanti, 2011). Open science encourages researchers to share data, ideas, and resources as a means to accelerate research without the restrictions imposed by the intellectual property (IP) system (Gold, 2016). In the open science model, "original discovery is rewarded with monetary and societal benefits, which create incentives for full disclosure and diffusion for scientific knowledge" (Merton, 1973). The open science model contrasts with the proprietary model of research that more traditional institutions tend to support (David \& Hall, 2006). The less inclusive proprietary model is one where exclusive property rights are seen as incentive for investments in science (de Beer, 2017). By comparison, spaces such as Genspace and Biocurious (biocurious.org) 


\title{
Inclusive Innovation in Biohacker Spaces: The Role of Systems and Networks
}

\author{
Jeremy de Beer and Vipal Jain
}

do not own any patent rights to discoveries made in the lab (Burke, 2011). Neither do they restrict projects that might lead to patentable inventions (Burke, 2011). Of course, those spaces' practices may not be universal, particularly as commercial interest in the discoveries, inventions, and innovations arising from biohacker spaces increases.

\section{Contextualizing Biohacker Spaces within the Innovation Ecosystem}

Having considered the characteristics of biohacker spaces, we now explore the relationship between biohacker spaces and other aspects of the innovation ecosystem that can make these spaces more or less inclusive.

Innovation emerging from biohacker spaces falls, typically, within the realm of "user innovation". User innovation is distinct from open innovation, although the terms are often but mistakenly used synonymously (de Beer, 2015). Open innovation, as Chesbrough (2006) describes, refers to inward and outward flows of knowledge across organizational boundaries. This innovation model tends to rely on the appropriation and exploitation of IP. In contrast, user innovation, as von Hippel (2005) defines it, is in "sharp contrast" to the traditional innovation model in which manufacturers rely on patents, copyrights, and other IP rights to protect, and then exchange, products and services. User innovation refers to products or services developed by individuals or firms to use themselves (von Hippel, 2005). von Hippel's most recent work on "free" innovation contextualizes user innovation within ecosystems that support the unrestricted flow of innovation (von Hippel, 2016). Closely tied to the concepts of user innovation and free innovation is peer production. It describes decentralized, collaborative, non-proprietary production of knowledge (Benkler, 2006).

The concepts of user innovation, free innovation, and peer production aptly describe the approach biohacking adopts. Biohackers are interested in developing new products to use themselves. They value collaboration and data sharing without the limitations imposed by proprietary models of innovation or regulatory constraints. At the same time, we argue that successful peer production depends on social networks in which the activities people engage in are connected by common values. And while "free" innovation may not come with market prices, every activity has some kind of associated direct, indirect, or opportunity costs.
These concepts raise important questions about the systemic factors that allow biohacker spaces to flourish and support more inclusive innovation in the knowledge economy. In that context, we want to explore two aspects of the broader innovation system that will help us understand how biohacker spaces do, and might better, promote inclusive innovation. These two aspects are discussed in the following sections: i) regulatory and legal systems and ii) social and financial networks.

\section{Flexible Regulatory and IP Systems}

A crucial factor in supporting and sustaining biohacker spaces is a flexible regulatory regime. Laws of general application apply, of course, to biohacker spaces. But two areas of law, in particular, warrant special attention in this context: biosafety regulations and IP laws and policies.

\section{Relaxed biosafety laws}

Permissive biosafety regulations enable biohackers to work on audacious research projects. They allow biohackers to engage in more inclusive activities - from undertaking research to commercializing new products and processes to undertaking sophisticated projects to engage the community. However, a rigid and prohibitive regulatory system can have a chilling impact on the research potential of these spaces. Here, we discuss the benefits of a relaxed regulatory system to support inclusive innovation, and then we discuss a number of safeguards to mitigate legitimate biosafety and biosecurity concerns that arise from biohacking.

There is no doubt that biohacking poses biosafety and security risks. The practice may instill fear in the public. Hence, some people prefer a strong regulatory approach to do-it-yourself (DIY) biology. However, a tight regulatory system can be, paradoxically, more problematic for public safety. Although a citizen can easily set up a low-cost lab by ordering equipment and chemicals online, a strict regulatory system may drive biohacking activities underground, or at least behind closed doors, meaning that government is unaware of the dangerous activities that may be going on (Kellogg, 2012). A relaxed regulatory system, where biohacking can be closely monitored, is therefore actually safer and more transparent.

Looser regulations are also beneficial in promoting innovation. Regulations are precisely what limit the extent of research activities that biohackers can undertake. For example, an important difference 


\title{
Inclusive Innovation in Biohacker Spaces: The Role of Systems and Networks
}

\author{
Jeremy de Beer and Vipal Jain
}

between North American and European biohacker spaces is the distinct regulatory environments in which they operate (Seyfried et al., 2014). European biohackers face stricter regulations regarding the type of activities they can undertake. For example, European biohacker spaces must be licensed to carry out any genetic engineering experiments. Some community labs, such as La Paillasse in Paris, have successfully obtained a license. Several other labs are still in the process of becoming certified, which restricts the ability to innovate there. As Robert Carlson, a bioentrepreneur based in the United States, explains, "[T]he only thing we do if we restrict access to these technologies is slow ourselves down and incentivize other countries to go faster. We can't afford to unilaterally disarm." (Kellogg, 2012).

In Canada, most biohacker spaces operate at Biosafety Level 1, which means that they can work with biological agents, namely, Risk Group 1 agents, that are not known to cause disease in healthy humans (Government of Canada, 2015). Unlike in Europe, activities conducted at Biosafety Level 1 are not regulated in Canada, which enables greater research autonomy. Experiments involving Risk Group 1 agents in Canada are exempt from licensing requirements. As a result, the research activities of most DIY biologists are not directly controlled; biohackers are, however, advised to adopt "safe practices" to help mitigate harm (Government of Canada, 2016).

The DIY biology community has independently taken steps to address safety concerns associated with amateur work. For example, the DIYbio website (diybio.org) set up a question-and-answer feature on biosafety (Landrain, 2013), which allows members of the community to submit questions on biosafety such as how to safely clean up chemicals for a particular experiment. These questions are answered by professional experts including biosafety officers.

Local biohacker spaces have also taken proactive steps to address safety issues. For example, BUGSS (bugss online.org), a biohacker space in Baltimore, has developed a chemical hygiene plan and a member safety training protocol that meets regulatory requirements (Scheifele \& Burkett, 2016). It is also common for local spaces to develop their own safety training protocol (Scheifele \& Burkett, 2016).

Other organizations also play a role in ensuring the safety of biohacker spaces. For example, a common public concern is that biohackers may take advantage of the existing system by building a dangerous pathogen in the lab. However, aside from the practical difficulties of actually working with pathogenic organisms, biohackers cannot simply order a pathogen's DNA (Maurer et al., 2009), not even in fragments. Member companies of the International Gene Synthesis Consortium (IGSC; genesynthesisconsortium.org) screen every DNA order against a database of sequences to determine if it includes pathogen DNA (Maurer et al., 2009). As a result of this process, successfully ordering pathogenic DNA is almost impossible. In addition to the measures biohacker spaces and associated organizations are adopting, biosafety risk is also mitigated through other safeguards built into the system. Even when biosafety regulations are relaxed, any new products that are created at biohacker spaces will have to go through necessary approval for commercialization. Depending on what product is developed, it may be subject to other national regulations before it can reach the marketplace.

The best way for government to address any biosafety concerns is by closely monitoring the biohacking movement through engagement and outreach. In the United States, the FBI has already started taking these steps (Wolinsky, 2016). They have been growing their presence in the DIY community and have successfully engaged it to openly talk about biosafety issues (Wolinsky, 2016). Canada is slowly catching up. In 2016, the Public Health Agency of Canada (PHAC; canada.ca/en/publichealth.html) engaged with the DIY biology community by organizing a national summit to bring together key players who are part of the growing movement (Government of Canada, 2017). The PHAC also provides free online courses on biosafety as part of its efforts to create a culture of safety (Government of Canada, 2017).

To make biohacking more inclusive, it is important that biosafety is achieved through education and outreach rather than restrictive regulation. In the United States, the National Science Advisory Board for Biosecurity (NSABB; osp.od.nih.gov/biotechnology/nsabb-faq/) supports this view (Kellogg, 2012). Tighter regulations have the potential to impede meaningful and collaborative research as well as the level of inclusive activities these spaces can undertake. That is why continued engagement with the movement is key. Not only does engagement allow government to monitor risks, it also helps would-be regulators better understand how the movement is changing the science and innovation landscape before responding speculatively to potential problems. 


\title{
Inclusive Innovation in Biohacker Spaces: The Role of Systems and Networks
}

\author{
Jeremy de Beer and Vipal Jain
}

\section{Flexible IP systems}

The recent CRISPR dispute - a fight over patents on technology that facilitates simple and low-cost genetic engineering - highlights some of the important implications of IP on accessibility of scientific research (BeckWatt \& Quainoo, 2016). Considered one of the biggest breakthrough technologies of the century, CRISPR allows scientists to make precise changes to specific strands of DNA at a more cost-efficient and faster rate than before (Ledford, 2016). A dispute arose between two feuding groups of scientists claiming patents over the gene editing technology (Beck-Watt \& Quainoo, 2016). Despite the powerful nature of the technology, a patent dispute does little to advance science. Not only does it amount to large legal costs but it also demonstrates the inability of the patent system to match the speed of innovation (Feldman, 2016). Companies are still racing to develop applications of the technology and it is uncertain whether they will obtain a license for it, especially given that litigation is likely to be ongoing for the foreseeable future (Feldman, 2016).

Unlike conventional biotechnology research, users of biohacker spaces seem less interested in formal IP measures to appropriate their research, and more interested in open approaches to science. There is a strong tension between the open nature of biohacking and the closed nature of the formal IP system. We argue that a flexible IP system is important for supporting the inclusive outcomes arising from biohacker spaces.

Biohacking innovation happens using open science ideology, in the shadow of formal IP systems that are otherwise seen to be so crucial for biotechnology research. Research suggests that IP protection is more widely utilized by large companies, who consider IP rights important (Hall \& Ham, 1999) in order to gain monopoly over an invention. Also, technologies such as pharmaceuticals and chemicals are highly patented (OECD, 2011). But, overall, only a small fraction of companies in all industries within high-income countries consider IP rights important (Jankowski, 2012).

Overuse of the IP system can impede biohacker spaces. IP rights create significant transactional and legal costs (de Beer, 2015). For example, the IP regime can be used to block biohackers from building on earlier inventions, which can potentially impede cumulative, sequential, or collaborative innovation (de Beer, 2015). IP rights can also impede inclusive innovation by restricting biohackers from undertaking projects aimed at achieving health, social, or environmental outcomes because of the transaction costs involved.
Furthermore, IP rights can constrain informal collaboration. One of the concerns reported by the Organisation for Economic Cooperation and Development (OECD, 2008) relates to the emergence of patent thickets, which describe overlapping IP rights (Shapiro, 2001). When IP rights are divided among various owners, it can result in a number of issues such as market delays, legal costs for accessing the technology, and dealing with owners who may not want to license the technology (de Beer, 2015; see also Schultz \& Urban, 2012).

Biohacker spaces demonstrate that innovation can arise outside of the formal IP system in a way that embraces open science and inclusivity. As von Hippel (2005) explains, organizations that embrace user or collaborative innovation have different attitudes towards IP. He also argues that there are other ways researchers can realize the value of innovation besides appropriation from IP. For example, biohacker spaces increase opportunities for people to participate in research as a result of reduced costs and increase access to scientific outputs (in the form of data and publication), allowing subsequent innovation.

A number of projects have emerged from biohacker spaces in the shadow of the formal IP system. For example, a group of biohackers developed Open Trons (opentrons.com), an open source lab robot to automate lab work (Wohlsen, 2014). The project originated from Genspace and raised well over $\$ 100,000$ on Kickstarter, meeting $125 \%$ of its fundraising goal (OpenTrons, 2015). Besides being a commercially successful campaign, the project also achieves other inclusive outcomes: it enhances understanding of lab automation through its open source technology and its low price compared to other lab automation robots enables access to this technology in labs that cannot afford the more expensive robots. In another example, a biohacker group in California is working to produce low cost open insulin, free of any patents (Di Franco et al., 2015; see also Ossolo, 2015), which can be significantly useful in improving access to health technologies.

For some innovators and their investors, there may be a role for IP to play at some stage in the commercialization process. However, marketplace framework policies should be developed in a way that support the innovative work emerging from these spaces (de Beer, 2015). Current IP laws and policies favour one model of innovation over another. As a result, those who wish to practice open innovation are forced to work within a system that supports closed innovation. We argue that policy- 


\title{
Inclusive Innovation in Biohacker Spaces: The Role of Systems and Networks
}

\author{
Jeremy de Beer and Vipal Jain
}

makers should offer equal support for those practicing user innovation, open innovation, and other forms of innovation as those practicing closed innovation. With more laws and policies that support open forms of innovation, biohackers will face fewer barriers to inclusive innovation.

\section{Biohacker Spaces Rely on Networks for Funding and Collaborations}

In this section, we discuss how biohacker spaces rely on both informal and formal networks to raise funding. Biohacker spaces raise funding differently from largescale industrial science and technology institutions. They rely on alternative financing strategies, often driven by social networks, crowdsourcing, and communities of practice.

\section{Funding models for biohacker spaces}

One of the key challenges many biohacker spaces face is access to funding. Biohackers need basic funding to purchase equipment and materials. Unlike large-scale industrial science and technology institutions, biohacker spaces rely on alternative financing strategies to raise money.

The DIY approach for setting up a lab can be more costeffective compared to conventional biotechnology. With the rapidly dropping cost for DNA synthesis and sequencing technology, biology is more accessible than it has ever been (Carlson, 2010). Using eBay, a molecular biology lab can be set up for a few thousand dollars containing the most basic tools (Kellogg, 2012). However, biological materials such as synthetic DNA sequences are still very expensive. In addition to the cost of tools, there may also be other costs in setting up a lab such as rent, utilities, and other start-up costs (Scheifele \& Burkett, 2016). These costs for setting up a biohacker space are often not supported by traditional sources of funding.

Under the traditional research model, funding flows from government to researchers through public research grants or university operating budgets. Funding may also flow from venture capitalists to researchers to support industrial research projects. Those traditional forms of funding are typically not available to biohacker spaces because these spaces operate differently.

For instance, traditional biotechnology research at public research institutions in Canada is heavily supported by a federal research agency, the Natural Sciences and Engineering Research Council (NSERC; nserc-crsng.gc.ca).
With an annual budget of $\$ 1.1$ billion CAD, NSERC is the largest source of funds for science and engineering research in Canada (NSERC, 2017). It funds a range of awards from graduate scholarships to post-doctoral fellowships to fund research tools and infrastructure. However, community labs are largely ineligible for these research funds. Because community labs are typically independently run, they may not qualify for federal research funding, which is primarily targeted at post-secondary institutions.

In addition to federal research funding, venture capital (VC) is another source of funding available, particularly for commercial research. Venture capitalists provide early-stage financing to companies in return for an equity stake (OECD, 2015). The acquisition of IP rights can signal commercial potential to venture capitalists (OECD, 2015). However, since VCs are interested in scalable projects with a high potential for growth, this form of financing may not be available to help finance local, small-scale biohacker spaces.

With limited access to capital, community labs are looking to alternate ways to fundraise. The new inclusive innovation model emerging in biohacking shows that funding can be acquired organically, through grassroots networks. More inclusive funding supports a greater diversity of people who undertake biology projects.

In particular, biohackers are looking to crowdfunding as an alternative to conventional VC. Crowdfunding allows anyone with an idea seeking capital to implement their idea through the use of a crowdfunding platform (Thring, 2012), and it typically involves distinct IP management strategies (de Beer et al., 2017b). Kickstarter, Indiegogo, and Kiva are some examples of the most popular crowdfunding platforms. Unlike traditional research grants, which impose many requirements and qualifications for funding eligibility (NSERC, 2017), crowdfunding is open to anyone with an idea, with minimal requirements. The success of the campaign largely depends on the merits of the idea and the campaign marketing.

Several labs such as Biocurious in the United States have used crowdfunding to set up their labs. Biocurious successfully raised $\$ 35,000$ USD through its campaign, helping fund equipment, tools, reagents, and its rent at a local facility for the first few months (Network for Open Scientific Innovation, 2011). Compared to research labs at universities and industries, which may cost hundreds of thousands to finance (Hoag, 2015), 


\title{
Inclusive Innovation in Biohacker Spaces: The Role of Systems and Networks
}

\author{
Jeremy de Beer and Vipal Jain
}

$\$ 35,000$ is comparatively cheaper and goes a long way in supporting access to tools to a wide range of community members.

Besides crowdfunding, practically most of the activities at the community labs are self-funded through membership and workshop fees (Landrain et al., 2013). The labs may also rely on private donations to raise money.

The combination of biohacking and crowdfunding demonstrates that future research projects can circumvent traditional funding sources and support more inclusive groups to undertake research projects. Anyone with a biotechnology idea can look to crowdfunding to raise capital for their research project. Considering how provident the managers of many biohacker spaces are, the availability of more research funding for these spaces can make a huge impact in supporting entrepreneurship and innovation outside of academic and industrial walls.

\section{Collaboration with formal institutions and informal networks}

The communities of people who use biohacker spaces tend to highly value the ability to conduct their work outside of academic and industrial walls, but they also value collaborations. They collaborate not just with formal actors in the traditional commercial innovation system but with informal actors as well, supporting more inclusivity.

Under the traditional biology research model, technology transfer allows universities and industries to diffuse technology from its place of origin to more people and places (Mansfield, 1975). The transfer can occur among universities, from university to industry, from government to industry, as well as between smaller companies and larger companies (Mansfield, 1975). It can occur horizontally or vertically depending on whether the technology moves from its application in one place to another or whether the process moves from basic to applied research or development (Mansfield, 1975). Our discussion here focuses on vertical technology transfer, where knowledge, skills, resources and technologies are shared in a way that ensures further development of technology into new products and services that are accessible to a wide range of people.

Many universities and industries have a formally designated office of technology transfer that identifies university-originated research with commercial potential (Santos, 2010). These offices play an important role in finding strategies to commercially exploit research, which may occur through licensing agreements with other industry partners to help bring technology to market (Santos, 2010). The rise of technology transfer in universities was largely influenced by the United States Bayh-Dole Act of 1980, which caused a major shift in academic entrepreneurship (Sampat, 2006). By allowing recipients of public funding to obtain IP rights on the outcomes of research, Bayh-Dole provides incentives to universities for commercially exploiting research. As a result, universities have become more interested in acquiring IP rights and value academic entrepreneurship (Popp, 2008).

In biotechnology companies, technology transfer can take place internally and externally. Particularly in large companies, technology transfer takes place internally from the research and development (R\&D) team to the manufacturing team to help commercialize the technology (Mansfield, 1975). Technology transfer can also take place from one company to another to outsource manufacturing activities (Mansfield, 1975). Many companies will conduct their own R\&D but lack infrastructure to commercially develop the technology. For instance, some companies may lack the resources to conduct clinical studies for the drug product. Transferring the technology to another company may help scale up the product and produce it faster and cheaper than in-house production.

Biohacker spaces tend to operate differently than academic and industry institutions. Biohacker spaces tend to rely on both formal and informal networks to support research and commercialization. Within formal networks, biohacker spaces value collaborations with government, universities, as well as industrial partners. Such collaborations allow biohackers to access financial support, equipment, and other resources. The collaborators may also benefit from the exchange as it presents an opportunity to harness innovative ideas emerging from the biohacking movement (Buys \& Bursnall, 2007).

Many spaces organize meet-ups and events to bring together diverse members of the community. These events not only help attract new members but also help encourage informal collaborations through knowledge exchange and skills transfer. They allow diverse interests and people from a range of disciples, age groups, and skill expertise to come together to achieve a common goal through interaction, information gathering, and coordinating research activities (Jassawalla \& Sashittal, 2007). 


\section{Inclusive Innovation in Biohacker Spaces: The Role of Systems and Networks}

\section{Jeremy de Beer and Vipal Jain}

By bringing the DIY biology ethos into the collaboration, biohacker spaces encourage ideas and resources to be shared. Through grassroots entrepreneurialism consisting of formal and informal collaborations, these spaces encourage inclusivity and have the potential to identify and exploit innovative ideas even with the limited resources they have. Together, this can help break down barriers between researchers and partners to create knowledge clusters that can "eliminate bottlenecks imposed by upstream research” (Gold, 2016).

\section{Conclusion}

Exploring biohacker spaces through a framework of inclusive innovation facilitates analysis of details related to four dimensions of inclusivity. By considering issues around biohacker spaces related to people, activities, outcomes, and governance, we have demonstrated one way to categorize and analyze the highly variable nature of these spaces. We find that biohacker spaces are contributing to a new innovation paradigm for biotechnology, outside of the traditional confines of - and more inclusive than - the triple-helix university-industry-government innovation system.

We have further added to the inclusive innovation analytical framework by introducing two sets of considerations related to innovation ecosystems that can make biohacker spaces more or less inclusive. Our research shows how biohacker spaces benefit from flexible IP policies, a relaxed regulatory framework, decentralized funding opportunities, and strong partnerships with formal and informal networks. Those who are researching, managing, or interested in supporting biohacker spaces can promote more inclusive innovation by focusing attention on the systemic factors we have identified.

\section{Acknowledgments}

This research was supported by the Social Sciences and Humanities Research Council (SSHRC) and the International Development Research Centre (IDRC). The authors gratefully acknowledge Salman Rana for graphical design work for this article; Sandra Schillo, Louise Earl, and Jeff Kinder, and the participants at the inclusive innovation workshop held in 2017 at the University of Ottawa; and Chris McPhee and an anonymous reviewer for substantive and editorial comments.

\section{About the Authors}

Jeremy de Beer is a Full Professor at the University of Ottawa's Faculty of Law, Common Law Section, where he is a member of the Centre for Law, Technology, and Society. He is a Senior Research Associate at the IP Unit, University of Cape Town and a cofounding director of the Open African Innovation Research network, Open AIR. $\mathrm{He}$ is online at www.JeremydeBeer.com.

Vipal Jain is a Juris Doctor candidate (2018) at the University of Ottawa's Faculty of Law, Common Law Section. She is a member of the Open African Innovation Research (Open AIR) network's New and Emerging Researcher Group, focusing on intellectual property law issues in Canada and elsewhere. She holds a BSc from the University of Toronto, where she specialized in Genetics and Biotechnology.

\section{References}

Aldridge, T. T., \& Audretsch, D. 2011. The Bayh-Dole Act and Scientist Entrepreneurship. Research Policy, 40(8): 1058-1067.

https://doi.org/10.1016/j.respol.2011.04.006

Bancroft, D. 2016. The 'Lunch Box' Sized Laboratory for Biohackers, Educators and Artists. Labiotech, March 22, 2016. Accessed February 15, 2018:

http://labiotech.eu/bento-lab-kickstarter-dna-biohacking-synbiostartup/

Beck-Watt, S., \& Quainoo, D. 2016. More Money, More Problems: The Science, the Law, and the Fight over CRISPR Patents. IP Osgoode, April 14, 2016. Accessed February 15, 2018:

http://www.iposgoode.ca/2016/04/more-money-more-problemsthe-science-the-law-and-the-fight-over-crispr-patents/

Benkler, Y. 2006. The Wealth of Networks. New Haven, CN: Yale University Press.

Burke, A. 2011. Citizen Science Takes Off: Could Community Labs Hatch the Next Generation of Bio Innovators? Forbes, October 25, 2011. Accessed February 15, 2018:

https://www.forbes.com/sites/techonomy/2011/10/25/citizenscience-takes-off-could-community-labs-hatch-the-nextgeneration-of-bio-innovators/

Buys, N., \& Bursnall, S. 2007. Establishing University-Community Partnerships: Processes and Benefits. Journal of Higher Education Policy and Management, 29(1): 73-86. http://dx.doi.org/10.1080/13600800601175797

Carlson, R. 2010. Biology is Technology. Cambridge, MA: Harvard University Press.

Chesbrough, H. 2006. Open Innovation: A New Paradigm for Understanding Industrial Innovation. Oxford: Oxford University Press. 


\section{Inclusive Innovation in Biohacker Spaces: The Role of Systems and Networks}

\section{Jeremy de Beer and Vipal Jain}

Crook, J. 2011. OpenPCR Machine Makes Your Basement a Crime Lab. Tech Crunch, August 9, 2011. Accessed February 15, 2018: https://techcrunch.com/2011/08/09/openpcr-machine-makesyour-basement-a-crime-lab/

CSLS. 2016. Developing an Inclusive Innovation Agenda for Canada: CSLS Research Report 2016-18. Ottawa: Centre for the Study of Living Standards (CSLS).

http://www.csls.ca/reports/csls2016-18.pdf

D'haeseleer, C., Juul, P., \& Rouskey, M. 2014. Real Vegan Cheese. BioCoder, Summer: 71-77.

David, P. A., \& Hall, B. H. 2006. Property and the Pursuit of Knowledge: IPR Issues Affecting Scientific Research. Research Policy, 35(6): 767-771. http://doi.org/10.1016/j.respol.2006.04.002

de Beer, J. 2015. “Open" Innovation Policy Frameworks: Intellectual Property, Competition, Investment \& Other Market Governance Issues. Prepared for Industry Canada: Ottawa. http://jeremydebeer.ca/wp-content/uploads/2017/08/OpenInnovation-Policy-Frameworks.pdf

de Beer, J. 2017. Open Innovation in Development - Integrating Theory Across Open Science, Open Education, and Open Data. Open African Innovation Research Working Paper No 3. OpenAIR: African Innovation Research.http://www.openair.org.za/publications/wp3open-innovation-in-development/

de Beer, J., Armstrong, C., Ellis, M., Kraemer-Mbula, E. 2017a. A Scan of South Africa's Maker Movement. Open African Innovation Research Working Paper No 9. OpenAIR: African Innovation Research. http://www.openair.org.za/publications/a-scan-of-south-africasmaker-movement/

de Beer, J., McCarthy, I. P., Soliman, A., Treen, E. 2017b. Click Here to Agree: Managing Intellectual Property when Crowdsourcing Solutions. Business Horizons, 60(2): 207-217. https://doi.org/10.1016/j.bushor.2016.11.002

Delfanti, A. 2011. Hacking Genomes: The Ethics of Open and Rebel Biology. International Review of Information Ethics, 15(9): 52-57.

Delfanti, A. 2013. Biohackers: The Politics of Open Science. London: Pluto Books.

dos Santos, M. E. 2010. The Science Transfer Series: Technology Transfer from Academic to Industry and Its Impact on University Management. Revista Odonto Ciência, 25(2): 118-119. http://dx.doi.org/10.1590/S1980-65232010000200002

European Commission. 1995. Green Paper on Innovation. Brussels: Office for Official Publications of the European Communities. http://aei.pitt.edu/id/eprint/1218

Feldman, R. 2016. The CRISPR Revolution: What Editing Human DNA Reveals About the Patent System's DNA. UCLA Law Review Discourse, 64: 392-410.

Franco, A. D., Zayner, J., Shi, Y., Muldavin, M., Chakrabarty, T., Anderson, D., Soneda, C., Bethencourt, R., Sotomayor, J., Ochoa, A., D'haeseleer, P., Nealand, S., Alekseyenko, A., Eberhand, T., Chavez, M., \& Buehamann. 2015. Open Insulin. Experiment. Accessed February 15, 2018:

https://experiment.com/projects/open-insulin/labnotes

Gold, R. E. 2016. Accelerating Transnational Research through Open Science: The Neuro Experiment. PLOS Biology, 14(12): e2001259. http://doi.org/10.1371/journal.pbio.2001259
Government of Canada. 2015. Canadian Biosafety Standard, 2nd Edition. Ottawa: Public Health Agency of Canada. http://canadianbiosafetystandards.collaboration.gc.ca/cbsncb/assets/pdf/cbsg-nldcb-eng.pdf

Government of Canada. 2016. Canadian Biosafety Handbook, 2nd Edition. Ottawa: Public Health Agency of Canada. http://canadianbiosafetystandards.collaboration.gc.ca/cbhgcb/index-eng.php

Government of Canada. 2017. DIY Biology: From Basement to Biolab. In The Science of Health. Ottawa: Government of Canada. Accessed February 15, 2018:

http://www.science.gc.ca/eic/site/063.nsf/eng/h_D79B5951.html? OpenDocument\#ws082825D8

Hall, B. H., \& Ham, R. M. 1999. The Patent Paradox Revisited: An Empirical Study of Patenting in the U.S. Semiconductor Industry 1979-1995. The RAND Journal of Economics, 32(1): 101-128.

Hoag, H. 2015. Lab Budget: A Numbers Game. Nature, 524: 127-128. http://doi.org/10.1038/nj7563-127a

iGEM UCL. 2012. A Survey on Biohackers and the Use of Biobricks. International Genetically Engineered Machine Competition. Accessed February 15, 2018: http://2012.igem.org/Team:University_College_London/HumanPr actice/DIYbio/DIYbio

Jankowski, J. E. 2012. Business Use of Intellectual Property Protection Documented in NSF Survey. In InfoBrief NSF 12-307. Alexandria, VA: National Science Foundation.

https://www.nsf.gov/statistics/infbrief/nsf12307/nsf12307.pdf

Jassawalla, A. R., \& Sashittal, H. C. 1998. An Examination of Collaboration in High-Technology New Product Development Processes. Journal of Product Innovation Management, 15(3): 237-254. https://doi.org/10.1016/S0737-6782(97)00080-5

Kellogg, S. 2012. The Rise of DIY Scientists: Is It Time for Regulation? Washington Lawyer, May 2012. Accessed February 15, 2018:http://www.dcbar.org/bar-

resources/publications/washington-lawyer/articles/may-2012diy-scientist.cfm

Kuhlmann, S., \& Rip, A. 2014. The Challenge of Addressing Grand Challenges: A Think Piece on How Innovation Can Be Driven towards the "Grand Challenges" as Defined under the Prospective European Union Framework Programme Horizon 2020. Brussels: European Commission; European Research and Innovation Area Board (ERIAB).

Landrain, T., Meyer, M., Perez, A. M., \& Sussan, R. 2013. Do-ItYourself Biology: Challenges and Promises for an Open Science and Technology Movement. Systems and Synthetic Biology, 7(3): 115-126. http://doi.org/10.1007/s11693-013-9116-4

Ledford, H. 2016. CRISPR: Gene Editing Is Just the Beginning. Nature News, March 7, 2016. Accessed February 15, 2018: https://www.nature.com/news/crispr-gene-editing-is-just-thebeginning- 1.19510

Mansfield, E. 1975. International Technology Transfer: Forms, Resource Requirements, and Policies. American Economic Review, 65(2): 372-376. http://www.jstor.org/stable/i331525 


\section{Inclusive Innovation in Biohacker Spaces: The Role of Systems and Networks}

\section{Jeremy de Beer and Vipal Jain}

Maurer, S. M., Fischer, M., Schwer, H., Stähler, C., Stähler, P., \& Bernauer, H. S. 2009. Making Commercial Biology Safer: What the Gene Synthesis Industry has Learned about Screening Customer and Orders. Working paper.

https://gspp.berkeley.edu/assets/uploads/page/Maurer_IASB_Scr eening.pdf

Merton, R. K. 1973. The Sociology of Science: Theoretical and Empirical Investigations. Chicago: University of Chicago Press. http://doi.org/10.1126/science

Meyer, M. 2012. Build Your Own Lab: Do-It-Yourself Biology and the Rise of Citizen Biotech-Economies. Journal of Peer Production, 2: 4 .

Network for Open Scientific Innovation. 2011. Biocurious: A Hackerspace for Biotech. The Community Lab for Citizen Science. Kickstarter. Accessed February 15, 2018:

https://www.kickstarter.com/projects/openscience/biocurious-ahackerspace-for-biotech-the-community

NSERC. 2017. Natural Science and Engineering Research Council of Canada. Accessed February 15, 2018:

http://www.nserc-crsng.gc.ca/NSERC-CRSNG/Index_eng.asp

OpenTrons. 2015. OpenTrons: Open Source Rapid Prototyping for Biology. Kickstarter. Accessed February 15, 2018: https://www.kickstarter.com/projects/932664050/opentronsopen-source-rapid-prototyping-for-biolog/updates

OECD. 2008. Open Innovation in Global Networks. Paris: Organization for Economic Cooperation and Development (OECD).

OECD. 2011. Intellectual Assets and Innovation: The SME Division, OECD Studies on SMEs and Entrepreneurship. Paris: Organisation for Economic Cooperation and Development (OECD). http://dx.doi.org/10.1787/20780990

OECD. 2015. IP-Based Financing of Innovative Firms. In Enquiries into Intellectual Property's Economic Impact: 457-477. Paris: Organisation for Economic Cooperation and Development (OECD). https://www.oecd.org/sti/ieconomy/Chapter9-KBC2-IP.pdf

Ossola, A. 2015. These Biohackers Are Making Open-Source Insulin. Popular Science, November 18, 2015. Accessed February 15, 2018: https://www.popsci.com/these-biohackers-are-making-opensource-insulin
Popp, B. E. 2008. Why Did Universities Start Patenting? InstitutionBuilding and the Road to the Bayh-Dole Act. Social Studies of Science, 38(6): 835-871. http://doi.org/10.1177/0306312708098605

Sampat, B. N. 2006. Patenting and US Academic Research in the 20th Century: The World before and after Bayh-Dole. Research Policy, 35(6): 772-789.

https://doi.org/10.1016/j.respol.2006.04.009

Scheifele, L. Z., \& Burkett, T. 2016. The First Three Years of a Community Lab: Lessons about Moving Forward. Journal of Microbiology \& Biology Education, 17(1): 81-85. https://dx.doi.org/10.1128\%2Fjmbe.v17il.1013

Schultz, J., \& Urban, J. M. 2012. Protecting Open Innovation: The Defensive Patent License as a New Approach To Patent Threats, Transaction Costs, and Tactical Disarmament. Harvard Journal of Law \& Technology, 26(1): 1-67.

Seyfried, G., Pei, L., \& Schmidt M. 2014. European Do-It-Yourself (DIY) Biology: Beyond the Hope, Hype and Horror. Bioessays, 36(6): 548-551.

http://doi.org/10.1002/bies.201300149

Shapiro, C. 2001. Navigating the Patent Thicket: Cross Licences, Patent Pools and Standard Setting. In A. B. Jaffe, J. Lerner \& S. Stern (Eds.), Innovation Policy and the Economy: 119-150. Cambridge, MA: The MIT Press.

Thring, D. E. 2012. Crowdfunding - Could It Help Finance Innovation in Canada? Mcmillan, April 2012. Accessed February 15, 2018: http://www.mcmillan.ca/crowdfunding--could-it-help-financeinnovation-in-Canada

von Hippel, E. 2005. Democratizing Innovation. Cambridge, MA: MIT Press.

von Hippel, E. 2016. Free Innovation. Cambridge, MA: MIT Press.

Wolinsky, H. 2016. The FBI and Biohackers: An Unusual Relationship. EMBO Reports, 16(6): 793-796. https://dx.doi.org/10.15252/embr.201642483

Wohlsen, M. 2014. This Robot Could Make Creating New Life Forms as Easy as Coding an App. Wired, November 20, 2014. Accessed February 15, 2018: https://www.wired.com/2014/11/opentrons-bio-robots/ 


\title{
Supporting Self-Determined Indigenous Innovations: Rethinking the Digital Divide in Canada
}

\author{
Jasmin Winter and Justine Boudreau
}

\author{
"To govern ourselves means to govern our stories and") \\ our ways of telling stories. It means that the rhythm of \\ the drumbeat, the language of smoke signals and our \\ moccasin telegraph can be transformed to the airwaves \\ and modems of our times. We can determine our use of \\ the new technologies to support, strengthen and enrich \\ our cultural communities.
}

\author{
Ahasiw Maskegon-Iskwew \\ Cree/French Métis New Media Artist \\ In "Drumbeats to Drumbytes Origins" (1994)
}

\begin{abstract}
This article seeks to revisit dominant narratives of digital technological development in Indigenous communities in Canada. By prioritizing Indigenous voices and drawing from concepts of self-determination and sovereignty, this analysis reorients discourse surrounding the "digital divide" towards a strength-based approach that positions Indigenous peoples as innovators and creators, not just consumers, of digital technologies. This article begins with a discussion of how dominant media has used technology and technological imagery to misrepresent Indigenous cultures and perpetuate colonial biases, and emphasizes the importance of making space for Indigenous future imagery. Following this is a discussion of digital storytelling and virtual landscapes, showcasing a small sample of Indigenous initiatives online, in video game and app development, and in augmented and virtual reality. Finally, this article considers the potential of "makerspaces" as a framework for future action to bridge theory and practice.
\end{abstract}

\section{Introduction}

The romanticized tale of Indigenous peoples' first interactions with cameras is all too familiar a narrative to the Western consciousness, portraying Indigenous peoples as fearful of the technology's ability to "steal souls" (Golub, 2004). Retrospectively, it is important to critically analyze what it truly was that 19th century photographers were "capturing" with their cameras, and how dominant media has used technology and technological imagery to hijack Indigenous realities and control the way that society views Indigenous peoples and cultures. Photography like that of Edward S. Curtis is often used as a reference point for this argument, as his pictures sought to explicitly erase any signs of modernity and reduce Indigenous lives to a simplistic, one-dimensional commodity that could be easily consumed by the colonial gaze. In his portraits, only expressionless faces and stoic poses were allowed, and traditional dress was mandatory - whether or not it came from the subject's own nation or the one over. In an infamous photograph titled "In a Piegan Lodge" (1910), Curtis' original image showed a clock (Figure 1), which he removed before publishing the edited version (Figure 2) (Stanford University, 2016).

Curtis bought into the colonial idea that it was the turn of the century and Indigenous peoples were disappearing (if not physically, then certainly culturally) and through his camera's lens, he thought himself able to salvage their legacy (Vizenor, 2000). In the words of Tsimshian-Haida writer Marcia Crosby (2002), this "salvage paradigm" dictates that those doing the saving choose what fragments of a culture they will salvage. In this case, Curtis was only salvaging his own perceptions, limiting control of Indigenous peoples over their own histories, their futures, and their relationship with technology. Curtis' photographs attempted to capture a 


\section{Supporting Self-Determined Indigenous Innovations: Rethinking the Digital Divide in Canada Jasmin Winter and Justine Boudreau}

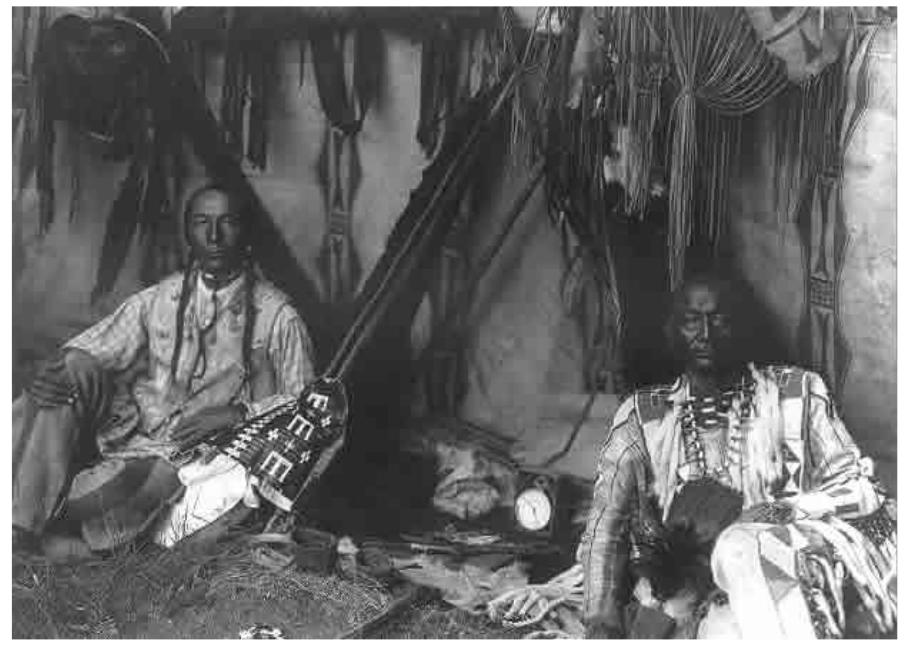

Figure 1. Original version of "In a Piegan Lodge"

(Edward S. Curtis, photographer, ca. 1910. Library of Congress: loc.gov/item/2002722455/)

static and "timeless" traditional Indigenous culture that would never change, one that could ultimately be used as a self-congratulatory reference point against which Eurocentric society could measure its own progressive evolution.

\section{Indigenous Worldviews and Future Imagery}

Mi'kmaw educator Marie Battiste and international human rights lawyer and advocate James (Sákéj) Youngblood Henderson (2011) outline the consequences of Western impositions of linear development models. They expose how a central concept behind Eurocentrism is "diffusionism", which is based on two assumptions: i) most human communities are uninventive, and ii) a few human communities (or places, or cultures) are inventive and are thus the permanent centres of cultural change or "progress". As Battiste and Henderson (2011) put it, "Diffusionism explains any progress made by non-Europeans as resulting from the spread of European ideas, which flow into the non-European world like air flows into a vacuum."

Julie Nagam (2016), a Professor of the History of Indigenous Art in North America, breaks down the binary associations of "civilized" and "savage" with technologically advanced and technologically unsophisticated, respectively. She emphasizes how Indigenous cultural knowledge is not static but in a constant state of flux, and is part of "a living and embodied practice", or in the words of author and historian Cynthia Landrum (2012), a "balancing act" between tradition

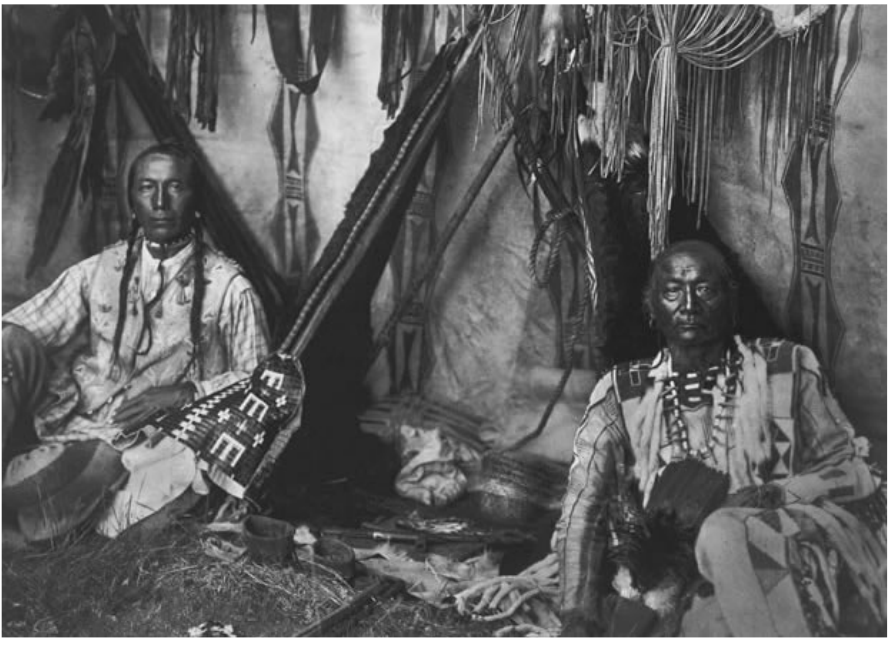

Figure 2. Published version of "In a Piegan Lodge", with the clock removed (Edward S. Curtis, photographer, 1911, in The North American Indian. scalar.usc.edu/works/performingarchive/in-a-piegan-lodge-l)

and modernity that does not dichotomize the past and present in a linear fashion. Nagam further contends that colonial impositions of timelessness and other "myths of modernity" have been thinly-veiled attempts at limiting the future for Indigenous peoples by presuming an inevitability in assimilation, echoing historic discourses that projected the disappearance of Indigenous peoples (Nagam, 2016). The work of Jason Lewis, a Professor and a Co-Founder of Aboriginal Territories in Cyberspace and the Initiative for Indigenous Futures, revolves around defying this suggestion. In a piece titled "A Brief (Media) History of the Indigenous Future," he states, "If you are not present in the future imaginary of the dominant culture - you're in trouble that means that they don't imagine you in the future... So we have to start proposing images of who we are and where we'll be" (Lewis, 2016). He goes on to outline five different ways to achieve this:

\section{Manifest the future with Indigenous peoples in it.}

2. Hybridize the present in new or extreme ways, modifying contemporary realities to open up future possibilities.

\section{Alter the past to lead to different futures.}

4. Shape digital infrastructure by engaging with digital media and digital culture.

5. Critique the past, and reflect on Indigenous creative engagements with technology. 


\section{Supporting Self-Determined Indigenous Innovations: Rethinking the Digital Divide in Canada Jasmin Winter and Justine Boudreau}

Lewis frames this plan of action using an Indigenous worldview of time and sustainability, which often calls for decisions to be made while thinking seven generations ahead and seven generations back. This circular way of thinking is just one example of how digital technological development may be approached differently when Indigenous peoples are able to assert their rights to digital self-determination and sovereignty, and there are countless more examples of how Indigenous innovators are already acting on Lewis' strategies.

\section{Rethinking the Digital Divide}

From a dominant international development perspective, documents such as the United Nations Declaration on the Rights of Indigenous Peoples (UN, 2008) lack any specific reference to technological development in their articulation of self-determination. This aspect has been better addressed at the meetings of the World Summit on the Information Society (WSIS; itu.int/net/wsis/), which were held in two phases in 2003 and 2005. During the first phase, more than 11,000 people from over 175 nations assembled in Geneva to discuss bridging technological divides. The WSIS has noted officially in their WSIS+10 Review Event:

"Indigenous and traditional knowledge are fundamental in building pathways to develop innovative processes and strategies for locally-appropriate sustainable development. This knowledge is integral to a cultural complex that also encompasses language, systems of classification, resource use practices, social interactions, ritual and spirituality. These unique ways of knowing are important facets of the world's cultural diversity, and provide a foundation for comprehensive knowledge society." (UNESCO, 2013)

Still, we argue that international literature continues to focus far too heavily on what technology can do for Indigenous peoples - not what Indigenous peoples have and can do with technology. To disrupt this pattern is to first and foremost re-focus discourse surrounding the digital divide from a needs-based approach to a strength-based approach, and subsequently prioritize support for bottom-up community initiatives.

According to interdisciplinary artist Cheryl L'Hirondelle: "A 'divide' evokes many different concepts and images. It is at once the opposite or taking away of multiplication, and it is the colonial tactic of gaining and maintaining power also known as a

\begin{abstract}
strategy of 'divide and conquer.' However, to many Native people a 'divide' also refers to the beautiful vistas and intricate landscapes of the geological term that connotes watersheds, ridges of land between two drainage basins, and/or that of the grandiosity of a continental divide." (L'Hirondelle, 2016)
\end{abstract}

L'Hirondelle makes a call to acknowledge Indigenous "pre-contact ingenuity as inventors and technologists experts in new media and avatars of innovation" (L'Hirondelle, 2016), with the aim of reformulating the very definition of technology. Her essay is an homage to the many "codetalkers, pathfinders, and cultural compilers" who came before her; those that have translated tradition and worldviews to ensure their accessibility as survival tools for future generations, much like a computer program that transforms source code into executable programs. She cites mnemonic devices such as the Plains tradition of pictorial calendars on tipis and skins, quillwork, weaving, beadwork, and Haudenosaunee wampum belts, among others, as examples of how data collection and documentary technologies have always been an integral part of Indigenous community-building.

Western impositions of dichotomous and binary thinking continue to place Indigenous peoples at the crossroads of false paradoxes that have limited their freedoms and placed Indigenous knowledge at the bottom of an imagined hierarchy. By recognizing and validating Indigenous epistemologies, or ways of knowing, we can better unpack the biases in Western thinking that have informed technological development practices and that have perpetuated economic, social, and cultural inequity. Within many Indigenous traditions of oral storytelling are lessons that directly address how to better engage with the multiplicity of life, often calling upon the Trickster (sometimes known as the Coyote): a dual character whose subversive behaviour helps the listener tease apart paradoxes. Steven Loft, editor of Coded Territories, likens digital technologies to the Trickster in the following terms: "Technology exists as shape shifter (not unlike the Trickster himself) neither inherently benign nor malevolent, but always acting and active, changing, transformative, giving effect to and affecting the world" (Loft, 2005). Digital technologies, therefore, hold incredible potential as tools to revitalize Indigenous stories in which are embedded Indigenous worldviews and ways of knowing that have strengthened communities since time immemorial. 


\section{Supporting Self-Determined Indigenous Innovations: Rethinking the Digital Divide in Canada Jasmin Winter and Justine Boudreau}

\section{Digital Storytelling}

In the words of prolific Coast Salish storyteller Lee Maracle: "Stories are the key to the endless oratory, the teachings, and the knowledge of our people. It's not all we are, but when we remember the story, the flood of knowledge locked behind it is let loose." (Maracle, 2015). Aman Sium and Erin Ritskes from the Ontario Institute for Studies in Education insist that stories become mediums for Indigenous peoples to both analogize colonial violence and resist it in real ways. They challenge liberal notions of stories as depoliticized acts of sharing or multicultural "show and tell," instead recognizing stories as acts of creative rebellion (Sium \& Ritskes, 2013). Judy Iseke, Canada Research Chair in Indigenous Knowledge and Research, also emphasizes the vital institution of eldership in traditional storytelling practices. Through the transgenerational memory transmitted by their stories, elders ensure the survival and continuance of Indigenous philosophies, theories, and epistemic traditions (Iseke \& Moore, 2011). Storytelling is in itself a tool for negotiating social priorities and contemporary community needs. Indigenous digital storytelling, therefore, can be used as a tool for Indigenous youth to learn about their identity, challenge negative representations of their culture, connect with others, and become agents of social change.

Jason Lewis and his partner, Mohawk multimedia artist Skawennati, summarize the impact that dominant technological media has had on Indigenous representation in the following terms:

"History has shown us that new media technologies can play a critical role in shaping how Western, technologically oriented cultures perceive Aboriginals. The camera, for instance, taught people that we all wore headdresses and lived in teepees. Cinema claimed that we spoke in broken English-if we spoke at all. [...] Traditional mass media such as newspapers, magazines, television, and film are expensive to produce and distribute and consequently exclude Aboriginal peoples. On the internet, we can publish for a fraction of the cost of doing so in the old media; we can instantly update what we publish in order to respond to misrepresentations, misunderstandings, and misreadings; and we can instantly propagate our message across a worldspanning network." (Lewis \& Fragnito, 2005)

Lewis and Skawennati have paved the way for Indigenous presence in digital spaces, beginning with the CyberPowWow project (cyberpowwow.net), which was launched in 1996. The site's main goals were to overcome stereotypes about Indigenous peoples, to help them shape the Internet, and to generate critical discourse about Indigenous art, technology, and community. These experiences built the foundation for Aboriginal Territories in Cyberspace, a research network based out of Concordia University in Montreal, Canada, and the Initiative for Indigenous Futures (abtec.org/iif/). In 2008, the Initiative for Indigenous Futures launched their Skins storytelling workshop, which have been applying these same principles through what author Naomi Alderman calls "the noise you're trying to get your children to turn down while you pen your thoughts about the future of location-based storytelling" (Alderman, 2015). Here, she is referring to video games, and Skins is founded on the practice of game modding, the term used to describe adapting or creating game content using commercial game engines. Through a mentorship model, participants take on game industry roles and are able to leverage the technical infrastructure of a game to create their own fully functional yet fully personalized game worlds based on community stories (Figure 3). Lameman and Lewis (2011) contend that video games, with their unique combination of story, design, code, architecture, art, animation, and sound, provide a rich medium that reflects traditions of oral storytelling and enables both developers and users to explore different strategies for pursuing cultural preservation and revitalization. Skins has had five iterations to date (all games are available online at: abtec.org/iif/workshops/past-workshops/), with the most recent workshop taking place in Honolulu, Hawai'i, at the request of Native Hawaiian community leaders. This has inspired other workshops such as Indigicade, the first installment of the collaboration between the Indigenous Routes Collective (indigenousroutes.ca) and Dames Making Games (dmg.to), which consisted of a month-long video game development session for Indigenous girls and women aged 13-24 in Toronto, Canada, during the summer of 2015 (Kestler-D'amours, 2015).

These workshops are giving rise to a new generation of Indigenous game designers who can provide alternatives to portrayals that have generally fallen into the Western game genre (with Indigenous characters as primitive enemies killed for reward) or science-fiction that perpetuates settler-colonial ideals of conquering seemingly uninhabited lands. They can also encourage the mobilization of companies such as Upper One Games (upperonegames.citci.org), the first Indigenousowned commercial gaming company in the United States, and the developers of the popular Never Alone

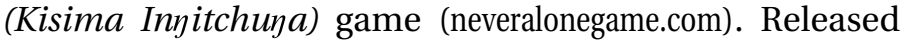




\section{Supporting Self-Determined Indigenous Innovations: Rethinking the Digital Divide in Canada Jasmin Winter and Justine Boudreau}
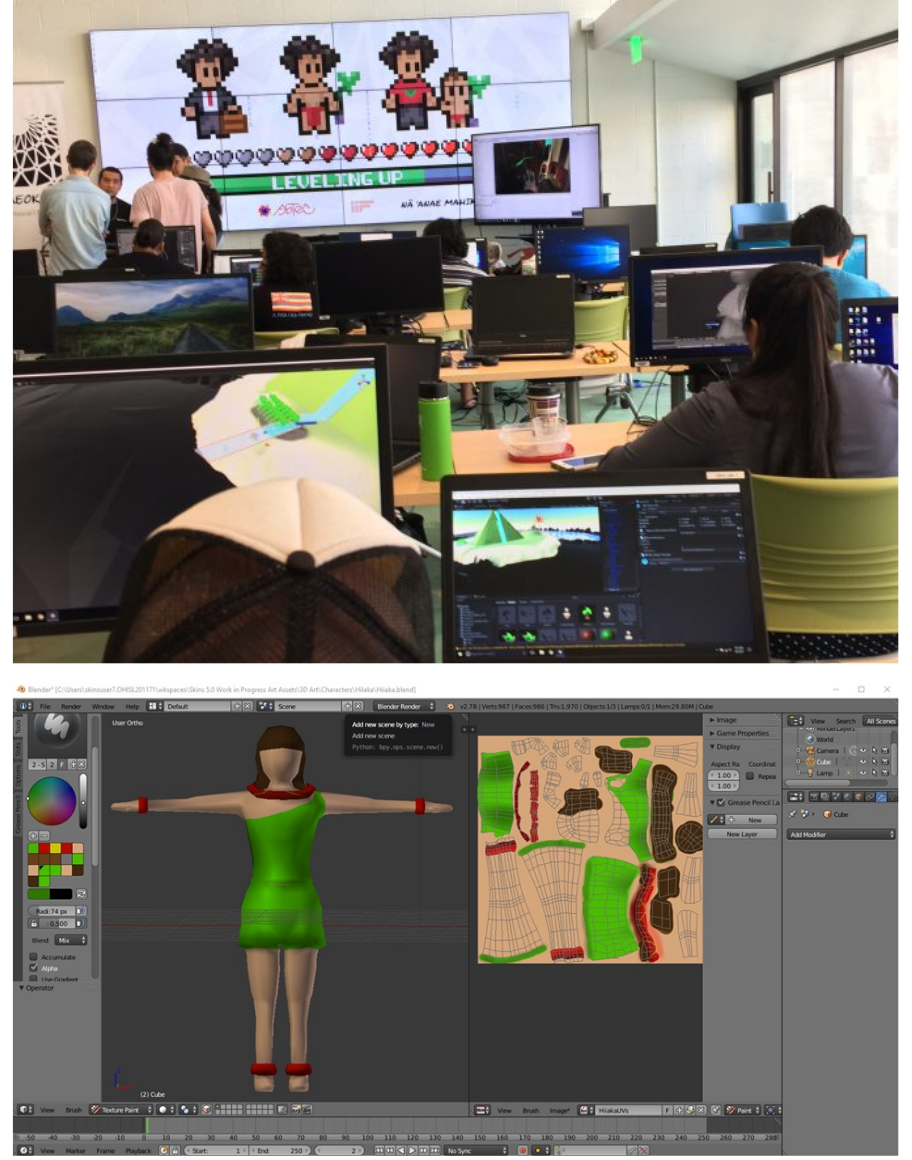

Figure 3. Photograph and screenshot from a Skins 5.0 workshop (Courtesy of Initiative for Indigenous Futures: skins.abtec.org/skins5.0/documentation/) in 2014, the puzzle-platformer adventure follows a young girl named Nuna and an arctic fox who set out to find the source of an external blizzard which threatens the survival of everything they have ever known (Figure 4). The game is based on the Iñupiaq tale, "Kunuuksaayuka", and is unique in the way that players can unlock live-action videos depicting Elders telling stories or showcasing different cultural practices and traditions that inspired the gameplay.

Envisioning Indigenous peoples at the forefront of video game development should come easily when one considers the longstanding tradition of telling stories that have helped communities virtualize their presence in the past, present, and future. However, when conceptualizations of the "real" world and the "virtual" world are dichotomized, Indigenous peoples find themselves once again stuck at another false paradox, one in which they face the need to challenge the trope of the "Ecological Indian" (Krech, 2000), a caricature of the complex relationship that Indigenous peoples have to place and the land.

\section{Virtual Landscapes}

Colonial assertions about the incompatibility of Indigenous ways of knowing and technology have been used to delegitimize claims to land in the past, manifesting in concepts such as "terra nullius", which is Latin for "nobody's land", explained in the following terms by author Alan Frost (1992):

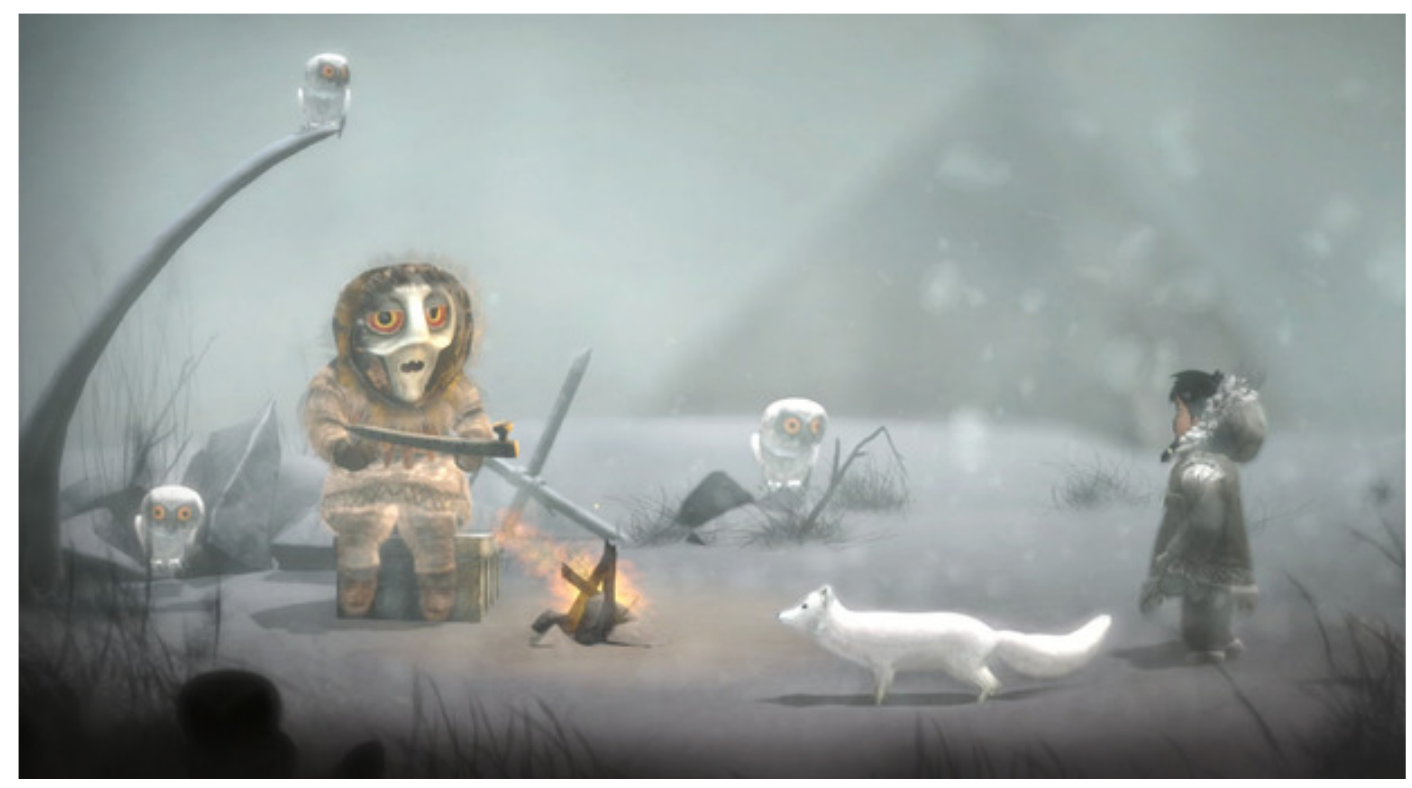

Figure 4. Screenshot of Never Alone (Screenshot courtesy of E-Line Media.) 


\section{Supporting Self-Determined Indigenous Innovations: Rethinking the Digital Divide in Canada Jasmin Winter and Justine Boudreau}

\begin{abstract}
"If Indigenous peoples had advanced beyond the state of nature only so far as to have developed language and the community of the family, but no further; if they had not yet mixed their labour with the earth in any permanent way; or if the region were literally uninhabited, then Europeans considered it to be terra nullius (i.e. belonging to no one), to which they might gain permanent title by first discovery and effective occupation."
\end{abstract}

This justification relies on a very specific interpretation of technological advancement, one that values labour and productiveness above language, community, and a balanced relationship with the environment. The idea that these things should be mutually exclusive is a fallacy, one that Indigenous innovators are challenging every single day. In "Terra Nullius, Terra Incognito," Jason Lewis (2005) turns the phrase on its head, suggesting that Indigenous people retain equal opportunities to gain place in virtual spaces. To quote Michelle Raheja, author of Reservation Reelism: Redfacing, Visual Sovereignty, and Representations of Native Americans in Film, digital space provides the land for "virtual reservations", which have the ability to transcend time and space, and it "initiates and maintains a dialectical relationship between the multiple layers of Indigenous knowledge systems - from the dream world to the topography of real or imagined landscapes" (Raheja, 2010).
Drawing once again from Cheryl L'Hirondelle:

"Connection to the land is what makes us Indigenous, and yet as we move forward into virtual domains we too are sneaking up and setting up camp - making this virtual and technologically mediated domain our own. However, we stake a claim here too as being an intrinsic part of this placethe very roots, or more appropriately routes. So let's use our collective Indigenous unconscious to remember our contributions and the physical beginnings that were pivotal in how this virtual reality was constructed." (L'Hirondelle, 2016)

This year, the Initiative for Indigenous Futures partnered with the Toronto International Film Festival (TIFF), imagineNATIVE Film and Media Arts Festival, and Pinnguaq, a Nunavut-based not-for-profit technology startup, to launch 2167 (imaginenative.org/2167/), a series that invited Indigenous innovators to create virtual reality projects set 150 years (seven generations) in the future. The works premiered in June 2017, including Blueberry Pie Under a Martian Sky by Scott Benesiinaabandan, which brings to life a prophetic Anishinaabe legend about a young boy who travels through a wormhole back to his people's place of origin and addresses concerns about the revitalization, growth, and evolution of the Anishinaabe language (TIFF, 2017).

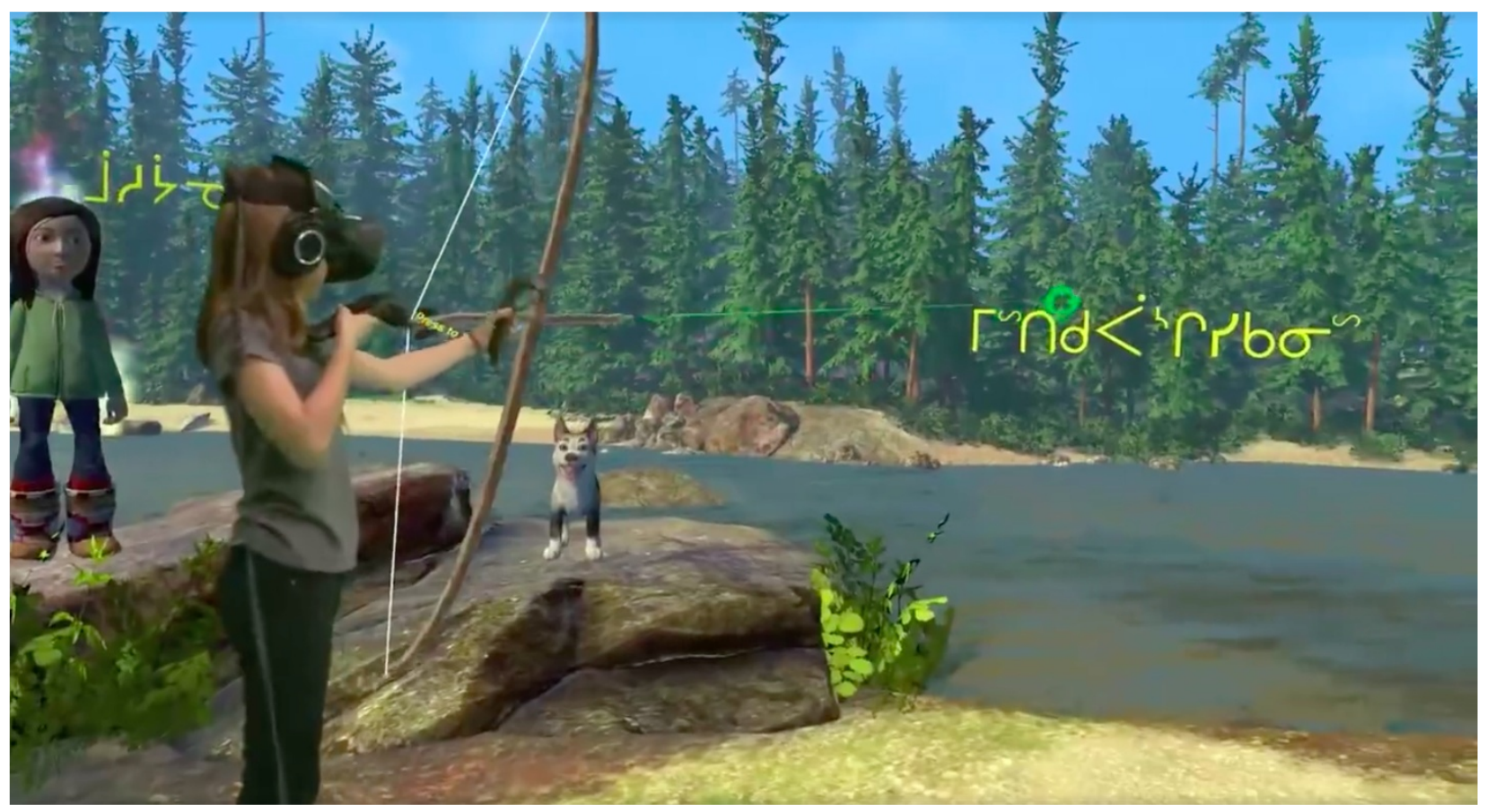

Figure 5. The Schoolū virtual camp (Screenshot courtesy of Katrina Metallic) 


\section{Supporting Self-Determined Indigenous Innovations: Rethinking the Digital Divide in Canada Jasmin Winter and Justine Boudreau}

As another example from Quebec, the company Minority Media has partnered with the James Bay Cree School Board to initiate a new virtual reality project called "Schoolū" (facebook.com/schooluvr/) that allows students to visit a virtual camp where they meet a little girl named Niipiish and her dog Achimush (Figure 5). While exploring the camp, Cree words that describe the seasons, the environment, and Cree traditions appear for the player to interact with as they wait for Niipiish's little brother's walking-out ceremony (Wapachee, 2016).

Adrian Duke, a technology entrepreneur from the Muscowpetung First Nation in Saskatchewan, is working on his own app called Wikiupedia (wikiupedia.com), which he describes as a "location-based story catching app that allows the Aboriginal community to share their stories, traditional knowledge, and any other information that they would like, using a bunch of different media sources" (Bambury, 2017). The app is named after a traditional Indigenous hut called a "wikiup". Like Wikipeida, users will be able to submit their own stories, which will be verified by cultural knowledge keepers. Like the infamous app Pokémon Go, users will have to go out and explore their local environment to unlock this knowledge (Bambury, 2017).

These examples are just some of many that help put the rest the notion that Indigenous peoples' local, context-specific place-based knowledge is somehow incompatible with digital technology. They also demonstrate how sovereignty in terms of land and territory is applicable to "visual sovereignty" or "screen sovereignty", which are descriptors for the importance of Indigenous control over their representations online, in video games, apps, and augmented and virtual reality development, and any medium that is helping information spread faster than ever before (Dowell, 2013). Indigenous innovators, using these new mediums to represent traditional knowledge, are demonstrating how Indigenous peoples have been navigating local and globalized contexts to connect with communities all over the world to advance their rights, balancing what unites Indigenous peoples internationally with what makes them unique and distinct. With all these examples in mind, it is easier to envision what Laurel Dyson (2004) of the University of Technology Sydney is saying when she argues that "Technology is only capable of furthering the agenda of the dominant culture if used to that end", reinforcing that Western hegemony need not be some invincible force.

\section{Makerspaces}

Finally, this article offers a practical pathway with which to address the digital divide, influenced by emerging "makerspaces", which are described by Roslund and Rogers (2013) as: "a general term for a place where people get together to make things. Makerspaces might focus on electronics, robotics, woodworking, sewing, laser cutting, programming, or some combination of those skills." The book entitled The Makerspace Playbook asserts that:

"Makerspaces come in all shapes and sizes, but they all serve as a gathering point for tools, projects, mentors, and expertise. A collection of tools does not define a makerspace. Rather, we define it by what it enables: tools." (EDUCAUSE, 2013)

Makerspaces are gaining traction in both entrepreneurial and community settings such as schools and libraries, and increasingly within rural settings through mobile makerspaces. A fundamental principle of makerspace culture is accessibility, and there is ample discussion of how to encourage inclusiveness and diversity, without having the terms become competing goals when one-size-fits-all approaches are applied.

The second author of this article, Justine Boudreau, is a Master's student in the Electronic Business Technologies program at the University of Ottawa, Canada, and has practical experience with makerspaces in Indigenous contexts. In March of 2016, a state of emergency was declared in Pimicikamak First Nation (Cross Lake, Manitoba) because of an increasing incidence of suicide, particularly among young people. Because of this,

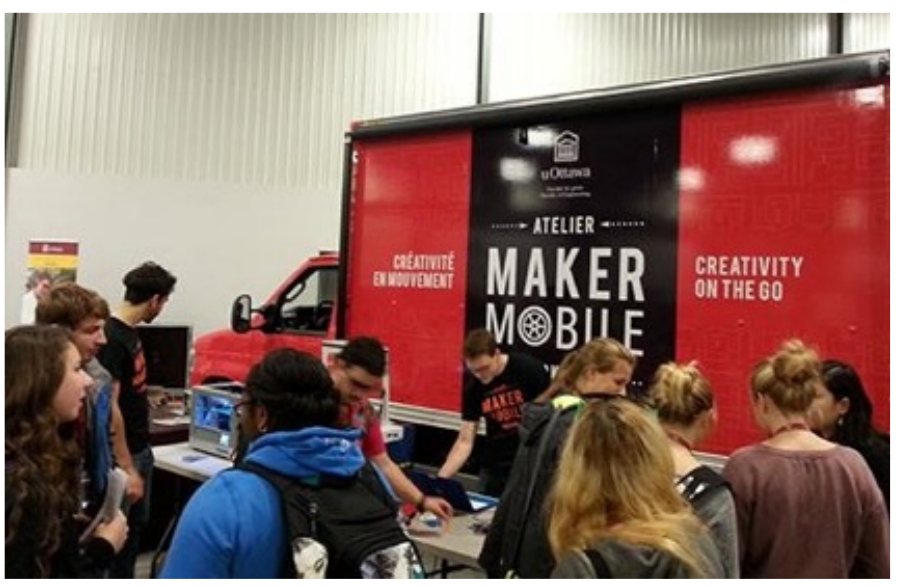

Figure 6. The uOttawa Maker Mobile (Photograph courtesy of Justine Boudreau) 


\section{Supporting Self-Determined Indigenous Innovations: Rethinking the Digital Divide in Canada Jasmin Winter and Justine Boudreau}

a local Indigenous artist reached out to the uOttawa Richard L'Abbé Makerspace (engineering.uottawa.ca/ makerspace) looking to see if they could provide some support. Through a partnership with Maker Mobile (engineering.uottawa.ca/makermobile), a sister organization that runs workshops in remote communities during the summer, and with funding from the University of Ottawa's Faculty of Engineering, a strategy to empower Cross Lake youth through community-driven making was set in motion. In advance of Boudreau and fellow student Danielle Taillon travelling to Winnipeg in early July, a 3D printer was bought and shipped to the University of Manitoba's Kidnetic program, with plans to bring and leave it in Cross Lake after teaching students and teachers how to use it. The curriculum details of the summer camp had to be modified upon Boudreau and Taillon's arrival as it was expected that there would be two age groups - up to about grade 7 and over grade 7 - but the participants ended up mostly being younger than grade 4 . The curriculum eventually included 3D modelling, 3D printing, coding, building structures on a budget, and making 3D printed jewelry. The days started slowly, with 10 to 15 students in the morning, and picked up after lunch with 20 to 30 students, a majority of which were girls. The activities usually lasted for around one and a half hours with breaks in between where everyone could spend some time outside. However, sometimes it was impossible to pull the kids away from their creations made using the Tinkercad (tinkercad.com) 3D modelling software, so the activity would continue throughout the afternoon. The activities were held in a computer lab where each participant had access to a computer, which made it easier to do $3 \mathrm{D}$ modelling and programming. There were not many adults around during the day, which made it harder to teach the kids how to use the 3D printer, but instructions were sent to the youth coordinator contact in the community. During that summer, three other communities near and on Manitoulin Island, Ontario, were visited in for week-long camps: Sheshegwaning First Nation, M'Chigeeng First Nation, and Whitefish River First Nation.

Unfortunately, because of the nature of these one-week summer camps, it is difficult to assess the outcomes of the project. The incredible creative and artisanal talents in the community can definitely make good use of a 3D printer. Children as well as adults have the capability to use this technology, and the hope is that it can provide a source of engagement and be a creative outlet for the community. If Maker Mobile would be able to return to any of the communities, the impact may be more tan- gible and the lasting effects of the visits would be more readily assessed. The hope is always to be able to go back and visit a community to be able to continue the learning as well as not leave an impression of abandonment. Unfortunately, because of the geographical distance, this is often not possible.

\section{Gathering STEAM}

As community spaces for innovation, makerspaces may serve as a point of discussion for how to encourage, for example, alternative pedagogies and educational practices to connect youth and elders to help promote intergenerational knowledge transmission. Drawing from innovations presented in this article, this could include building equipment for land-based education, hunting, and trapping, all the while encouraging language revitalization. Consider a recent example from 2017, when Boudreau joined the Marker Mobile team to introduce Indigenous youth at Gloucester High School in Ottawa, Canada, to principles of engineering and innovation through a program called InSTEM (actua.ca/en/ programs/national-aboriginal-outreach-program). At the Ontario Makers and Mentors Innovation Conference in November of that year, Paula Hall, Vice-Principal at Gloucester High School, presented some of the final projects created by these students, one of which included a prototype for a water filtration system for communities without access to clean drinking water (Hall, 2017).

Moreover, this article has purposefully emphasized how Indigenous innovations often lie at the intersection of art and technology, promoting a STEAM (science, technology, engineering, art, and math) model rather than just STEM. Wapikoni (wapikoni.ca), a project based in Quebec, while not officially labelling itself a makerspace, is the most far-reaching initiative to bring digital tools to northern Indigenous communities to date. The team has been conducting a travelling audiovisual studio that has trained and allowed Indigenous youth to see their stories come to life for screenings across Canada since 2004.

Earlier, we discussed Julie Nagam's assertion that Indigenous cultural knowledge is always evolving as part of "a living and embodied practice" (Nagam, 2016). Through her project titled "Transactive Memory Keepers (TMK): Indigenous Public Engagement in Digital and New Media Labs and Exhibitions", Nagam hopes to honour Indigenous innovations like the ones presented in this article, and draw inspiration from Wapikoni, by investigating the potential for building an open-source 


\section{Supporting Self-Determined Indigenous Innovations: Rethinking the Digital Divide in Canada Jasmin Winter and Justine Boudreau}

digital media mobile lab created by Indigenous peoples and for Indigenous communities. The TMK project, while still considering tools such as $3 \mathrm{D}$ printers and laser cutters, sees digital and new media tools as most relevant. The TMK project contends that "the principals of Indigenous methodologies are collaboration, learning by doing, and involving community members" (Nagam, 2015). In this sense, the project proposes that thinking about makerspaces in Indigenous communities should mean connecting contemporary Indigenous innovations to makerspace theories, and back to traditional Indigenous knowledge in a circular way that finds the common thread of community wellbeing. A fundamental research question that will be addressed is: If you bring a mobile lab into a community, and produce great results, how does the community benefit over the long term without ongoing access to the full equipment, and what happens to the project mentors or people involved? The answers to this, of course, will necessarily draw from Indigenous understandings of sustainability such as the seventh generation principle. Focusing an Indigenous makerspace on strengthening digital infrastructure and information and communication technologies has the added benefit of connecting communities to instructors and mentors even when they cannot physically be there.

Perhaps the most challenging aspect of the TMK project will be digging deep into the "open source" philosophy, which is characteristic of existing makerspace communities, as the makerspace model has its roots as a response to corporate patents and commercialization. For Indigenous communities, however, the flip side of all the potential that technology holds to revitalize Indigenous stories and worldviews is apprehension towards a Western form of liberalism that does not adequately address the appropriation of knowledge and culture. Coming full circle, it is this sound logic that has fostered apprehension towards technologies (such as the camera) yielded by European hands, not the technologies themselves. Technological development projects in Indigenous communities must explicitly acknowledge the logic of colonial institutions and legislation, which have attacked Indigenous knowledge transmission and data collection through isolating communities both geographically as well as socially, through the fracturing of familial ties and the punishment of language use and ceremonies. At the very least, these projects should promote intellectual property standards that reflect Indigenous ways of knowing. Ideally, future projects will take note of Indigenous-led initiatives like the ones presented in this article, and focus on facilitating Indigenous control over project designs to foster technological self-determination and sovereignty.

\section{Conclusion}

Rejecting needs-based, solution-oriented fixes to the socalled "digital divide" necessitates a process of challenging Eurocentric myths of modernity and recognizing how Indigenous peoples have always been innovators when it comes to tools of survival. Technological development in Indigenous communities demands a more thoughtful, and oftentimes more uncomfortable, approach to reconciliation that looks to the past in order to look to the future. This article has presented but a sample of the plethora of ways in which Indigenous peoples are making space in digital environments for their worldviews and ways of knowing, and projecting themselves into a future that dominant society would have them believe will not exist. Makerspaces, while brimming with potential as a pathway towards strengthbased technological development, can only truly do so if their project designs are informed by Indigenous worldviews and methodologies that draw on the strengths of Indigenous communities.

In conclusion, yes, visit websites created by Indigenous peoples. Use their apps, play their video games, and witness their presence in augmented and virtual reality, but do so critically, acknowledging that these virtual landscapes do not offer access to another lived experience. Listen closely, instead, to the lessons about our world, the "real", the "virtual", and everything in between, that are more relevant now than ever. Keeping the above in mind, this article serves primarily as an introduction to the topic, and there is much to explore when it comes to each initiative. 


\section{Supporting Self-Determined Indigenous Innovations: Rethinking the Digital \\ Divide in Canada Jasmin Winter and Justine Boudreau}

\section{About the Authors}

Jasmin Winter is a recent graduate of the Master's in Development Practice program at the University of Winnipeg, which stands on Treaty 1 territory. Originally from Vancouver, on the unceded lands of Coast Salish peoples, Jasmin was raised by a European father and a Chinese mother. This article contains material from a Major Research Paper that was graciously supervised by Dr. Julie Nagam. Jasmin completed a field placement with the Initiative for Indigenous Futures in the summer of 2017, and was a research assistant for the Transactive Memory Keepers project. She is currently working for the First Nations Technology Council in British Columbia. She is incredibly grateful to have had these opportunities to support Indigenous-determined innovations.

Justine Boudreau completed her undergraduate degree in Mechanical Engineering at the University of Ottawa, Canada, and is now working on a Master's degree in Electronic Business Technologies. During the last three years, she has spent her time playing with new technology and diversifying her knowledge. She spent almost two years working with the Maker Mobile delivering workshops and integrating new curriculum for robotics and women in science and engineering. She then moved on to work for the uOttawa Richard L'Abbé Makerspace while teaching and running the first and second year engineering design courses run through the Makerlab.

\section{References}

Alderman, N. 2015. The First Great Works of Digital Literature Are Already Being Written. The Guardian, October 13, 2015. Accessed February 15, 2018:

https://www.theguardian.com/technology/2015/oct/13/videogames-digital-storytelling-naomi-alderman

Bambury, B. 2017. Tech Entrepreneur Adrian Duke is Building an Augmented Reality App to Tell Indigenous Stories. CBCRadio Day 6, March 10, 2017.

http://www.cbc.ca/radio/day6/episode-328-cia-secrets-leakedphyllis-diller-s-gag-file-virtual-indigenous-history-and-more1.4015018/tech-entrepreneur-adrian-duke-is-building-anaugmented-reality-app-to-tell-indigenous-stories-1.4015037

Battiste, M., \& Henderson, J. (Sákéj) Y. 2011. Eurocentrism and the European Ethnographic Tradition. In M. C. Sunseri (Ed.), Racism, Colonialism, and Indigeneity in Canada: 11-19. Oxford: Oxford University Press.
Crosby, M. 2002. Construction of the Imaginary Indian. In J. Giltrow (Ed.), Academic Reading: Reading and Writing Across the Disciplines: 488-498. Peterborough, Canada: Broadview Press.

Dowell, K. 2013. Sovereign Screens: Aboriginal Media on the Canadian West Coast. Lincoln, NE: University of Nebraska Press.

Dyson, L. E. 2004. Cultural Issues in the Adoption of Information and Communication Technologies by Indigenous Australians. In F. Sudweeks \& C. Ess (Eds.), Proceedings of the Fourth International Conference on Cultural Attitudes towards Technology and Communication (CATaC): 58-71. Karlstad, Sweden, June 27-July 1, 2004.

Frost, A. 1992. Old Colonisations and Modern Discontents: Legacies and Concerns. In Proceedings of the Inaugural Conference of The Samuel Griffith Society: 116-126. Hilton-on-the-Park, Melbourne. http://www.samuelgriffith.org.au/papers/html/volume\%201/chap 11.htm

Golub, A. 2004. Copyright and Taboo. Anthropological Quarterly, 77(3): 521-530.

https://doi.org/10.1353/anq.2004.0039

Hall, P. 2017. InSTEM: Empowering Indigenous Youth through Social Change. Presented at the Ontario Makers and Mentors Innovation Conference, Ottawa, Canada.

Iseke, J., \& Moore, S. 2011. Community-based Indigenous Digital Storytelling with Elders and Youth. American Indian Culture and Research Journal, 35(4): 19-38. http://www.ourelderstories.com/wpcontent/uploads/pdf/CommunityBasedIndigenousDigitalStorytell ing_2011.pdf

Kestler-D'Amours, J. 2015. Creating Video Games Help Indigenous Girls Boost Self-Confidence. The Star, June 15, 2015. Accessed February 15, 2018:

https://www.thestar.com/news/gta/2015/06/15/creating-videogames-help-indigenous-girls-boost-self-confidence.html

Krech, S. 2000. The Ecological Indian: Myth and History. New York: W.W. Norton \& Company.

Lameman, B. A., \& Lewis, J. E. 2011. Skins: Designing Games with First Nations Youth. Journal of Game Design and Development Education, 1: 54-63.

Landrum, C. L. 2012. Kicking Bear, John Trudell, and Anthony Kiedis (of the Red Hot Chili Peppers): "Show Indians" and Pop-Cultural Colonialism. The American Indian Quarterly, 36(2): 182-214.

Lewis, J. E. 2005. Terra Nullius, Terra Incognito. Blackflash, 21(3): 16-19.

Lewis, J. E. 2016. A Brief (Media) History of the Indigenous Future. Public, 27(54): 36-50.

Lewis, J. E., \& Fragnito, S. T. 2005. Aboriginal Territories in Cyberspace. Cultural Survival, 29(2): 29-31. https://www.culturalsurvival.org/publications/cultural-survivalquarterly/aboriginal-territories-cyberspace

Loft, S. 2005. Aboriginal Media Art and the Postmodern Conundrum: A Coyote Perspective. In Townsend, M., Claxton, D. \& Loft, S. (Eds.), Transference, Tradition, Technology: Native New Media Exploring Visual \& Digital Culture: 88-103. Banff, Canada: Walter Phillips Gallery Editions 


\section{Supporting Self-Determined Indigenous Innovations: Rethinking the Digital \\ Divide in Canada Jasmin Winter and Justine Boudreau}

L'Hirondelle, C. 2016. Codetalkers Recounting Signals of Survival. In K. Swanson \& S. Loft (Eds.), Coded Territories: Tracing Indigenous Pathways in New Media Art: 147-168. Calgary: Calgary University Press.

Maracle, L. 2015. Memory Serves: Oratories. Edmonton, Canada: NeWest Press.

Maskegon-Iskwew, A. 1994. Drumbeats to Drumbytes Origins. Drumbytes.org: Aboriginal Media Art. Accessed February 17, 2018: http://drumbytes.org/about/origins-1994.php

Nagam, J. 2015. About the Project. Transactive Memory Keepers: Digital and New Media Mobile Laboratories. Accessed September 19, 2017:

http://www.transactivememorykeepers.org

Nagam, J. 2016. Deciphering the Refusal of the Digital and Binary Codes of Sovereignty/Self-Determination and Civilized/Savage. Public, 27(54): 78-89.

https://doi.org/10.1386/public.27.54.78_1

Raheja, M. H. 2010. Reservation Reelism: Redfacing, Visual Sovereignty, and Representations of Native Americans in Film. Lincoln, NE: University of Nebraska Press.

Roslund, S., \& Rodgers, E. 2013. Makerspaces: 21st Century Skills Innovation Library: Makers as Innovators. North Mankato, NM: Cherry Lake Publishing.

Sium, A., \& Ritskes, E. 2013. Speaking Truth to Power: Indigenous Storytelling as an Act of Living Resistance. Decolonization: Indigeneity, Education \& Society, 2(1): I-X. http://www.decolonization.org/index.php/des/article/view/19626 $/ 16256$

TIFF. 2017. 2167: Indigenous Filmmakers and Artists Imagine Indigenous Life 150 Years in the Future in New VR projects. Toronto International Film Festival (TIFF). Accessed February 15, 2018:

http://www.tiff.net/events/2167/

UN. 2008. United Nations Declaration on the Rights of Indigenous Peoples. New York: United Nations (UN).

http://www.un.org/esa/socdev/unpfii/documents/DRIPS_en.pdf

UNESCO. 2013. World Summit on the Information Society (WSIS): Towards Knowledge Societies for Peace and Sustainable Development. Paris: United Nations Educational, Scientific and Cultural Organization (UNESCO).

Vizenor, G. 2000. Edward Curtis: Pictorialist and Ethnographic Adventurist. Essay based on presentation at University of California, Berkeley, October 6-7, 2000.

http://www.e-scoala.ro/american/us_cultures/c4d.html

Wapachee, C. 2016. James Bay Students Learn Cree. CBC News, November 3, 2016. Accessed February 15, 2018: http://www.cbc.ca/news/canada/north/james-bay-studentslearn-cree-in-virtual-reality-1.3835500

Citation: Winter, J., \& Boudreau, J. 2018. Supporting Self-Determined Indigenous Innovations: Rethinking the Digital Divide in Canada. Technology Innovation Management Review, 8(2): 38-48.

http://doi.org/10.22215/timreview/1138

Keywords: Indigenous, innovation, digital, technology, makerspaces (cc) BY 


\title{
Convergent Innovation in Food through Big Data and Artificial Intelligence for Societal-Scale Inclusive Growth
}

\author{
Laurette Dubé, Pan Du, Cameron McRae, Neha Sharma, \\ Srinivasan Jayaraman, and Jian-Yun Nie
}

\author{
"Collectively, we have only begun to scratch the surface" \\ of what is the biggest potential market opportunity in \\ the history of commerce. Those in the private sector who \\ commit their companies to more inclusive capitalism \\ have the opportunity to prosper and share their \\ prosperity with those who are less fortunate.
}

C. K. Prahalad \& Stuart L. Hart (2002)

In "The Fortune at the Bottom of the Pyramid"

\begin{abstract}
Inclusive innovation has not yet reached societal scale due to a well-entrenched divide between wealth creation and social equity. Taking food as the initial test bed, we have proposed the convergent innovation model to address such challenges still facing 21st century society by bridging sectors and disciplines around an integrated goal on both sides of the social-economic divide for innovations that target wealth creation with an upfront consideration of its externalities. The convergent innovation model is empowered by two key enablers that integrate an advanced digital infrastructure with leading scientific knowledge on the drivers of human behaviour in varying contexts. This article discusses the structure, methods, and development of an artificial intelligence platform to support convergent innovation. Insights are gathered on consumer sentiment and behavioural drivers through the analysis of user-generated content on social media platforms. Empirical results show that user discussions related to marketing, consequences, and occasions are positive. Further regression modelling finds that economic consequences are a strong predictor of consumer global sentiment, but are also sensitive to both the actual price and economic awareness. This finding has important implications for inclusive growth and further emphasizes the need for affordable and accessible foods, as well as for consumer education. Challenges and opportunities inspired by the research results are discussed to inform the design, marketing, and delivery of convergent innovation products and services, while also contributing to dimensions of inclusion and economic performance for equitable health and wealth.
\end{abstract}

\section{Introduction}

Inclusive innovation has been proposed as a framework to reduce inequities that have oftentimes accompanied wealth creation and modern development since the onset of the first industrial revolution (Schillo \& Robinson, 2017). Inclusive economic growth has been defined as "growth that not only creates new economic opportunities, but also one that ensures equal access to the op- portunities created for all segments of society, particularly for the poor" (Ali \& Son, 2007). More recently, the OECD has called for inclusiveness in "economic growth that creates opportunities for all segments of the population and distributes the dividends of increased prosperity, both monetary and non-monetary terms, fairly across society" (Planes-Satorra \& Paunov, 2017). Yet, leading economists are reporting unprecedented increases in inequities within and across countries 


\section{Convergent Innovation in Food through Big Data and Artificial Intelligence for Societal-Scale Inclusive Growth $L$. Dube, $P$. Du, C. McRae, N. Sharma, S. Jayaraman, and J.-Y. Nie}

around the world (Piketty, 2014) at the price of constraining human, social, and economic progress for all population segments in future generations (Stiglitz, 2016). As a sign of modern economies needing to modify paths to economic development, in the advanced industrial economy of the United States, overall life expectancy at birth has actually decreased for two years in a row and more so for poor and other disadvantaged population segments (Kochanek et al., 2016). Wealth is rising unequally and it is increasingly concentrated in fewer hands, with the benefits of innovation also shared unequally.

Considering the role that innovation has played in economic growth since the onset of the first industrial revolution (Beinhocker, 2007; Drayton \& Budinich, 2010; Dubé et al., 2014), inclusive innovation holds significant promise for addressing social and economic inequities. Inclusive innovation projects typically aim to improve the welfare of lower-income and marginalized groups by enabling their full participation in the production and consumption of social and commercial goods, services, or programs (Chataway et al., 2014; Pansera \& Martinez, 2017). Social entrepreneurs are bringing sophisticated technical solutions, business acumen, and increasing investment to address inequities in both industrialized and developing economies (Martin \& Osberg, 2007, 2015). Commercial firms operating on different scales now place innovative supports for the most vulnerable and disadvantaged groups living in the communities where they operate as part of their corporate responsibility strategies (Campbell, 2007).

Pioneered by Prahalad and Hart (2002), bottom-of-thepyramid and other forms of frugal and lower-cost commercial innovation have penetrated resource-poor markets in emerging economies and value-conscious markets in both developing and industrialized countries. As governments and civil society groups struggle for greater impact and longer-term viability from social supports that still often assume never-ending access to governmental or philanthropic funds, innovations targeted to bottom-of-the-pyramid markets have a high potential for economic growth in emerging economies for domestic and multinational businesses while also addressing the needs of disadvantaged populations (Prahalad \& Hammond, 2002; Prahalad \& Hart, 2002). However, such innovations occupy a limited share of national and global wealth-creation systems in both developing and industrialized countries, and the significance of their social and economic impact for individuals, organizations, and society remains limited (Dubé et al., 2012).
Constraints that still prevent the above instances of inclusive innovation from reaching societal scale are tied to a structural divide between pathways of poverty alleviation and those of wealth creation that have emerged from the linear and siloed features of Western-centric development since the first industrial revolution (Gillespie et al., 2013; Moodie et al., 2013). This divide is between the private sector - which typically focuses on technological innovation and economic growth that carefully caters to targeted customer needs - and the government and civil society sectors - which typically use a "one size fits all" approach to ensure acceptable conditions for health, education, and other social goods for all. This divide creates a disconnect between, on the one hand, the still predominantly rights-based human development approach deployed by governments and civil society to support the poor through social welfare and community mobilization to reach subsistence (Devaux et al., 2009), and, on the other hand, a precisely targeted economic focus driving wealth-creation activities in value chains and markets as industrialized urban societies develop (Reardon et al., 2012). Furthermore, two major negative externalities of existing partners of economic growth - namely healthcare and environmental costs - are now threatening the financial viabilities of governments in industrialized and developing countries alike. It is clear that investments and policies in current models of inclusive innovation will not suffice unless such "externalities" become mainstream in all industrial innovation.

With innovation accounting for $50 \%$ to $80 \%$ of all social and economic progress tied to modern development (Croitoru, 2012), it is only through innovating the way we innovate that we can go beyond what has been possible so far in simultaneously advancing paths of wealth creation and poverty alleviation in a way that fosters lasting human and environmental health. As information is key to transformation in complex dynamic systems (Hammond \& Dubé, 2012), the most recent developments in artificial intelligence, big data, and digital technologies can serve as key catalysts for creating an adequate and lasting supply and demand for such innovation across the socio-economic spectrum and around the world. Such a catalyst requires a transformation of both our methods of innovation as well as the current practices of a broad spectrum of stakeholders, including consumers. In fact, individuals themselves often feel divided and conflicted between their expectations, intentions, and actual behaviours as consumers resulting in increased consumption for immediate gratification or to support long-term health goals and social or environmental causes. With modern society experi- 


\section{Convergent Innovation in Food through Big Data and Artificial Intelligence for Societal-Scale Inclusive Growth $L$. Dube, $P$. Du, C. McRae, N. Sharma, S. Jayaraman, and J.-Y. Nie}

encing the fourth industrial revolution - where information and digital technologies are in the process of replacing fuel and other physical resources as drivers of both social and economic development - convergent innovation has been proposed as a next-generation approach to both inclusive and mainstream innovation that will bridge the social-commercial disconnect in both consumers' minds and innovation systems to build supply and demand for societal-scale solutions (Dubé et al., 2012; Dubé et al., 2014).

In this article, we offer a brief review of the convergent innovation approach that has taken food as an initial test bed, and we report on the early stages of a research program designed with the objectives to: i) develop the structure and methods for an artificial intelligence digital platform to support convergent innovation; and ii) generate consumer insights on sometimes conflicting demand drivers for convergent innovation, with a focus on user-generated content through social media. We review management research on user-generated content to inform our social media analysis for convergent innovation in food, then we report on the structure and methods used for the artificial intelligence platform. Next, we report the results from a first empirical analysis of user-generated content. We conclude by discussing the challenges and possibilities presented by the research results.

\section{Convergent Innovation}

Convergent innovation, which has been in development for more than a decade taking the food domain as a test bed (Figure 1), is an intersectoral translational framework that aims to innovate the way we innovate to address some of the most complex challenges and possibilities facing 21 st Century society.

The convergent innovation framework combines technical, social, and institutional innovation and bridges science, policy, and action through a unique blend of digital technologies and social capital with human creativity and agency. The aim is to invent a 21 st century intersectorality to improve lives, promote equity and health, and accelerate environmental sustainability - at the same time and through the same pathways where wealth is being created individually and collectively. The multifaceted intersectorality underlying convergent innovation combines: i) natural, life, social, and engineering sciences; ii) economic systems and the larger natural and social systems within which they reside; iii) public, private, and civil society actors in each of these systems; and iv) the various scales at which mechanisms, actors, and institutions are operating.

The operational deployment of convergent innovation at scale may be made possible at this point in time by

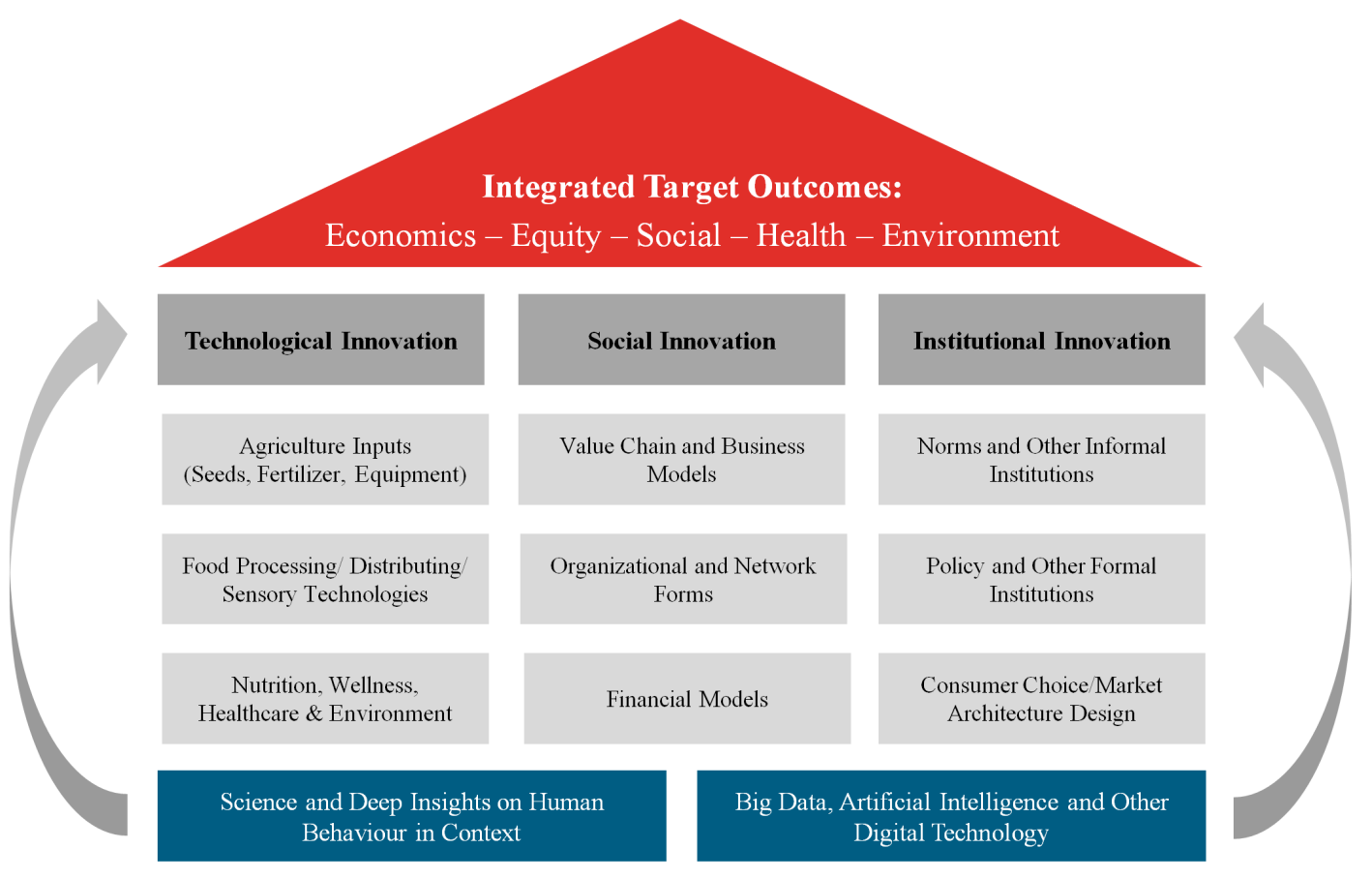

Figure 1. Convergent innovation: Behavioural change and ecosystem transformation solutions (Adapted from Dubé et al., 2014) 


\section{Convergent Innovation in Food through Big Data and Artificial Intelligence for Societal-Scale Inclusive Growth $L$. Dubee, P. Du, C. McRae, N. Sharma, S. Jayaraman, and J.-Y. Nie}

two key enablers. First, is the unique digital infrastructure that defines the 4th industrial revolution, including recent advancements in big data, artificial intelligence, and integrative analytics to map and bridge knowledge and its operational interfaces with policy and action. The second key enabler integrates cutting-edge scientific knowledge on complex drivers of human behaviour in varying contexts and their linkages to biological and social outcomes, accelerated by the conceptual and methodological development in genomics, neuroscience, and behavioural economics. The nomination of Richard Thaler, the father of behavioural economics, as the 2017 Nobel Laureate of Economics is a clear signal of the scientific significance of both rational and nonrational processes, and the importance of contexts, in our understanding of the drivers of real-world human behaviour. In terms of observed changes in the drivers of human behaviours, there are promising shifts from short-term gratifiers - such as pleasurable experiences, convenience, and status - towards longer-term normative considerations for oneself and society. However, discrepancies often remain between what one thinks, what one intends to do, and what one does (Dubé et al., 2008; Lin \& Chang, 2012). This makes convergent innovation in food quite challenging. Creating a convergent innovation platform (Figure 2) requires deep insights into consumer behaviour empowered by advanced data and computer science capabilities to characterize individual and contextual diversity in the drivers of food choice and behaviour, as well as the corresponding characteristics of innovation, strategies, and operations.

\section{Using Social Media and Artificial Intelligence in Management and Innovation}

In this article, we focus on user-generated content from social media as a source of behavioural insights for convergent innovation. User-generated content refers to any forms of content, such as discussion posts, that are created by end consumers of an online system (e.g., Twitter) and are publically available. The proliferation and increasing availability of user-generated content have revolutionized industry in a new world that blurs the lines between the physical, digital, and biological spheres. Applications of user-generated content extend into a new realm of industrial innovation that takes consumer needs as the entry point for innovation. Usergenerated content can be used to gain meaningful insights from individuals in their often time-conflicting societal roles as consumers, patients, and citizens. Product attributes that tailor to one of these roles are often conflicting with those that are essential for meeting

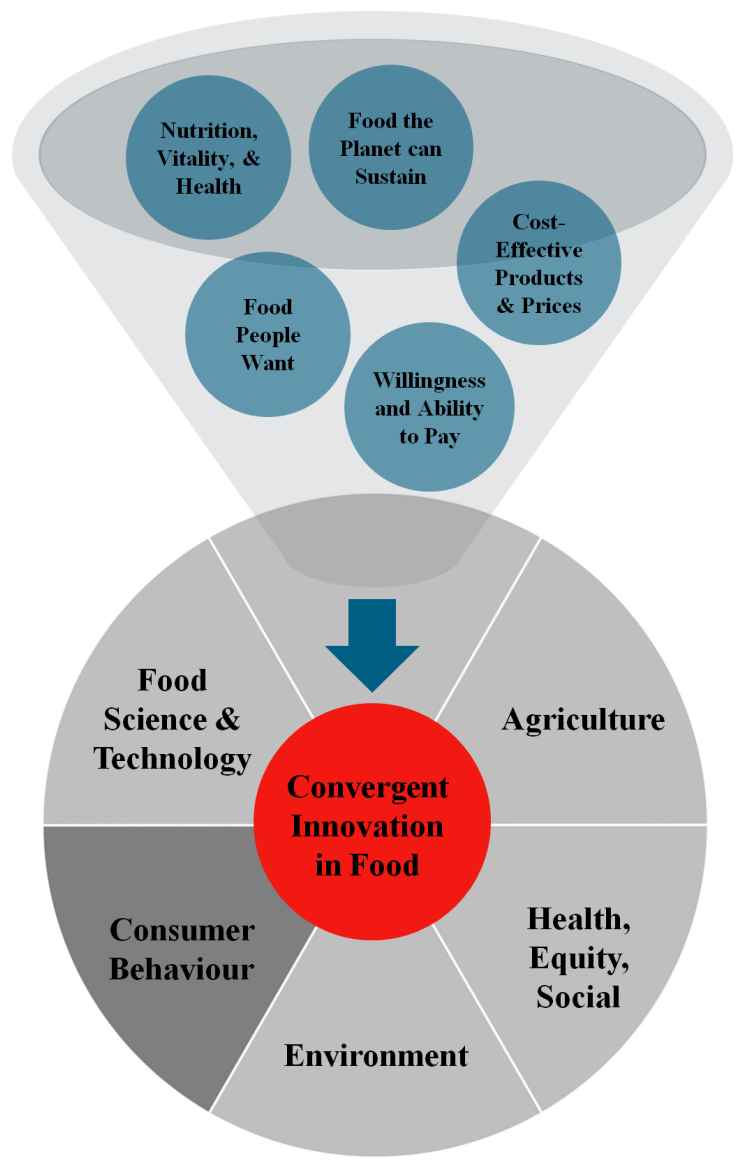

Figure 2. Platform for convergent innovation in food

the needs for other roles. In the context of food, motives and product characteristics that typically please consumers (e.g., taste and convenience) often rate poorly when considering their role as a patient or citizen. Moreover, for food, consumer packaged goods have typically been the focus of marketing research and practice. Yet, consumer packaged goods are just one of many forms food can take. Big data obtained from usergenerated content, in the context of retailing, opens immense opportunities along the dimensions of insights relating to consumers, markets, products, purchase/loyalty intent, and advertising at varying time and location-points across physical and digital channels (Bradlow et al., 2017).

\section{Consumer emotion and experience}

Innovators and marketers can enrich their understanding of consumers through user-generated content by capturing their behavioural complexity to inform the adaptive design of more competitive and consumercentric value chains (Kwark et al., 2017). In this new 


\section{Convergent Innovation in Food through Big Data and Artificial Intelligence for Societal-Scale Inclusive Growth $L$. Dubee, P. Du, C. McRae, N. Sharma, S. Jayaraman, and J.-Y. Nie}

"market 4.0", information and consumer insights are connected with physical technologies to investigate consumer voices, opinions, and reactions to products and services (Pang et al., 2015; Thomopoulos et al., 2015). Thus far, consumer and marketing research on user-generated content has utilized both supervised and unsupervised text mining for the examination of word co-occurrence and sentiments, extracting product characteristics, quality dimensions (e.g., product cost and product extension), consumer opinions towards brands, and more broadly, general personality characteristics of the consumer (Culotta \& Cutler, 2016; Golbeck et al., 2011; Willems \& Top, 2015). These techniques allow researchers to better exploit the data and automate processes that traditionally relied on human intervention (Lee \& Bradlow, 2011). By using technology to understand such drivers of behaviour, marketing and business strategies can be developed that contribute to society's journey towards sustainable development and affordable healthcare (Dubé et al., 2014; Hammond \& Dubé, 2012) and reach the consumer diet and market.

\section{Word of mouth and recommendations}

New computational methods for the analysis of usergenerated content allow researchers to dive deeply into the understanding of affective experiences through the dimensions of valence (i.e., attractiveness or adverseness) and activation (i.e., awareness and engagement) (De Choudhury et al., 2012). Electronic word-of-mouth communications through social media platforms have a significant influence on consumer behaviour (Babic Rosario et al., 2016). High variability and large volumes of electronic word-of-mouth communications have the largest impact on purchasing behaviour (Babic Rosario et al., 2016). Computational advancements in opinion mining and sentiment analysis allow for businesses to better understand consumer communications and recommendations in relation to their products and services (Pang \& Lee, 2006).

\section{Purchase/loyalty intent}

Consumer purchase intent and loyalty can also be used by businesses to better understand their consumers. Purchase and loyalty intent can be measured through user-generated content (e.g., a tweet expressing a consumer's desire to purchase a product or service). Intent may be extracted through word- or phrase-based features, as well as through grammatical patterns (Reardon et al., 2014). Furthermore, user-generated content can be classified according to the four stages of the consumer decision journey (i.e., consideration, evaluation, purchase, and post-purchase) (Vázquez et al., 2014).
Marketers and innovators can use insights gathered in relation to purchase and loyalty intent for personalized marketing efforts, demand planning, and market-level sensing, as well as to inform innovation and new product development (Reardon et al., 2014).

\section{Market and competitive intelligence}

The analysis and utility of user-generated content extend beyond understanding behaviour at the individual level and allows for scalable monitoring and analysis of broader markets, with applications for marketing intelligence and competitive intelligence. However, it is important to note that user-generated content is only one component of omnichannel retailing, and considerations for a broader research perspective are needed as consumers move through channels (physical and digital) in their buying process (Verhoef et al., 2015). User-generated content can be used to predict market trends and outcomes (Asur \& Huberman, 2010) and gather competitor intelligence in regards to competing companies' products, promotions, sales, etc. from external sources (Dey et al., 2011). The value of user-generated content from social media sites, analyzed through text-mining and natural language processing technologies, are effective modalities to extract business value and inform strategy (He et al., 2013). Together, the monitoring of consumers, markets, and competitors through user-generated content can be used to inform product development and innovation pipelines.

\section{Product design}

Inclusive innovation and convergent innovation models can leverage technological platforms using artificial intelligence and natural language processing to design more consumer-centric products that benefit consumers and the broader health and economic systems. Empirical research that explores the uses of user-generated content from social networking sites in product development and innovation is sparse (Roberts \& Candi, 2014). However, it is evident that user-generated content can be used for market research to better inform product development, engage with consumers to codesign new products, and better collaborate in the overall development process in an agile manner (Piller et al., 2012; Roberts \& Candi, 2014). Although some researchers have started to use a methodology driven by data mining to analyze user-generated content for next-generation product design, it has yet to be applied to realtime, population-level user-generated content for product development or to predict consumer responses to new products and their respective features (Goel \& Goldstein, 2013; Tuarob \& Tucker, 2015). 


\section{Convergent Innovation in Food through Big Data and Artificial Intelligence for Societal-Scale Inclusive Growth $L$. Dube, $P$. Du, C. McRae, N. Sharma, S. Jayaraman, and J.-Y. Nie}

\section{Advertising}

It is evident that the insights gathered through the analysis of user-generated content can be applied to many areas of business strategy and practice. In particular, these insights can be used by firms to market and advertise content in a precise way that resonates with consumers. Marketers can tailor advertising efforts to fulfill consumer needs for information, personal identity, and social interaction (Knoll \& Proksch, 2017). At an individual level, user-generated content can also be leveraged to precisely advertise to consumers based on user profiles and the content they post (Tucker, 2014). By better-equipping marketers with computational tools that meet the needs and wants of consumers, innovators can better build demand for 21st century products and services that better bridge the divide between health and wealth.

\section{Building an Artificial Intelligence Platform for Convergent Innovation in Food}

To support convergent innovation, we have begun the development of integrated modular artificial intelli- gence platforms. The present article focuses on the social media platform that allows us to collect discussions from social media and to extract users' opinions and sentiments towards different aspects of food. The overall architecture, as shown in Figure 3, is broadly divided into three layers: i) the data collection and management layer, ii) the analysis layer, and iii) the application layer.

The functional stack covers the entire workflow for public opinion analysis towards food. The solution can be easily adapted to other domains with the support of corresponding domain knowledge. The main duty of the first data layer is two-fold: i) to acquire domain-related data from different social media platforms such as Twitter and Facebook; and ii) to manage the ever-increasing data to support efficient input/output operations for future processes. The second analysis layer is a complete text-mining workflow that also informs the construction of the food ontology and acquisition of data using intermediate results. The final layer includes various domain-specific applications built upon the analysis results to support decision making.

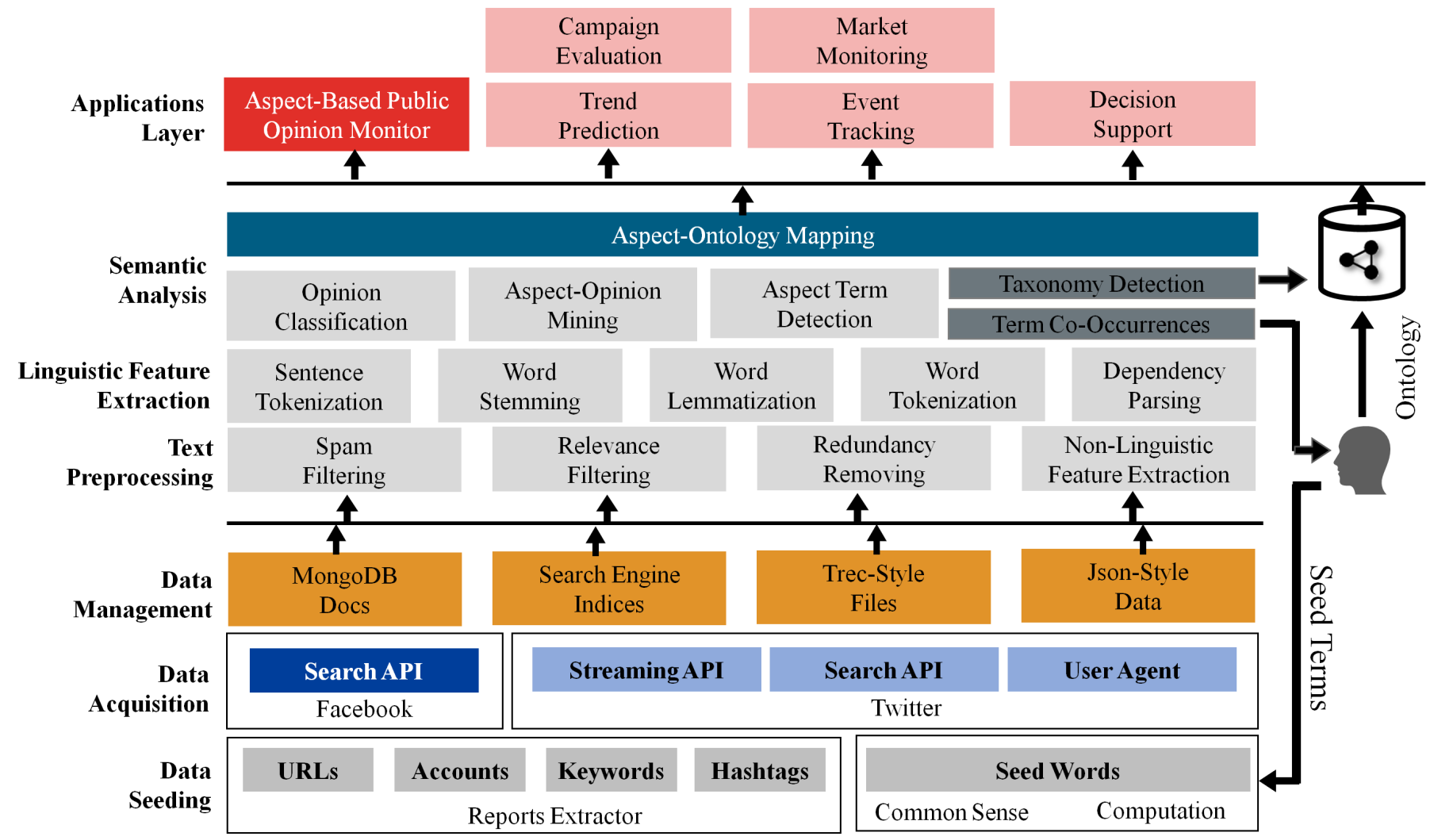

Figure 3. Overview of the artificial intelligence platform architecture 


\section{Convergent Innovation in Food through Big Data and Artificial Intelligence for Societal-Scale Inclusive Growth $L$. Dubee, P. Du, C. McRae, N. Sharma, S. Jayaraman, and J.-Y. Nie}

\begin{abstract}
Data layer
The data layer can be further divided into the functions of seed word acquisition, data collection, and data management. Seed words are used to form search queries submitted to the social media platforms (e.g., Twitter) to collect data. Seed words are domain-specific and are strongly related to the topics investigated (in our case, food). Industry reports, iterative text analysis, and common sense were used to acquire seed words. The candidate words from these sources are manually filtered. For our platform, 359 seed words were collected (including words, phrases, and hashtags) for food.
\end{abstract}

Given the selected seed words, data is collected in three different ways: i) searching historical data (up to 30 days) via the official application programming interface of Twitter; ii) searching streaming data from social media (Twitter and Facebook) application programming interfaces using the seed words; and iii) using a simulated user-agent to receive new posts on social media. Additionally, we also identify a set of known website URLs and Facebook accounts that are related to food. Data from the corresponding sites are collected automatically.

The data acquired from different social platforms are stored and managed in several different ways depending on the processing purpose. MongoDB is used for real-time input/output operations. The Trec-style data format is used for building search indices and conducting pseudo-relevance feedback searches for relevance filtering. Json-style files are used for intermediate analyzing of results.

\section{Analysis layer}

Five types of utilities compose the analysis layer and reflect the processing sequences to which the digital corpus is submitted - i) preprocessing, ii) feature extraction, iii) semantic analysis, iv) taxonomy extraction, and v) aspect-ontology mapping - as described below.

1. Preprocessing: The purpose of preprocessing is to filter out possible spam and to recognize the structure of the collected raw data. To filter spam and irrelevant posts, we used the Galago search engine to identify the top results using the seed words and expand search queries based on these top results. The expanded queries allow us to rank the data collected. We consider the low-ranked data as spams. This step filters the number of posts collected down to about $60 \%$. The other $40 \%$ of the collection is more prone to spams and low-quality posts. Non-linguistic features such as URLs, time, geolocation, mentions, emojis, retweets, replies, and likes are also extracted in this step.

2. Feature extraction: Each text goes through a series of linguistic analysis to recognize the part-of-speech (i.e., noun, verb, etc.) of words and the dependency relation between words (e.g., between verb and subject), to recognize phrases that are stored in our ontology and to transform (or lemmatize) a word into its stem (e.g., "computing", "computed", "computes", and "computation" to "comput"). The connection between the words and phrases in a discussion and the entities stored in our ontology will allow us to identify what aspect of food the discussion is about.

3. Semantic analysis: Our semantic analysis focuses on sentiment analysis - to extract the sentiment (or opinion) the user expressed about food or an aspect of food (target) in a discussion. We use our ontology to identify the aspect of food in the discussion, and a sentiment dictionary (SentiWordnet) to identify sentiment words. Target-opinion pairs are extracted by a classical approach based on grammatical rules: an opinion is assumed to be related to a target if they follow some grammatical pattern. For example, from the sentence "My dessert bar was so yummy at yesterday's event!!", we can identify "dessert bar" as belonging to the "product" aspect, and "yummy" as a sentiment word. The two elements are connected in the sentence through a syntactic relation subject-predicative. Thus, they form a target-opinion pair $<$ dessert bar, yummy $>$.

4. Taxonomy extraction and 5. Aspect-ontology mapping: As mentioned, the ontology (or concept hierarchy of the application) is a key component to connect words in a sentence to food and food aspects. For our platform on food innovation, we performed a statistical analysis on word occurrences on all the raw data collected, with the most frequent words manually filtered and structured into a hierarchy.

\section{Application layer}

In the current work, the application layer was built to explore the aspects of food based on public opinion analysis. We consider five aspects of food to inform convergent innovation: behaviour, health, consequence, marketing, and characteristics. The application layer will include several tools, but only the first tool - aspect-based public opinion monitoring - is presently implemented. 


\section{Convergent Innovation in Food through Big Data and Artificial Intelligence for Societal-Scale Inclusive Growth $L$. Dubé, P. Du, C. McRae, N. Sharma, S. Jayaraman, and J.-Y. Nie}

\section{A New Approach to Semantic Analytics}

This article presents a novel approach to the aggregation of population-level metadata to predict future market trends and support the development of products and marketing strategies. The early insights in key components of convergent innovation in food will serve as a springboard for articulating the formal knowledge structure that will enable different users to interact with the digital platforms and will define appropriate interfaces between diverse disciplinary and sectoral datasets, models, and rules (Figure 4).

The sentiment analysis (Abbasi et al., 2008; Feldman, 2013; Liu, 2012) follows the path from left to right in Figure 4. As mentioned earlier, natural language pro- cessing techniques (Ding et al., 2015; Maas et al., 2011; Nasukawa \& Yi, 2003) such as sentence tokenization, word tokenization, stemming, lemmatization, dependency tree parsing, etc. are leveraged to acquire linguistic features for extraction of aspect terms and opinion terms as well as their relations. Rules (Liu, 2012) and automatic text-classification approaches (Mullen \& Collier, 2004) were implemented for sentiment extraction. The aspects about food are identified using our ontology (Figure 5), and sentiment words are identified using external knowledge resources such as SentiWordnet (Baccianella et al., 2010; Miller, 1995).

The first task of sentiment analysis is to determine the polarity (positive, negative, or neutral) of a sentiment. In SentiWordnet, each synset (a set of synonymous

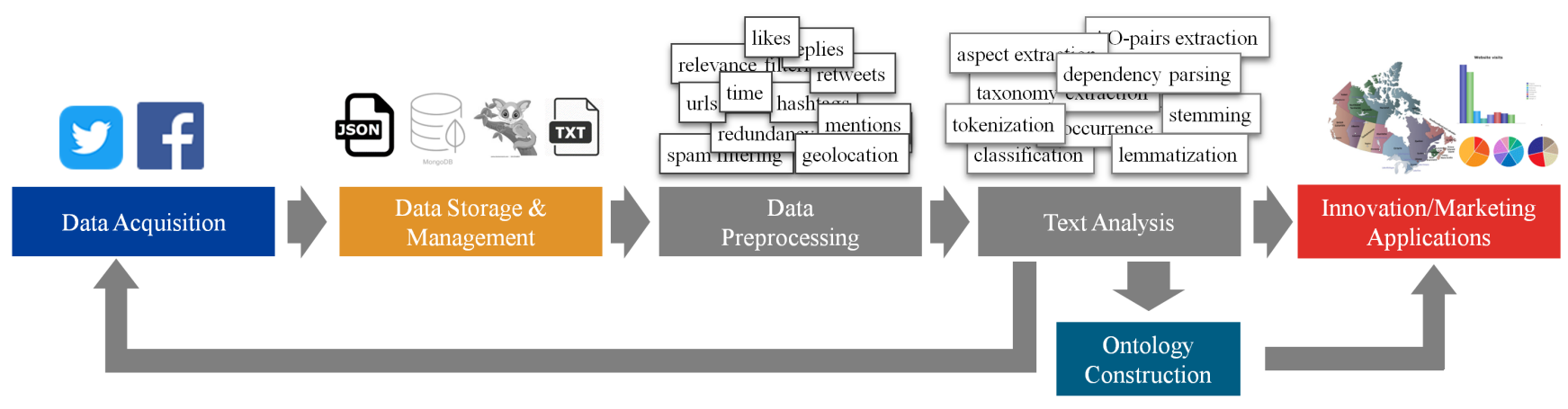

Figure 4. The digital platform architecture

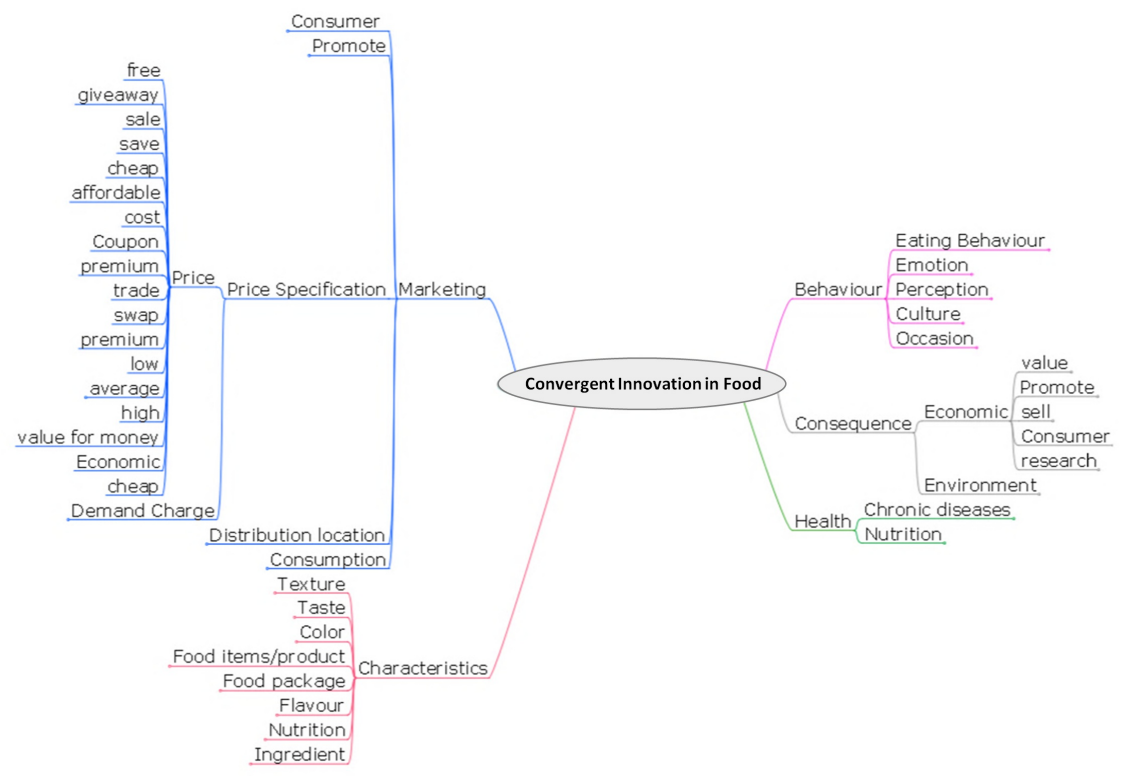

Figure 5. Vocabulary tree structure for convergent innovation in food 


\section{Convergent Innovation in Food through Big Data and Artificial Intelligence for Societal-Scale Inclusive Growth $L$. Dube, $P$. Du, C. McRae, N. Sharma, S. Jayaraman, and J.-Y. Nie}

words) is assigned three scores: Pos, Neg, and Obj, describing their polarity distribution in general. For example, for a synset of "yummy", Pos(yummy)=0.75, $\operatorname{Neg}$ (yummy) $=0.25, \operatorname{Obj}$ (yummy) $=0$. We simply assign the strongest polarity to the opinion in our current implementation. Thus, our earlier example of $<$ dessert bar, yummy> will be extended to the following triple $<$ dessert bar, yummy, positive $>$. This method can be further extended in the future to take into account the context (e.g., considering the target the opinion word is describing). The triples extracted from sentences form the set of basic opinions recognized from user discussions.

The focus of the present exploratory study is to look at consumer behaviour in relation to food using data from social media. To this end, we use the basic opinions extracted for the analysis of sentiment scores, distributions, and influence on global sentiment (Figure 6). Results from the analysis uncover consumer likes/dislikes about food aspects, as well as the drivers of behaviour through regression modelling.

\section{Results}

Over 26 million posts about food from Twitter and about 1 million posts from Facebook were collected during the summer and fall of 2017. Most posts do not express an explicit sentiment or opinion. From this set of data, about 70,000 target-opinion pairs were extracted. The distribution of opinions on different aspects, and how the opinions on an aspect influence the global sentiment of the user and post, were the subjects of our analysis.

\section{Sentiment probability distribution}

From the extracted set of associations between the aspects and sentiments, we performed statistical analysis on the distribution of sentiments across aspects of the first- and second-order, concerning the aspects included in our ontology. The distribution of sentiments about the first level aspects (marketing, behaviour, health, consequence and characteristics) is summarized in Table la. The distribution on the sub-aspects is shown in Table $1 \mathrm{~b}$. Each value in the tables represents the joint probability. For example, $P$ (Marketing, positive) $=0.135$, meaning that $13.5 \%$ of the sentiments detected are positive about marketing. In Table $1 \mathrm{~b}$, each number represents the joint probability of sub-aspect and polarity among the sentiments related to that aspect. For example, among all the sentiments expressed on sub-aspects of marketing, $30.7 \%$ are positive about the sub-aspect price specification. Notice that in Table $1 b$, we only count the sentiments expressed on the subaspects, while ignoring those that are expressed on the aspects directly.

Here, we observe that social media users discuss marketing $(P=0.135)$ and the consequences of food $(P=0.133)$ more positively than other aspects. Marketing-related aspects include price, promotional activities, placement, and industrial sector, and are mostly discussed with a neutral sentiment with a slightly positive tendency. Similarly, environmental and economic consequences are discussed with a mostly neutral-topositive sentiment. Food characteristics, including colour, texture, nutrition, packaging, and preparation method were also discussed with a mostly positive sentiment. In general, social media consumers tend to talk about food with neutral (57.6\% of discussions) to positive (37.9\% of discussions) sentiment. Only $4.5 \%$ of discussions included a negative sentiment towards food overall.

The results of second-order sentiment aspects are presented in Table 1b. Within marketing, discussions in

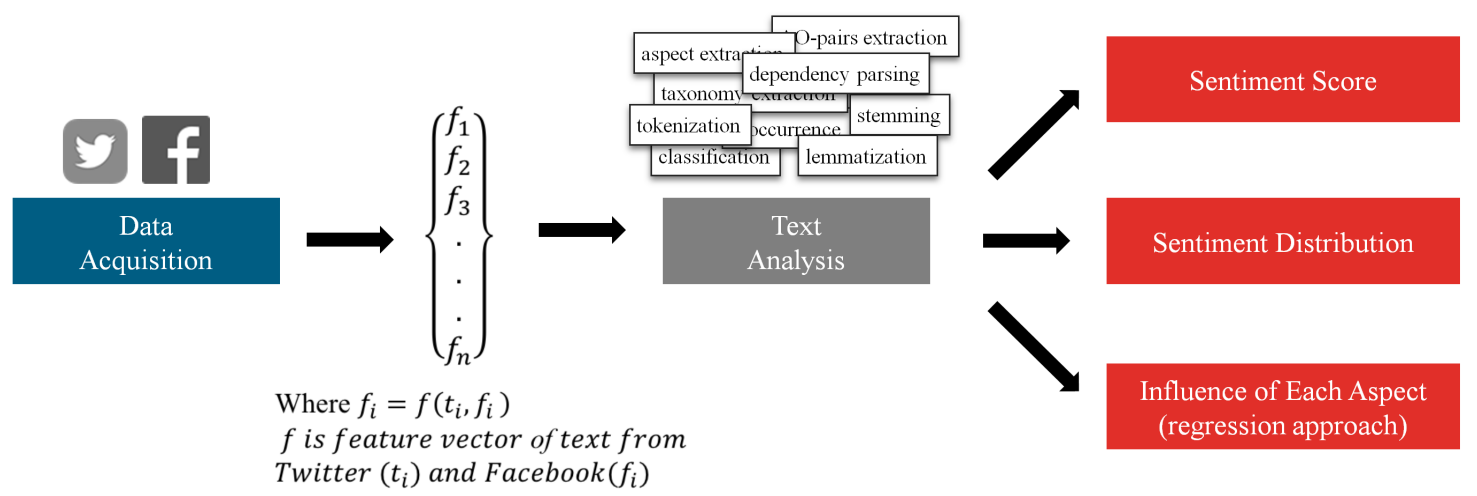

Figure 6. Flowchart for empirical analysis 
Convergent Innovation in Food through Big Data and Artificial Intelligence for

Societal-Scale Inclusive Growth $L$. Dubee, P. Du, C. McRae, N. Sharma, S. Jayaraman, and J.-Y. Nie

Table 1. Sentiment distribution of aspects and sub-aspects

a. Sentiment distribution on aspects

\begin{tabular}{|l|c|c|c|c|}
\hline Aspects & Positive & Negative & Neutral & Total \\
\hline Marketing & 0.135 & 0.014 & 0.278 & 0.427 \\
\hline Behaviour & 0.018 & 0.000 & 0.002 & 0.020 \\
\hline Health & 0.008 & 0.001 & 0.001 & 0.010 \\
\hline Consequence & 0.133 & 0.012 & 0.278 & 0.423 \\
\hline Characteristics & 0.085 & 0.018 & 0.017 & 0.120 \\
\hline Total & 0.379 & 0.045 & 0.576 & \\
\hline
\end{tabular}

b. Sentiment distribution on sub-aspects

\begin{tabular}{|c|c|c|c|c|}
\hline Sub-Aspect & Positive & Negative & Neutral & Total \\
\hline \multicolumn{5}{|l|}{ Marketing } \\
\hline Price specification & 0.307 & 0.029 & 0.651 & 0.987 \\
\hline Promotion & 0.002 & 0.000 & 0.000 & 0.002 \\
\hline Consumer & 0.002 & 0.002 & 0.001 & 0.005 \\
\hline Consumption & 0.005 & 0.001 & 0.000 & 0.006 \\
\hline Total (marketing) & 0.316 & 0.032 & 0.652 & \\
\hline \multicolumn{5}{|l|}{ Behaviour } \\
\hline Emotion & 0.000 & 0.000 & 0.005 & 0.005 \\
\hline Culture & 0.019 & 0.000 & 0.010 & 0.029 \\
\hline Eating behaviour & 0.002 & 0.000 & 0.000 & 0.002 \\
\hline Perception & 0.021 & 0.000 & 0.022 & 0.043 \\
\hline Occasion & 0.826 & 0.015 & 0.080 & 0.921 \\
\hline Total (behaviour) & 0.868 & 0.015 & 0.117 & \\
\hline \multicolumn{5}{|l|}{ Health } \\
\hline Nutrition & 0.610 & 0.101 & 0.110 & 0.821 \\
\hline Benefit & 0.000 & 0.006 & 0.003 & 0.009 \\
\hline Well & 0.130 & 0.024 & 0.012 & 0.166 \\
\hline Total (health) & 0.74 & 0.131 & 0.125 & \\
\hline \multicolumn{5}{|l|}{ Consequence } \\
\hline Environment & 0.002 & 0.000 & 0.000 & 0.002 \\
\hline Economic & 0.312 & 0.029 & 0.656 & 0.997 \\
\hline Total (consequence) & 0.314 & 0.029 & 0.656 & \\
\hline \multicolumn{5}{|l|}{ Characteristics } \\
\hline Product & 0.274 & 0.009 & 0.026 & 0.309 \\
\hline Packaging & 0.001 & 0.000 & 0.000 & 0.001 \\
\hline Taste & 0.009 & 0.000 & 0.002 & 0.011 \\
\hline Texture & 0.002 & 0.000 & 0.001 & 0.003 \\
\hline Colour & 0.002 & 0.000 & 0.001 & 0.003 \\
\hline Ingredients & 0.424 & 0.140 & 0.108 & 0.672 \\
\hline Total (characteristics) & 0.712 & 0.149 & 0.138 & \\
\hline
\end{tabular}




\section{Convergent Innovation in Food through Big Data and Artificial Intelligence for Societal-Scale Inclusive Growth $L$. Dubee, P. Du, C. McRae, N. Sharma, S. Jayaraman, and J.-Y. Nie}

relation to price are most probable to be neutral $(P=0.651)$, or positive $(P=0.307)$ to a lesser extent, hinting that consumers have a slightly positive association with food prices on a global scale. As for the behaviour sub-aspect, nearly all discussions are associated with positive eating occasions (e.g., birthdays or holidays). Consumers also have a tendency to discuss nutrition in relation to health. Most social media posts surrounding nutrition are positive $(P=0.610)$ in nature (e.g., discussion of high-protein content with positive sentiment). Health benefits and wellness are less discussed by consumers. The economic consequences of food (i.e., economic impacts) are frequently discussed with a neutral $(65.6 \%)$ or positive $(31.2 \%)$ sentiment, whereas the environmental impact of food is less discussed. As for food characteristics, we evaluated aspects of packaging, taste, texture, colour, ingredients, and product. Ingredients and products are the most discussed aspects of food characteristics, according our analysis. Although a large proportion of discussions regarding ingredients are positive $(42.4 \%)$, a noticeable proportion of discussion also expresses negative opinions (14\%). The results of this analysis reveal that consumers discuss products and ingredients most on social media. The present analysis is limited in terms of depth (i.e., number of levels we can uncover below each aspect). Future studies will address data limitations to dive deeper into acquiring more meaningful insights (e.g., what type of texture is most positive or negative). The insights gleaned from this analysis and future iterations will inform the development and marketing of food products aimed at the convergent innovation sweet spot illustrated in Figure 2.

\section{Influence of each aspect on sentiment}

The aspects explored in this analysis may contribute different degrees to the overall sentiments expressed by a consumer expressed in a post or any unit of user-generated content, therefore impacting demand for food in general or for specific products or contexts. To determine the influence of each aspect, we evaluated the sentiments of an aspect in relation to its prediction of the global sentiment of user-generated content. We use linear regression modelling to calculate the regression coefficients for each aspect (Kutner et al., 2004; Seber \& Lee, 2012), as shown in Table 2 . The sentiment of an aspect valence is between -1 and 1 : -1 (negative), 0 (neutral), or 1 (positive). The regression formula is as follows:

$$
\text { Sentiment }_{\text {post }}=\sum_{\text {aspect }_{i}} \alpha_{i} * \text { Sentiment }_{i}+S_{0}(1)
$$

where Sentiment $t_{\text {post }}$ is the global sentiment valence of a post; Sentiment $t_{i}$ is the sentiment valence of aspect $_{i} ; a_{i}$ is its coefficient, which reflects the importance of the aspect for the global sentiment; $S_{O}$ is a constant which captures the general trend of sentiment in tweets, independently from the aspects.

To perform the regression analysis, we have to detect the global sentiment of a post. Therefore, a trained classifier was used to analyze the social media data. Applying this classifier, each post was automatically assigned a sentiment valence between -1 and 1 .

The regression task aims to reproduce the global sentiment polarities using the sentiments about food aspects observed in the post. Table 2 shows the coefficients obtained hierarchically in the linear regressions. In Table 2a, general sentiment predictions are made from the sentiments of the first-level aspects. In Table $2 b$, the sentiment of the aspect is predicted from those on the second-level aspects. In Table 2c, the sentiment of subaspects level 2 is predicted from those of the level 3 (subsub-aspects). Notice that when we move down to suband sub-sub-aspects, we have more and more data sparseness, where fewer sentiments are expressed on lower-level aspects. Therefore, the analysis cannot be done at a very deep level with the data collected.

The global sentiment results infer that the overall sentiment of the food is strongly correlated with marketing $\left(a_{i}=0.032, p<0.01\right)$, behaviour $\left(a_{i}=0.203, p<0.001\right)$, consequences $\left(a_{i}=0.031, \quad p<0.01\right)$, and characteristics $\left(a_{i}=0.069, p<0.001\right)$ sub-aspects. Health is not found to be a significant predictor of food sentiment.

Further analysis was conducted on how the sentiments of second-order aspects influence that of an aspect (Table 2b). Again, a linear regression was performed using a sub-corpus for each of the aspects, where the tweets in the sub-corpus only contain tweets relating to the aspect and its sub-aspects. Most sub-aspects in level 2 were found not to be significant. Within marketing, price specification $\left(a_{i}=0.288, p<0.10\right)$ and promotional activities $\left(a_{i}=0.051, p<0.10\right)$ are significant predictors of positive global food sentiments, with the price having the strongest effect. Relatedly, the economic consequences $\left(a_{i}=0.034, p<0.10\right)$ of food are also significant predictors of global sentiment. Sub-aspects found in the layers under behaviour, health, and characteristics were non-significant predictors of global sentiment. 


\section{Convergent Innovation in Food through Big Data and Artificial Intelligence for Societal-Scale Inclusive Growth $L$. Dube, $P$. Du, C. McRae, N. Sharma, S. Jayaraman, and J.-Y. Nie}

Table 2. Hierarchical estimation of contribution of aspects and sub-aspects to global sentiment

a. Level 1 coefficients

\begin{tabular}{|l|l|}
\hline Aspects & \multicolumn{1}{|c|}{$\boldsymbol{\alpha}_{\boldsymbol{i}}$} \\
\hline Marketing & $0.032^{\dagger}$ \\
\hline Behaviour & $0.203 \S$ \\
\hline Health & 0.015 \\
\hline Consequences & $0.031^{\dagger}$ \\
\hline Characteristics & $0.069 \S$ \\
\hline
\end{tabular}

Significance:

$>0.10$ non-significant

$* 0.10-0.05$

*** $0.05-0.01$

$\dagger 0.01-0.001$

$\S<0.001$ b. Level 2 coefficients

\begin{tabular}{|ll|}
\hline Sub-Aspects & \multicolumn{1}{|c|}{$\boldsymbol{\alpha}_{\boldsymbol{i}}$} \\
\hline Marketing & \\
\hline Consumer & 0.042 \\
Price specification & $0.288^{*}$ \\
Promotion & $0.051^{*}$ \\
Consumption & 0.107 \\
\hline Behaviour & \\
\hline Emotion & 0.046 \\
Culture & 0.164 \\
Eating behaviour & 0.578 \\
Perception & 0.081 \\
Occasion & 0.103 \\
\hline Health & \\
\hline Nutrition & 0.02 \\
Benefit & 0.001 \\
Healthy & 0.199 \\
Wellness & 0 \\
\hline Consequence & \\
\hline Environment & 0 \\
Economic & $0.034^{*}$ \\
\hline Characteristics & \\
\hline Product & 0.218 \\
Packaging & 0.198 \\
Taste & 0.064 \\
Texture & 0.101 \\
Colour & -0.086 \\
Ingredients & 0.029 \\
\hline
\end{tabular}

c. Level 3 Aspects coefficients

\begin{tabular}{|ll|}
\hline Sub-Sub-Aspects & \multicolumn{1}{c|}{$\boldsymbol{\alpha}_{\boldsymbol{i}}$} \\
\hline Economic & \\
\hline Promote.Awareness & $0.278^{*}$ \\
Research.Question & 0.464 \\
Sell.Demand & -0.051 \\
Sell.Price & $0.034^{*}$ \\
Research.Report & -0.128 \\
Promote.Target & -0.752 \\
\hline Price Specification & \\
\hline Price.Affordable & -0.096 \\
Charge.Value & 0.232 \\
Price.Cheap & -0.005 \\
Price.Cost & 0 \\
Price.High & 0.236 \\
Charge.Tax & 0 \\
Price.Sale & 0.197 \\
Charge.Affordable & -0.096 \\
Price.Low & 0.426 \\
Charge.Cost & $0.035^{*}$ \\
Charge.Profit & 0 \\
Price.Giveaway & 0.066 \\
Charge.Rate & -0.167 \\
Charge.Bill & -0.199 \\
Charge.Cheap & -0.005 \\
\hline & \\
& \\
& \\
& \\
& \\
& \\
& \\
& \\
&
\end{tabular}

Price specification and economic consequences may be further decomposed with a third level. Although most sub-sub-aspects in this level were non-significant, price $\left(a_{i}=0.034, p<0.10\right)$ and promotional awareness $\left(a_{i}=0.278, p<0.10\right)$ were significant predictors of positive global sentiments, with promotional awareness having the largest effect. Cost $\left(a_{i}=0.035, p<0.10\right)$ was also a significant predictor of positive sentiment associated with price specification.

The above analysis constrains sub-aspects to impact global sentiment hierarchically, meaning that each sub-aspect is the predictor of the sentiment of the immediate superior sub/aspect, with ultimately the five first-level aspects (marketing, behaviour, health, consequences, and characteristics) being predictors of the global sentiments. To capture more of the richness of user generated content, we conducted a complementary analysis where all level 2 sub-aspects were used as direct predictors of global sentiments. Predictors of a global positive sentiment emerged as culture $\left(a_{i}=0.205, p<0.001\right)$, emotion $\left(a_{i}=0.031, p<0.05\right)$, and perception $\left(a_{i}=0.033, p<0.01\right)$. Related to the characteristics of food products themselves, colour $\left(a_{i}=0.165, p<0.05\right)$, packaging $\left(a_{i}=0.100, p<0.10\right)$, taste $\left(a_{i}=0.424, p<0.001\right)$, texture $\left(a_{i}=0.126, p<0.001\right)$, and ingredients $\left(a_{i}=0.044\right.$, $p<0.05)$ were significant predictors of sentiment. Taste had the largest effect. Nutrition $\left(a_{i}=0.083, p<0.05\right)$, under health, was also significant. 


\section{Convergent Innovation in Food through Big Data and Artificial Intelligence for Societal-Scale Inclusive Growth $L$. Dube, $P$. Du, C. McRae, N. Sharma, S. Jayaraman, and J.-Y. Nie}

Table 3. Estimation of contribution of level 2 sub-aspect to global sentiment

\begin{tabular}{|l|l|}
\hline Sub-Aspect & \multicolumn{1}{|c|}{$\alpha_{i}$} \\
\hline Behaviour.Culture & $0.205 \S$ \\
\hline Behaviour.Eating_Behaviour & 0.805 \\
\hline Behaviour.Emotion & $0.031^{* *}$ \\
\hline Behaviour.Occasion & -0.043 \\
\hline Behaviour.Perception & $0.033^{\dagger}$ \\
\hline Characteristics.Food_Colour & $0.165^{* *}$ \\
\hline Characteristics.Ingredient & $0.044^{* *}$ \\
\hline Characteristics.Package & $0.100^{*}$ \\
\hline Characteristics.Product & 0.039 \\
\hline Characteristics.Taste & $0.424 \S$ \\
\hline Characteristics.Texture & $0.126 \S^{\S}$ \\
\hline Consequence.Economic & $0.168^{*}$ \\
\hline Consequence.Environment & 0.107 \\
\hline Health.Benefit & 0.221 \\
\hline Health.Nutrition & $0.083^{* *}$ \\
\hline Health.Well & 0.007 \\
\hline Marketing.Consumer & $0.369^{* *}$ \\
\hline Marketing.Consumption & $0.289^{* *}$ \\
\hline Marketing.Price Specification & 0.635 \\
\hline Marketing.Promote & $0.232^{\dagger}$ \\
\hline Significance: $>0.10$ non-significant \\
\hline$* 0.05-0.01$ \\
$\dagger$ & $0.01-0.001$ \\
\hline
\end{tabular}

\section{Conclusion and Future Research}

Results show that positive and negative drivers of demands for convergent innovation in food, as expressed in this digital social media corpus, bear on their own belief systems, experiences, and culture, as well as the characteristics of the food they associate with and the expected consequences that motivate their behaviour. Environmental concerns did not emerge as salient and significant to consumer sentiments in this corpus, which may be tied to the present ontological structure as well as to the sample composition. Further research will explore this issue. In addition, although we report results from estimation for the overall user-generated content corpus, similar analyses could be performed for sub-samples formed on the basis of consumer segments, type of food, competitive products, geographical markets, etc.
From the perspective of inclusive innovation being concerned primarily with economic equity issues, the results presented in Table 2 revealed not only that economic consequence is a strong predictor of consumer global sentiment but that it is also sensitive to both the actual price and economic awareness. This underscores the importance of the complementary strategy to not only make food accessible at the appropriate price but also to inform and educate consumers of the value and ways to estimate price as it may be related to nutrition and other dimensions of what they need. This may be particularly relevant for disadvantaged population segments that are typically the target of inclusive innovation efforts.

An important limitation to the early-state results presented in this article is that, despite attempts to collect sufficient data, we have faced data sparseness problems that may lead to counterintuitive conclusions. The current corpus supports the analysis of the first-order aspects in the ontology hierarchy. However, to understand the lower-level concepts (aspects), a much larger corpus will be needed to provide sufficient support for each aspect, especially when the concept space keeps expanding. As a limitation of the current study, further exploration of the aspects of behaviour and health have been excluded and will be considered in future work.

In spite of these limitations, the results of the present study reflect the rich diversity of positive and negative drivers of consumer demand for food products covering the full spectrum from expected consequences to cultural, social, and emotional features of the experience, to characteristics of the consumption occasion, to actual product design features and the marketing mix. Although this first extraction and analysis do not allow us to capture the set of relationships between these influential factors, future work will combine relevant theoretical and empirical basis with deep learning and other artificial intelligence methods to trace the pathways through which a vibrant ecosystem can be created that supports the supply and demand of a portfolio of food that people need, want, and are willing and able to pay for, and that the ecosystem actors are able and willing to produce. These results add to the existing understanding of consumer behaviour for food most often theorized from an unhealthy/tasty bipolar view for both advantaged and disadvantaged populations, and provides insights on the complex systems of beliefs, motives, and goals encompassing familial and social bonds and norms, cultural meanings, and other considerations impacting consumer responses to food innovation or communication. Our results provide insights to 


\section{Convergent Innovation in Food through Big Data and Artificial Intelligence for Societal-Scale Inclusive Growth $L$. Dubee, P. Du, C. McRae, N. Sharma, S. Jayaraman, and J.-Y. Nie}

find or create a convergence path among systems of food beliefs, motives, and goals leading to individual healthy food behaviours that are sustainable from all these perspectives be they biological, psychological, cultural, economic, or environmental. In fact, research reporting results of geographical analysis of user-generated content in the future will provide geo-referenced information on the influence of food and food cues on food choice and suggest possibilities of fine-grained differentiation of consumer insights for better-targeted convergent innovation in food.

The future scope envisioned for the integrated digital architecture for convergent innovation in food is to combine the social media platform with others modules enabling the dynamic integration of past and present sectoral and intersectoral knowledge and metrics. We also plan to move toward predictive models that can link complex webs of relationships involved in specific innovation and marketing practices with their single and collective economic, social, and environmental outcomes that will benefit the firm and society.

\section{Acknowledgements}

Funding for the research programs reported in this article comes partly from an SSHRC operating grant (\#4352014-1964), a FRQSC team grant (\#2015-SE-179342), and seed project funding from the International Development Research Centre (\#107400-006) to Laurette Dubé. Additional support comes from the Global Pulse Innovation Platform at the McGill Centre for the Convergence of Health and Economics.

\section{About the Authors}

Laurette Dubé is a Full Professor and holds the James McGill Chair of Consumer and Lifestyle Psychology and Marketing at the Desautels Faculty of Management of McGill University in Montreal, Canada. Her research interest bears on the study of affects and behavioural economic processes underlying consumption and lifestyle behaviour and how such knowledge can inspire more effective health and marketing communications in both real life and technology-supported media. She is the Founding Chair and Scientific Director of the McGill Centre for the Convergence of Health and Economics (MCCHE). The MCCHE was created to foster partnerships among scientists and decision makers from all sectors of society to encourage a more ambitious notion of what can be done for more effective health management and novel pathways for social and business innovation.

Pan Du is a Research Associate in the Department of Computer Science and Operational Research at the Université de Montréal, Canada. Before that, Pan was an Assistant Professor at the Chinese Academy of Sciences. He received his $\mathrm{PhD}$ from the Institute of Computing Technology of the Chinese Academy of Sciences. His research interests lie in text mining, information retrieval, machine learning, and social network analysis. He has published academic papers in various conferences and journals. He is a recipient of the 2016 "Science and Technology Progress Award" of the Chinese Institute of Electronics for his contribution to a web-scale text mining system.

Cameron McRae is a Senior Research Analyst at the McGill Centre for the Convergence of Health and Economics in Montreal, Canada. Since joining the centre in 2014, he has led many translational research projects to support innovation in the agricultural, food, and health sectors. Cameron has strong interdisciplinary training at the nexus of science, technology, and management, with a Bachelor of Science in Pharmacology from McGill University, a Graduate Certificate in Business Administration from John Molson School of Business, and a Master of Health Informatics from the University of Toronto. Previously, Cameron has worked in both the public and private sectors to support strategy and practice in the areas of governance, business development, and business/market intelligence related to life sciences and digital health.

Continued on next page... 


\section{Convergent Innovation in Food through Big Data and Artificial Intelligence for Societal-Scale Inclusive Growth $L$. Dubee, P. Du, C. McRae, N. Sharma, S. Jayaraman, and J.-Y. Nie}

Neha Sharma is currently pursuing her $\mathrm{PhD}$ at the Department of Bioresource Engineering at McGill University in Montreal, Canada. She completed her Master's degree in Biochemical Engineering from Harcourt Butler Technical University, India. The title of her Master's research project was "Optimization of Process parameters for Bacterial solid-state fermentation of Nattokinase to prevent myocardial infarction", which culminated in principles of food processing, microbiology, and bioprocessing. Her Bachelor's degree in Biotechnology is from IMS Engineering College, India, where she took various courses in molecular biology, genetic engineering, bioprocess engineering, fermentation biotechnology, food biotechnology, and environmental biotechnology, etc. In her final year, her Bachelor's project was based on the study of plant extracts and their antimicrobial properties.

Srinivasan Jayaraman is a Research Associate/Visiting Scholar at the Desautels Faculty of Management, at McGill University in Montreal, Canada. He obtained his Bachelor's degree in Electronics and Instrumentation Engineering from Bharathidasan University, India, his MTech degree in Biomedical Engineering from SASTRA University in Thanjavur, India, and his doctorate from the School of Bioscience at the Indian Institute of Technology Madras in Chennai, India. Previously, he has held roles at TCS Innovation Labs, the University of Nebraska Lincoln, the New Jersey Institute of Technology, and INRS-EMT Canada. His research interests include human behavioural and performance modelling, ontology, ergonomics, personalized diagnosis systems, wearable devices, biosignal processing, and human-machine interfaces. In 2011, he won the MIT-TR35 young innovator award Indian edition and was recognized as one among the Top 50 most impactful social innovators (global listing) by World CSR Congress \& World CSR Day at 2016.

Jian-Yun Nie is a Professor in Computer Science at the University of Montreal, Canada, and is associated with the IVADO institute. He obtained a PhD degree from Université Joseph Fourier of Grenoble, France. He specializes in information retrieval, natural language processing, and artificial intelligence. He has been doing research in these areas for 30 years and has published many papers on these topics. He has served as general chair and PC chair for several conferences in the area of information retrieval. He is on the board of several international journals, including Information Retrieval Journal. He has been an invited researcher at several institutions (Tsinghua University, Peking University) and companies (Microsoft Research, Baidu, and Yahoo!).

\section{References}

Abbasi, A., Chen, H., \& Salem, A. 2008. Sentiment Analysis in Multiple Languages. ACM Transactions on Information Systems, 26(3): 1-34. https://doi.org/10.1145/1361684.1361685

Ali, I., \& Son, H. H. 2007. Measuring Inclusive Growth. Asian Development Review, 24(1): 11-31.

Asur, S., \& Huberman, B. A. 2010. Predicting the Future with Social Media. In Proceedings of the 2010 IEEE/WIC/ACM International Conference on Web Intelligence and Intelligent Agent Technology (WI-IAT): 492-499.

https://doi.org/10.1109/WI-IAT.2010.63

Babić Rosario, A., Sotgiu, F., De Valck, K., \& Bijmolt, T. H. A. 2016. The Effect of Electronic Word of Mouth on Sales: A Meta-Analytic Review of Platform, Product, and Metric Factors. Journal of Marketing Research, 53(3): 297-318. https://doi.org/10.1509/jmr.14.0380

Baccianella, S., Esuli, A., \& Sebastiani, F. 2010. SentiWordNet 3.0: An Enhanced Lexical Resource for Sentiment Analysis and Opinion Mining SentiWordNet. In Proceedings of the Seventh International Conference on Language Resources and Evaluation (LREC'10), May 19-21, Valletta, Malta.

Beinhocker, E. D. 2007. The Origin of Wealth: The Radical Remaking of Economics and What It Means for Business and Society. Boston, MA: Harvard Business Press.

Bradlow, E. T. T., Gangwar, M., Kopalle, P., \& Voleti, S. 2017. The Role of Big Data and Predictive Analytics in Retailing. Journal of Retailing, 93(1): 79-95.

https://doi.org/10.1016/j.jretai.2016.12.004

Campbell, J. L. 2007. Why Would Corporations Behave in Socially Responsible Ways? An Institutional Theory of Corporate Social Responsibility. Academy of Management Review, 32(3): 946-967. http://doi.org/10.5465/AMR.2007.25275684

Chataway, J., Hanlin, R., \& Kaplinsky, R. 2014. Inclusive Innovation: An Architecture for Policy Development. Innovation and Development, 4(1): 33-54. https://doi.org/10.1080/2157930X.2013.876800

Croitoru, A. 2012. Schumpeter, J.A., 1934 (2008), The Theory of Economic Development: An Inquiry into Profits, Capital, Credit, Interest and the Business Cycle. Journal of Comparative Research in Anthropology and Sociology, (2): 137-148.

Culotta, A., \& Cutler, J. 2016. Mining Brand Perceptions from Twitter Social Networks. Marketing Science, 35(3): 343-362.

https://doi.org/10.1287/mksc.2015.0968

De Choudhury, M., Counts, S., \& Gamon, M. 2012. Not All Moods are Created Equal! Exploring Human Emotional States in Social Media. In Proceedings of the 6th International AAAI Conference on Weblogs and Social Media: 66-73.

Devaux, A., Horton, D., Velasco, C., Thiele, G., López, G., Bernet, T., Reinoso, I., \& Ordinola, M. 2009. Collective Action for Market Chain Innovation in the Andes. Food Policy, 34(1): 31-38. https://doi.org/10.1016/j.foodpol.2008.10.007 


\section{Convergent Innovation in Food through Big Data and Artificial Intelligence for Societal-Scale Inclusive Growth $L$. Dubé, P. Du, C. McRae, N. Sharma, S. Jayaraman, and J.-Y. Nie}

Dey, L., Haque, S. M., Khurdiya, A., \& Shroff, G. 2011. Acquiring Competitive Intelligence from Social Media. In Proceedings of the 2011 Joint Workshop on Multilingual OCR and Analytics for Noisy Unstructured Text Data, September 17, 2011, Beijing, China. https://doi.org/10.1145/2034617.2034621

Ding, X., Liu, T., Duan, J., \& Nie, J. 2015. Mining User Consumption Intention from Social Media Using Domain Adaptive Convolutional Neural Network. In Proceedings of the Twenty-Ninth AAAI Conference on Artificial Intelligence: 2389-2395. January 25-29, 2015, Austin, TX.

Drayton, B., \& Budinich, V. 2010. A New Alliance for Global Change. Harvard Business Review, 88(9): 56-64.

Dubé, L., Bechara, A., Böckenholt, U., Ansari, A., Dagher, A., Daniel, M., DeSarbo, W. S., Fellows, L. K., Hammond, R. A., Huang, T. T.K., Huettel, S., Kestens, Y., Knäuper, B., Kooreman, P., Moore, D. S., \& Smidts, A. 2008. Towards a Brain-to-Society Systems Model of Individual Choice. Marketing Letters, 19(3-4): 323-336. https://doi.org/10.1007/s11002-008-9067-9

Dubé, L., Jha, S., Faber, A., Struben, J., London, T., Mohapatra, A., Drager, N., Lannon, C., Joshi, P. K., \& McDermott, J. 2014. Convergent Innovation for Sustainable Economic Growth and Affordable Universal Health Care: Innovating the Way We Innovate. Annals of the New York Academy of Sciences, 1331(1): 119-141.

http://doi.org/10.1111/nyas.12548

Dubé, L., Pingali, P., \& Webb, P. 2012. Paths of Convergence for Agriculture, Health, and Wealth. Proceedings of the National Academy of Sciences, 109(31): 12294-12301. https://doi.org/10.1073/pnas.0912951109

Feldman, R. 2013. Techniques and Applications for Sentiment Analysis. Communications of the ACM, 56(4): 82-89. https://doi.org/10.1145/2436256.2436274

Gillespie, S., Haddad, L., Mannar, V., Menon, P., \& Nisbett, N. 2013. The Politics of Reducing Malnutrition: Building Commitment and Accelerating Progress. The Lancet, 382(9891): 552-569. https://doi.org/10.1016/S0140-6736(13)60842-9

Goel, S., \& Goldstein, D. G. 2013. Predicting Individual Behavior with Social Networks. Marketing Science, 33(1): 82-93. https://doi.org/10.1287/mksc.2013.0817

Golbeck, J., Robles, C., \& Turner, K. 2011. Predicting Personality with Social Media. In Proceedings of CHI'11: Extended Abstracts on Human Factors in Computing Systems: 253-262. https://doi.org/10.1145/1979742.1979614

Hammond, R. A., \& Dubé, L. 2012. A Systems Science Perspective and Transdisciplinary Models for Food and Nutrition Security. In Proceedings of the National Academy of Sciences, 109(31): 12356-12363.

https://doi.org/10.1073/pnas.0913003109

He, W., Zha, S., \& Li, L. 2013. Social Media Competitive Analysis and Text Mining: A Case Study in the Pizza Industry. International Journal of Information Management, 33(3): 464-472. https://doi.org/10.1016/j.ijinfomgt.2013.01.001

Knoll, J., \& Proksch, R. 2017. Why We Watch Others' Responses to Online Advertising-Investigating Users' Motivations for Viewing User-Generated Content in the Context of Online Advertising. Journal of Marketing Communications, 23(4): 400-412. https://doi.org/10.1080/13527266.2015.1051092
Kochanek, K. D., Murphy, S. L., Xu, J., \& Arias, E. 2016. Mortality in the United States, 2016. NCHS Data Brief No. 293. Atlanta, GA: National Center for Health Statistics (NCHS).

Kutner, M. H., Nachtsheim, C. J., \& Neter, J. 2004. Applied Linear Regression Models (4th Ed.). New York: McGraw-Hill/Irwin.

Kwark, Y., Chen, J., \& Raghunathan, S. 2017. User-Generated Content and Product Design of Competing Firms. Management Science, Forthcoming. https://doi.org/10.1287/mnsc.2017.2839

Lee, T. Y., \& Bradlow, E. T. 2011. Automated Marketing Research Using Online Customer Reviews. Journal of Marketing Research, 48(5): 881-894. https://doi.org/10.1509/jmkr.48.5.881

Lin, Y.-C., \& Chang, C. A. 2012. Double Standard: The Role of Environmental Consciousness in Green Product Usage. Journal of Marketing, 76(5): 125-134. https://doi.org/10.1509/jm.11.0264

Liu, B. 2012. Sentiment Analysis and Opinion Mining. Synthesis Lectures on Human Language Technologies, 5(1): 1-167. https://doi.org/10.2200/S00416ED1V01Y201204HLT016

Maas, A. L., Daly, R. E., Pham, P. T., Huang, D., Ng, A. Y., \& Potts, C. 2011. Learning Word Vectors for Sentiment Analysis. In Proceedings of the 49th Annual Meeting of the Association for Computational Linguistics: Human Language Technologies: 142-150. Portland, Oregon, June 19-24, 2011.

Martin, R. L., \& Osberg, S. 2007. Social Entrepreneurship: The Case for Definition. Stanford Social Innovation Review, Spring 2007: 29-39.

Martin, R. L., \& Osberg, S. 2015. Getting Beyond Better: How Social Entrepreneurship Works. Boston, MA: Harvard Business Review Press.

Miller, G. A. 1995. WordNet: A Lexical Database for English. Communications of the ACM, 38(11): 39-41.

https://doi.org/10.1145/219717.219748

Moodie, R., Stuckler, D., Monteiro, C., Sheron, N., Neal, B., Thamarangsi, T., Lincoln, P., \& Casswell, S. 2013. Profits and Pandemics: Prevention of Harmful Effects of Tobacco, Alcohol, and Ultra-Processed Food and Drink Industries. The Lancet, 381(9867): 670-679.

https://doi.org/10.1016/S0140-6736(12)62089-3

Mullen, T., \& Collier, N. 2004. Sentiment Analysis Using Support Vector Machines with Diverse Information Sources. In Proceedings of the 2004 Conference on Empirical Methods in Natural Language Processing: 412-418. July 25-26, Barcelona, Spain.

Nasukawa, T., \& Yi, J. 2003. Sentiment Analysis: Capturing Favorability Using Natural Language Processing. In Proceedings of the 2nd International Conference on Knowledge Capture: 70-77. October 23-25, Sanibel Island, Florida.

Pang, B., \& Lee, L. 2006. Opinion Mining and Sentiment Analysis. Foundations and Trends in Information Retrieval, 2(1-2): 91-231.

Pang, Z., Chen, Q., Han, W., \& Zheng, L. 2015. Value-Centric Design of the Internet-of-Things Solution for Food Supply Chain: Value Creation, Sensor Portfolio and Information Fusion. Information Systems Frontiers, 17(2): 289-319.

https://doi.org/10.1007/s10796-012-9374-9 


\section{Convergent Innovation in Food through Big Data and Artificial Intelligence for Societal-Scale Inclusive Growth $L$. Dubee, P. Du, C. McRae, N. Sharma, S. Jayaraman, and J.-Y. Nie}

Pansera, M., \& Martinez, F. 2017. Innovation for Development and Poverty Reduction: An Integrative Literature Review. Journal of Management Development, 36(1): 2-13. https://doi.org/10.1108/JMD-02-2015-0013

Piketty, T. 2014. Capital in the Twenty-First Century. Boston, MA: Harvard University Press.

Piller, F., Vossen, A., \& Ihl, C. 2012. From Social Media to Social Product Development: The Impact of Social Media on Co-Creation of Innovation. Die Unternehmung, 66(1): 7-27.

Planes-Satorra, S., \& Paunov, C. 2017. Inclusive Innovation Policies: Lessons from International Case Studies. OECD Science, Technology and Industry Working Papers, 2017(2): 1. Paris: Organisation for Economic Co-operation and Development (OECD).

Prahalad, C. K., Hart, S. L. 2002. The Fortune at the Bottom of the Pyramid. Strategy+Business, 26: 54-67.

Prahalad, C. K., \& Hammond, A. 2002. Serving the World's Poor, Profitably. Harvard Business Review, 80(9): 48-59.

Reardon, T., Chen, K. Z., Minten, B., Adriano, L., Dao, T. A., Wang, J., \& Gupta, S. D. 2014. The Quiet Revolution in Asia's Rice Value Chains. Annals of the New York Academy of Sciences, 1331(1): 106-118.

http://doi.org/10.1111/nyas.12391

Reardon, T., Timmer, C. P., \& Minten, B. 2012. Supermarket Revolution in Asia and Emerging Development Strategies to Include Small Farmers. Proceedings of the National Academy of Sciences, 109(31): 12332-12337. https://doi.org/10.1073/pnas.1003160108

Roberts, D. L., \& Candi, M. 2014. Leveraging Social Network Sites in New Product Development: Opportunity or Hype? Journal of Product Innovation Management, 31(S1): 105-117. http://doi.org/10.1111/jpim.12195

Schillo, R. S., \& Robinson, R. M. 2017. Inclusive Innovation in Developed Countries: The Who, What, Why, and How. Technology Innovation Management Review, 7(7): 34-46. https://timreview.ca/article/1089

Seber, A. J., \& Lee, G. A. F. 2012. Linear Regression Analysis (2nd Ed.). Hoboken, NJ: John Wiley \& Sons.

Stiglitz, J. E. 2016. An Agenda for Sustainable and Inclusive Growth for Emerging Markets. Journal of Policy Modeling, 38(4): 693-710. http://dx.doi.org/10.1016/j.jpolmod.2016.05.012

Thomopoulos, R., Croitoru, M., \& Tamani, N. 2015. Decision Support for Agri-Food Chains: A Reverse Engineering ArgumentationBased Approach. Ecological Informatics, 26(P2): 182-191. https://doi.org/10.1016/j.ecoinf.2014.05.010

Tuarob, S., \& Tucker, C. S. 2015. Quantifying Product Favorability and Extracting Notable Product Features Using Large Scale Social Media Data. Journal of Computing and Information Science in Engineering, 15(3): 31003. http://doi.org/10.1115/1.4029562

Tucker, C. E. 2014. Social Networks, Personalized Advertising, and Privacy Controls. Journal of Marketing Research, 51(5): 546-562. https://doi.org/10.1509/jmr.10.0355
Vázquez, S., Muñoz-García, Ó., Campanella, I., Poch, M., Fisas, B., Bel, N., \& Andreu, G. 2014. A Classification of User-Generated Content into Consumer Decision Journey Stages. Neural Networks, 58: $68-81$. https://doi.org/10.1016/j.neunet.2014.05.026

Verhoef, P. C., Kannan, P. K., \& Inman, J. J. 2015. From Multi-Channel Retailing to Omni-Channel Retailing. Introduction to the Special Issue on Multi-Channel Retailing. Journal of Retailing, 91(2): $174-181$. https://doi.org/10.1016/j.jretai.2015.02.005

Willems, D. J. M., \& Top, J. L. 2015. Social Media: Embedding in the eFoodLab Framework. Report 1532. Wageningen, Netherlands: Wageningen UR Food \& Biobased Research.

Citation: Dubé, L., Du, P., McRae, C., Sharma, N., Jayaraman, S., \& Nie, J.-Y. 2018. Convergent Innovation (cc) BY in Food through Big Data and Artificial Intelligence for Societal-Scale Inclusive Growth. Technology Innovation Management Review, 8(2): 49-65.

http://doi.org/10.22215/timreview/1139

Keywords: convergent innovation, artificial intelligence, user-generated content, social media, food 


\section{Author Guidelines}

These guidelines should assist in the process of translating your expertise into a focused article that adds to the knowledge resources available through the Technology Innovation Management Review. Prior to writing an article, we recommend that you contact the Editor to discuss your article topic, the author guidelines, upcoming editorial themes, and the submission process: timreview.ca/contact

\section{Topic}

Start by asking yourself:

- Does my research or experience provide any new insights or perspectives?

- Do I often find myself having to explain this topic when I meet people as they are unaware of its relevance?

- Do I believe that I could have saved myself time, money, and frustration if someone had explained to me the issues surrounding this topic?

- Am I constantly correcting misconceptions regarding this topic?

- Am I considered to be an expert in this field? For example, do I present my research or experience at conferences?

If your answer is "yes" to any of these questions, your topic is likely of interest to readers of the TIM Review.

When writing your article, keep the following points in mind:

- Emphasize the practical application of your insights or research.

- Thoroughly examine the topic; don't leave the reader wishing for more.

- Know your central theme and stick to it.

- Demonstrate your depth of understanding for the topic, and that you have considered its benefits, possible outcomes, and applicability.

-Write in a formal, analytical style. Third-person voice is recommended; first-person voice may also be acceptable depending on the perspective of your article.

\section{Format}

1. Use an article template: .doc .odt

2. Indicate if your submission has been previously published elsewhere. This is to ensure that we don't infringe upon another publisher's copyright policy.

3. Do not send articles shorter than 2000 words or longer than 5000 words.

4. Begin with a thought-provoking quotation that matches the spirit of the article. Research the source of your quotation in order to provide proper attribution.

5. Include a 2-3 paragraph abstract that provides the key messages you will be presenting in the article.

6. Provide a 2-3 paragraph conclusion that summarizes the article's main points and leaves the reader with the most important messages.

7. Include a 75-150 word biography.

8. List the references at the end of the article.

9. If there are any texts that would be of particular interest to readers, include their full title and URL in a "Recommended Reading" section.

10. Include 5 keywords for the article's metadata to assist search engines in finding your article.

11. Include any figures at the appropriate locations in the article, but also send separate graphic files at maximum resolution available for each figure. 


\section{Issue Sponsor}

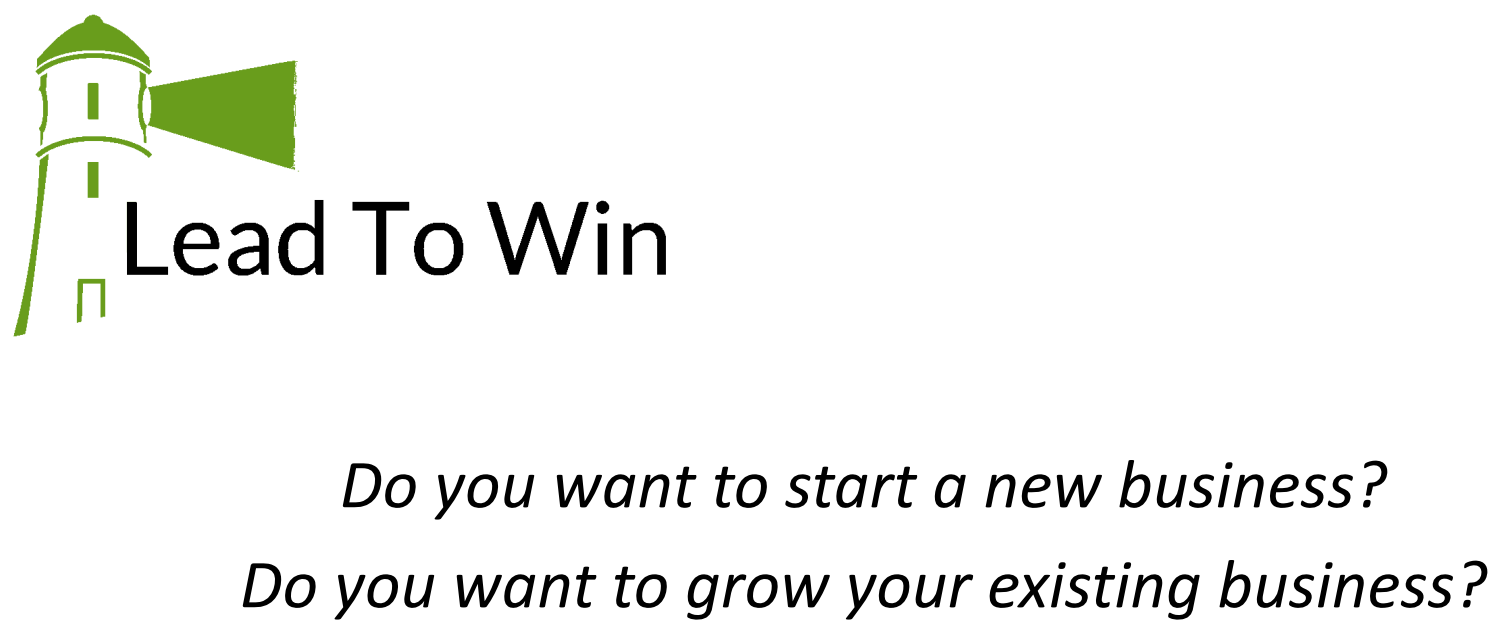

Lead To Win is a free business-development program to help establish and grow businesses in Canada's Capital Region.

Benefits to company founders:

- Knowledge to establish and grow a successful businesses

- Confidence, encouragement, and motivation to succeed

- Stronger business opportunity quickly

- Foundation to sell to first customers, raise funds, and attract talent

- Access to large and diverse business network

\section{Apply Now}

* Twitter

f Facebook

in Linkedin

E Eventbrite

9 Slideshare

- YouTube

- Flickr 


\section{Academic Affiliations and Funding Acknowledgements}

Canadà
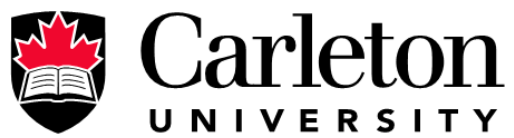

U N I V E R S I T Y

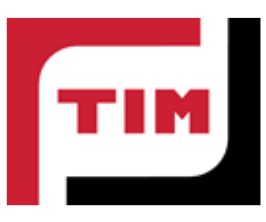

The Federal Economic Development Agency for Southern Ontario (FedDev Ontario; feddevontario.gc.ca) is part of the Innovation, Science and Economic Development portfolio and one of six regional development agencies, each of which helps to address key economic challenges by providing regionallytailored programs, services, knowledge and expertise.

- The TIM Review receives partial funding from FedDev Ontario's Investing in Regional Diversification initiative.

Technology Innovation Management (TIM; timprogram.ca) is an international master's level program at Carleton University in Ottawa, Canada. It leads to a Master of Applied Science (M.A.Sc.) degree, a Master of Engineering (M.Eng.) degree, or a Master of Entrepreneurship (M.Ent.) degree. The objective of this program is to train aspiring entrepreneurs on creating wealth at the early stages of company or opportunity lifecycles.

- The TIM Review is published in association with and receives partial funding from the TIM program. 